Genetic, haplotype and functional investigations on rare monogenic diseases

Ph.D. Thesis

Katalin Farkas 


\title{
Genetic, haplotype and functional investigations on rare monogenic diseases
}

\author{
Ph.D. Thesis
}

\author{
Katalin Farkas M.Sc. \\ Graduate School of Clinical Medicine \\ University of Szeged
}

Supervisor:

Nikoletta Nagy MD, Ph.D.

Department of Medical Genetics

Department of Dermatology and Allergology

MTA-SZTE Dermatological Research Group

University of Szeged

Szeged

2016 


\section{TABLE OF CONTENTS}

LIST OF PUBLICATIONS

$\begin{array}{lr}\text { 1. INTRODUCTION } & 8\end{array}$

1.1. Rare diseases $\quad 8$

1.2. LEOPARD syndrome 9

1.2.1. Clinical symptoms 9

1.2.2. Genetic background 9

1.3. The CYLD mutation-caused disease spectrum $\quad 10$

1.3.1. Multiple familial trichoepithelioma type $1 \quad 10$

1.3.2. Familial cylindromatosis $\quad 10$

1.3.3. Brooke-Spiegler syndrome $\quad 10$

1.3.4. Genetic background 11

1.4. Aims 13

2. PATIENTS AND METHODS 15

2.1. Patients 15

2.1.1. Hungarian pedigree affected by LEOPARD syndrome 15

2.1.2. Spanish pedigree affected by multiple familial trichoepithelioma type $1 \quad 16$

2.1.3. Dutch patient affected by familial cylindromatosis 17

2.1.4. Austrian patient affected by Brooke-Spiegler syndrome $\quad 17$

2.1.5. Hungarian pedigree from Szekszárd affected by $\begin{array}{ll}\text { Brooke-Spiegler syndrome } & 18\end{array}$

2.1.6. Anglo-Saxon pedigree affected by Brooke-Spiegler syndrome 19

2.1.7. Hungarian pedigree from Szeged affected by

Brooke-Spiegler syndrome 20

2.2. Methods 21

2.2.1. DNA isolation 21

2.2.2. Polymerase chain reaction (PCR) amplification 22

2.2.3. Gel electrophoresis and gel documentation 22

$\begin{array}{ll}\text { 2.2.4. Sequencing } & 22\end{array}$ 
2.2.5. Haplotype analysis

2.2.6. Immunoprecipitation

2.2.7. Western blot analysis

3. RESULTS

3.1. Genetic investigation of the protein-tyrosine phosphatase nonreceptor - type 11 (PTPN11) gene

3.2. Genetic, haplotype and functional investigation of the cylindromatosis $(C Y L D)$ gene

3.2.1. Genetic investigation of the Spanish pedigree

3.2.2. Haplotype analysis of the Spanish pedigree, the Dutch and the Austrian patients

3.2.3. Genetic investigation of the Hungarian pedigree from Szekszárd

3.2.4. Haplotype analysis of the Hungarian pedigree from Szekszárd and the Anglo-Saxon pedigree

3.2.5. Genetic investigation of the Hungarian pedigree from Szeged

3.2.6. Functional investigation of the Hungarian pedigree from

Szeged

4. DISCUSSION

4.1. Comparison of the patient suffering from LEOPARD syndrome with the literature

4.2. Haplotype analysis of the patients carrying the recurrent nonsense p.Arg758X CYLD mutation represents a mutational hotspot in the gene

4.3. Haplotype analysis of the patients carrying the recurrent nonsense p.Arg936X CYLD mutation represents a mutational hotspot in the gene

4.4. The functional analysis of the newly identified missense mutation represents a disease-causing mutation in the $C Y L D$ gene

4.5. Mutations on the CYLD gene 40

4.6. Distribution of the mutations in the CYLD protein 43 
4.7. Genotype and phenotype correlations in case of patients carrying $C Y L D$ mutation

4.8. Geographical occurrence of $C Y L D$-mutation caused disease spectrum

5. SUMMARY

6. ACKNOWLEDGEMENT

7. ELECTRONIC DATABASE INFORMATION

8. REFERENCES

9. APPENDIX 


\section{LIST OF PUBLICATIONS}

\section{Publications providing the basis of the dissertation}

I. Nemes E*, Farkas K*, Kocsis-Deák B, Drubi A, Sulák A, Tripolszki K, Dósa P, Lakatos F, Nagy N, Széll M. Phenotypical diversity of patients with LEOPARD syndrome carrying the worldwide recurrent p.Tyr279Cys PTPN11 mutation. Arch Derm Res 2015; 307(10):891-895. IF: 1,902

*E. Nemes and K. Farkas contributed equally to this work.

II. Farkas K, Kocsis-Deák B, Sánchez LC, Martínez AM, Corell JJ, Botella AM, Benito GM, López RR, Vanecek T, Kazakov DV, Kromosoeto JN, van den Ouweland AM, Varga J, Széll M, Nagy N. The CYLD p.R758X worldwide recurrent nonsense mutation detected in patients with multiple familial trichoepithelioma type 1, Brooke-Spiegler syndrome and familial cylindromatosis represents a mutational hotspot in the gene. BMC Genet 2016; 17(1):36. IF: 2,397

\section{Publications directly related to the subject of the dissertation}

I. Nagy N, Farkas K, Kinyo A, Nemeth IB, Kis E, Varga J, Bata-Csorgo Z, Kemeny L, Szell M. A novel missense mutation of the $C Y L D$ gene identified in a Hungarian family with Brooke-Spiegler syndrome. Exp Dermatol 2012; 21(12):967-969.

II. Nagy N, Rajan N, Farkas K, Kinyo A, Kemeny L, Szell M. A Mutational Hotspot in CYLD Causing Cylindromas: A Comparison of Phenotypes Arising in Different Genetic Backgrounds. Acta Derm-Venereol 2013; 93(6):743-745.

III. Nagy N, Farkas K, Tripolszki K, Sulák A, Kemény L, Széll M. A cylindromatosis gén mutációi által okozott genodermatosisok. Bör Vener Szemle 2014; 90:(5) 185-193. 
IV. Nagy N, Farkas K, Kemény L, Széll M. Phenotype-genotype correlations for clinical variants caused by CYLD mutations. Eur J Med Genet 2015; 58(5):271278. IF: $\mathbf{1 , 4 6 6}$

V. Nagy N, Farkas K, Kemeny L, Szell M. Knowledge explosion for monogenic skin diseases. World J Dermatol 2015; 4(1):44-49.

\section{Publications indirectly related to the subject of the dissertation}

I. Farkas K, Nagy N, Kinyo A, Kemeny L, Szell M. A newly identified missense mutation of the HR gene is associated with a novel, unusual phenotype of Marie Unna Hereditary Hypotrichosis 1 including limb deformities. Arch Derm Res 2012; 304(8):679-681. IF: 2,708

II. Farkas K, Paschali E, Papp F, Valyi P, Szell M, Kemeny L, Nagy N, Csoma Z. A novel sevenbase deletion of the CTSC gene identified in a Hungarian family with Papillon-Lefévre syndrome. Arch Derm Res 2013; 305(5):453-455. IF:2,270

III. Nagy N, Farkas K, Bacsa S, Németh IB, Bata-Csörgő Zs, Kemény L, Széll M. NRP1 Activates NF-kB Signaling Pathway and Initiates Proliferation in Keratinocytes. Int J Genomic Med 2013; $1: 102$.

IV. Fazekas B, Polyánka H, Bebes A, Tax G, Szabó K, Farkas K, Kinyó Á, Nagy F, Kemény L, Széll M, Ádám É. UVB-dependent changes in the expression of fast-responding early genes is modulated by huCOP1 in keratinocytes. J Photochem Photobiol B-Biology 2014; 140:215-222. IF:2,803

V. Horvath E, Farkas K, Herczegfalvi A, Nagy N, Szell M. Identification of a novel missense GLRA1 gene mutation in hyperekplexia: a case report. J Med Case Rep 2014; 8(1):233.

VI. Kinyo A, Valyi P, Farkas K, Nagy N, Gergely B, Tripolszki K, Torok D, Bata-Csorgo Z, Kemeny L, Szell M. A newly identified missense mutation of the EDA1 gene in a Hungarian patient with Christ-Siemens-Touraine syndrome. Arch Derm Res 2014; 306(1):97-100. IF:2,270

VII. Nagy N, Farkas K, Kinyó Á, Fazekas B, Szabó K, Kollár E, Sztano B, Meszes A, Beke D, Kemény L, Rovó L, Széll M. A synonimous polymorphism of APCDD1 affects translation efficacy and is associated with androgenic alopecia. J Life Sci (Libertyville) 2014; 8(2):106-114. 
VIII. Nagy N, Valyi P, Csoma Z, Sulak A, Tripolszki K, Farkas K, Paschali E, Papp F, Toth L, Fabos B, Kemeny L, Nagy K, Szell M. CTSC and Papillon-Lefèvre syndrome: detection of recurrent mutations in Hungarian patients, a review of published variants and database update. Molecular Genetics \& Genomic Medicine 2014; 2(3):217-228.

IX. Vályi P, Farkas K, Tripolszki K, Sulák A, Széll M, Nagy N, Nagy K. Rekurrens európai misszensz mutáció egy magyar Papillon-Lefévre szindrómában szenvedő családban. Fogorvosi Szemle 2014; 107(3):87-92.

X. Gajda A, Horvath E, Hortobagyi T, Gergev G, Szabo H, Farkas K, Nagy N, Szell M, Sztriha L. Nemaline Myopathy Type 2 (NEM2): Two Novel Mutations in the Nebulin (NEB) Gene. J Child Neurol 2015; 30(5):627-630. IF:1,666

XI. Hamon Y, Legowska M, Fergelot P, Dallet-Choisy S, Newell L, Vanderlynden L, Kord Valeshabad A, Acrich K, Kord H, Charalampos T, Morice-Picard F, Surplice I, Zoidakis J, David K, Vlahou A, Ragunatha S, Nagy N, Farkas K, Széll M, et al. Analysis of urinary cathepsin C for diagnosing Papillon-Lefèvre syndrome. FEBS J 2016; 283(3):498-509. IF: 4,001

XII. Sulak A, Toth L, Farkas K, Tripolszki K, Fabos B, Kemeny L, Valyi P, Nagy K, Nagy N, Szell M. One mutation, two phenotypes: a single nonsense mutation of the CTSC gene causes two clinically distinct phenotypes. Clin Exp Dermatol 2016; 41(2):190-195. IF: 1,092

XIII. Tripolszki K, Knox R, Parker V, Semple R, Farkas K, Sulák A, Horváth E, Széll M, Nagy N. Somatic mosaicism of the PIK3CA gene identified in a Hungarian girl with macrodactyly and syndactyly. Eur J Med Genet 2016; [Epub ahead of print] IF: 1,466 


\section{INTRODUCTION}

\subsection{Rare diseases}

Rare diseases affect only a small percentage of the population. Their incidence is 1:2000 or less as defined by the European Union. Rare diseases affect nationwide only a few patients, but altogether they affect a significant portion of the population since their thousands of different types are known. In general, these disorders are less known than the common ones. They occur rarely in the everyday practice of the medical practitioners and less attention is paid for the research of these diseases (Kelsall et al., 2013). However, rare diseases can vary greatly. They can cause mild, severe or very severe symptoms and can be associated with phenotypic diversity like common diseases. Their symptoms can impair the life quality of the patient significantly and they can also result in stigmatization and difficulties in socialization (Kelsall et al., 2013).

Regarding common diseases, several predisposing factors might play a role in their development, such as environmental, life style and genetic factors. In contrast to common diseases, rare diseases are usually monogenic, meaning that one defined genetic alteration, one gene defect and consequently failure of one protein can be critical and can lead to the development of the disease. According to our current knowledge, the number of different human monogenic disorders is estimated to be more than 10000 (Orphanet Database, www.orpha.net). According to the data of the WHO, the global prevalence of monogenic diseases is approximately 10:1000 at birth (Kelsall et al., 2013). These diseases usually follow the rules of Mendelian inheritance and they are inherited in autosomal or sex chromosome-linked and dominant or recessive mode.

In my thesis, I have summarized the results of my genetic investigations in rare, very stigmatizing monogenic diseases: LEOPARD syndrome and the clinical variants of the cylindromatosis gene $(C Y L D)$ mutation-caused disease spectrum such as multiple familial trichoepithelioma type 1 (MFT1), familial cylindromatosis (FC) and Brooke-Spiegler syndrome (BSS). 


\subsection{LEOPARD syndrome}

\subsubsection{Clinical symptoms}

LEOPARD syndrome (LS, MIM 151100) is a rare monogenic disorder belonging to the family of neuro-cardiofacio-cutaneous syndromes (Spatola et al., 2015). It is inherited as an autosomal dominant trait with full penetrance and variable expressivity (Digilio et al., 2002; Legius et al., 2002). The major features of LS include multiple lentigines, electrocardiographic conduction abnormalities, ocular hypertelorism, pulmonary stenosis, abnormal genitalia, retardation of growth and sensorineural deafness, this is why the syndrome is referred with the LEOPARD acronym (Digilio et al., 2006; Legius et al., 2002). In the literature there are some other names of the disease as multiple lentigines syndrome, Moynahan syndrome or progressive cardiomyopathic lentiginosis. The symptoms were first described by Zeisler and Becker in 1936, and then the acronym was created by Gorlin in 1969.

\subsubsection{Genetic background}

LS is the consequence of mutations located in the protein-tyrosine phosphatase nonreceptor-type 11 (PTPN11) gene. The locus of the gene responsible for LS is localized at $12 \mathrm{q} 24$. The PTPN11 gene contains 16 exons, the last one is untranslated, and 15 introns (Figure 1). The gene encodes a cytoplasmic protein tyrosine phosphatase (SHP-2), which regulates intracellular signaling and controls several distinct developmental processes (Sarkozy et al., 2008; Tartaglia et al., 2001).

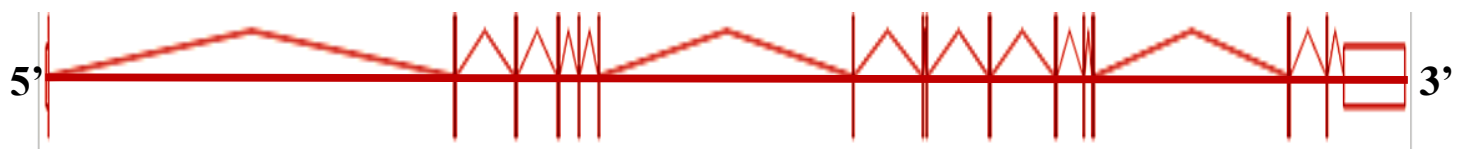

Figure 1. Schematic drawing of the protein-tyrosine phosphatase nonreceptor-type 11 (PTPN11) gene (Ensembl Genome Browser). The horizontal line illustrates the gene, the vertical lines represent the location and the size of exons.

So far 12 mutations in the PTPN11 gene have been found to cause LS. In about $85 \%$ of the cases a heterozygous missense mutation is detected in the exon 7 , 12 or 13. Among the so far identified missense mutations, there are two 
(p.Tyr279Cys and p.Thr468Met), which account for about $65 \%$ of all LS cases worldwide (Kalev et al., 2010; Limongelli et al., 2008).

\subsection{The $C Y L D$ mutation-caused disease spectrum}

\subsubsection{Multiple familial trichoepithelioma type 1}

Multiple familial trichoepithelioma type 1 (MFT1; MIM 601606) is an autosomal dominant condition characterized by numerous firm skin-colored papules that are trichoepitheliomas (follicular tumors). The tumors grow slowly in size and number throughout life, often producing significant cosmetic disfigurement. Trichoepitheliomas are small benign skin-colored tumors and are typically present at the center of the face, mostly around the nose, periorbitally and in the nasolabial folds (Uede et al., 2004). Histologically, trichoepitheliomas are characterized by basaloid cells with peripheral palisades that are arranged in nests or cribriform patterns surrounded by dense stroma and fibroblasts (Alsaad et al., 2007).

\subsubsection{Familial cylindromatosis}

Familial cylindromatosis (FC, MIM 132700) is also an autosomal dominantly inherited disorder. Patients with FC have cylindromas, which are slowly growing benign tumors that are usually located on the scalp and face. Typically, they appear as multiple turban-like protrusions on the scalp, which are also referred as turban tumors (Uede et al., 2004). Cylindromas are histologically characterized by dermal nodules of epithelial cells: large cells with abundant cytoplasm occur at the center of the tumors, whereas small basaloid cells occur at the periphery. The cells are lined by membrane-like basement material and arranged in a "jigsaw puzzle" pattern (Lian and Cockerell, 2005). Cylindromas express hair keratins (Massoumi et al., 2006).

\subsubsection{Brooke-Spiegler syndrome}

Brooke-Spiegler syndrome (BSS, MIM 605041) is also a rare monogenic skin disease characterized by the development of a wide variety of benign skin appendage tumors, such as trichoepitheliomas, cylindromas and/or spiradenomas (Brooke, 1892; 
Spiegler, 1899). The first symptoms of BSS are small skin-colored papules, which occur in childhood and adolescence (Evans, 1954; Sima et al., 2010). These tumors grow slowly in size and continue appear throughout the lifetime of the patient (Blake and Toro, 2009). Expression of the papules exhibits wide variation among and within affected families (Poblete et al., 2002). Spiradenomas are purple benign nodular tumors, which are usually located on the trunk or limbs (Uede et al., 2004). Histologically, spiradenomas are composed of large tumor nests comprising two types of epithelial cells (Obaidat et al., 2007). Large light-colored cells with abundant cytoplasm at the center of the nests are surrounded by small darker cells at the periphery (Obaidat et al., 2007; Michal et al., 1999). Spiradenomas rarely become malignant but can transform into spiradenocarcinomas (Cooper et al., 1985; Engel et al., 1991; Chou et al., 2004). Hybrid tumors can also occur, such as spiradenocylindromas, which exhibit the characteristics of both cylindromas and spiradenomas (Kazakov et al., 2005; Kazakov et al., 2008; Pizinger and Michal, 2000).

\subsubsection{Genetic background}

MFT1, FC and BSS have been independently mapped to chromosome 16q12q13 by several groups (Biggs et al., 1995; Biggs et al., 1996; Bignell et al., 2000). First, FC was mapped to this region in 1995 (Biggs et al., 1995), and its candidate gene, the CYLD gene, was identified in 2000 (Bignell et al., 2000). Later BSS was mapped to the same region in 2000 (Fenske et al., 2000). In the mapped region, the same causative gene was identified in 2002 (Gutierrez et al., 2002). Regarding MFT1, the same causative gene was identified in 2003 (Hu et al., 2003). In the mapped region, the cylindromatosis (CYLD) gene [NM_015247] was identified as the causative gene responsible for the development of these three diseases (Bignell et al., 2000). The gene spans $56 \mathrm{~kb}$ and contains 20 exons, the first 3 of which are untranslated, and 19 introns (Figure 2). 


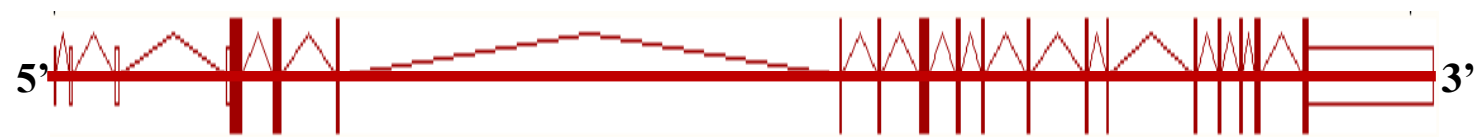

Figure 2. Schematic drawing of the cylindromatosis (CYLD) gene (Ensembl Genome Browser). The horizontal line illustrates the gene, the vertical lines represent the location and the size of exons.

The tumor suppressing CYLD gene encodes an enzyme with deubiquitinase activity. The CYLD enzyme post-translationally modifies its target proteins by removing Lys63-linked ubiquitin chains (Kovalenko et al., 2003). The protein interacts with several members of the NF-KB signaling pathway, including TNFreceptor-associated factor proteins (TRAF2, TRAF6 and TRAF7) and the NEMO protein as a negative regulator of the NF-kB signaling pathway (Haglund and Dikic, 2005). CYLD is involved in the regulation of several biological processes, such as cell proliferation and inflammation (Gao et al., 2008) (Figure 3).

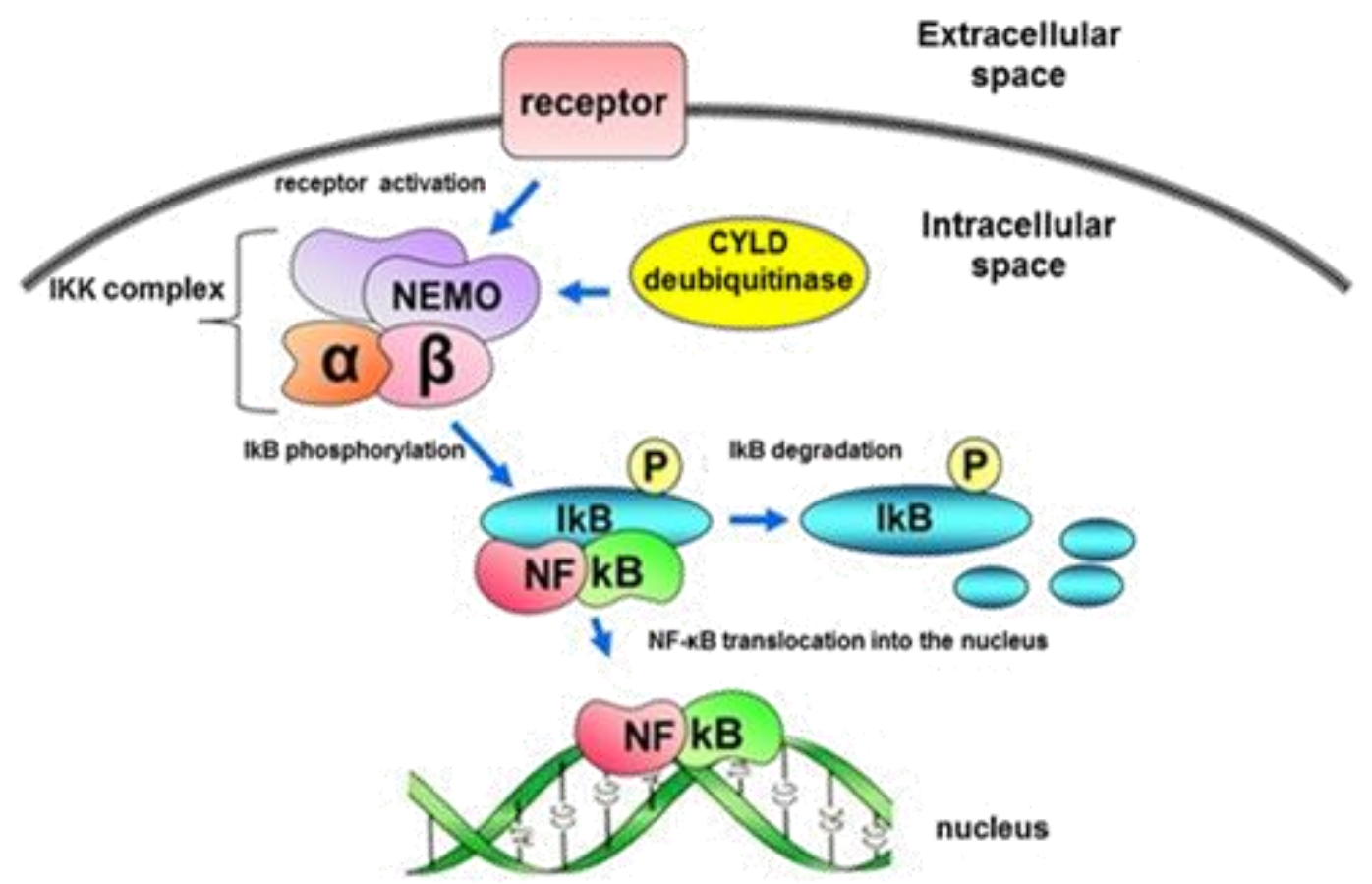

Figure 3. Model of the effect of CYLD deubiquitinase enzime on the activation of $N F-\kappa B$ signaling pathway. CYLD protein has a role in the regulation of $N F-\kappa B$ signaling pathway throuhg the deubiquitination of NEMO protein.

To date, a total of 95 mutations have been reported for the CYLD gene. In 2000, the first 21 mutations of the CYLD gene were identified in the affected members of 21 families with FC (Bignell et al., 2000). Since 2000, several reports have described mutations in the CYLD gene in different cases from around the world (Blake and Toro, 2009). In addition to BSS and FC, mutations of the CYLD gene 
have also been reported in patients with MFT1 (Hu et al., 2003). BSS, FC and MFT1 show overlapping phenotypic features: some BSS patients develop multiple skin appendage tumors including cylindromas, trichoepitheliomas, and spiradenomas, whereas patients with FC develop only cylindromas, and patients with MFT1 develop only trichoepitheliomas (Brooke, 1892; Spiegler, 1899; Ancell, 1842; Fordyce, 1892; Zhang et al., 2004) (Table 1).

\begin{tabular}{|l|c|c|c|}
\hline & $\begin{array}{c}\text { Familial } \\
\text { cylindromatosis } \\
\text { (FC) }\end{array}$ & $\begin{array}{c}\text { Brooke-Spiegler } \\
\text { syndrome (BSS) }\end{array}$ & $\begin{array}{c}\text { Multiple familial } \\
\text { trichoepithelioma } \\
\text { type 1 (MFT1) }\end{array}$ \\
\hline $\begin{array}{l}\text { OMIM } \\
\text { ID }\end{array}$ & 132700 & 605041 & 601606 \\
\hline $\begin{array}{l}\text { Clinical } \\
\text { symptoms }\end{array}$ & $\begin{array}{c}\text { Predominantly } \\
\text { cylindromas }\end{array}$ & $\begin{array}{c}\text { Cylindromas, } \\
\text { trichoepitheliomas, } \\
\text { spiradenomas }\end{array}$ & $\begin{array}{c}\text { Predominantly } \\
\text { trichoepitheliomas }\end{array}$ \\
\hline $\begin{array}{l}C Y L D \\
\text { mutations }\end{array}$ & $\begin{array}{c}\text { Any type of } \\
\text { mutation }\end{array}$ & Any type of mutation & $\begin{array}{c}\text { Any type of mutation, } \\
\text { mostly missense }\end{array}$ \\
\hline
\end{tabular}

Table 1. Phenotypes caused by mutations of CYLD gene.

BSS, FC and MFT1 were originally described as distinct clinical entities, but due to their overlapping clinical symptoms and their manifestation within the same families, they are now considered as clinical variants that represent a phenotypic spectrum of a single entity (Lee et al., 2005; Welch et al., 1968; Young et al., 2006; Oranje et al., 2008).

\subsection{Aims}

In my thesis, the primary aim was to summarize the results of the genetic and functional investigations in stigmatizing rare monogenic disorders: LS and the clinical variants of the $C Y L D$ mutation-caused disease spectrum such as BSS, FC and MFT1.

Concerning LS, the aim was to identify the underlying causative genetic abnormality in a 51-year-old Hungarian male patient. Besides, the genetic investigations aiming to identify the disease-causing mutation, it was also among my 
goals to compare this variant with the reported ones in the literature in order to define genotype-phenotype correlations and Hungarian population specific mutations.

Regarding CYLD mutation-caused disease spectrum, my aim was to investigate families and sporadic cases affected by BSS, FC or MFT1 in order to identify the underlying genetic abnormalities. I have also aimed to perform further genetic investigations including haplotype analysis to demonstrate whether different cases and families affected by different clinical variants of the CYLD mutationcaused disease spectrum carrying the same $C Y L D$ mutation are the consequence of the same founder event or independent mutational events. In case of novel mutations, I have also aimed to perform functional investigations to prove their ability to impair the function of the encoded CYLD enzyme. Besides these investigations, my further goals were to describe genotype-phenotype correlations and population specific mutation database.

Since rare diseases can affect only a few families in Hungary, it was also among my goals to build international strong co-operations with the researchers and clinicians working in this field. In my thesis, I have summarized my investigations, which have been performed on not only Hungarian, but Spanish, Dutch and Austrian patients carrying the same $C Y L D$ mutation. 


\section{PATIENTS AND METHODS}

\subsection{Patients}

\subsubsection{Hungarian pedigree affected by LEOPARD syndrome}

A 51-year-old Hungarian male patient was admitted to the cardiology unit of the Orosháza Hospital (Orosháza, Hungary) with dizziness and palpitation. On investigation, facial anomalies including ocular hypertelorism, palpebral ptosis, dysmorphic ear, slight mandibular prognathism (Figure 4a) and pigmentation abnormalities such as multiple lentigines (Figure 4b) and café-au-lait spots (Figure 4c) were also observed. Cardiology investigations revealed third degree atrioventricular block (Figure 4d). The patient is deaf and dumb since he was born and mild growth as well as mental retardations were also present. Urological investigation revealed mild genital abnormalities such as atrophic testes. These clinical symptoms suggested LS.
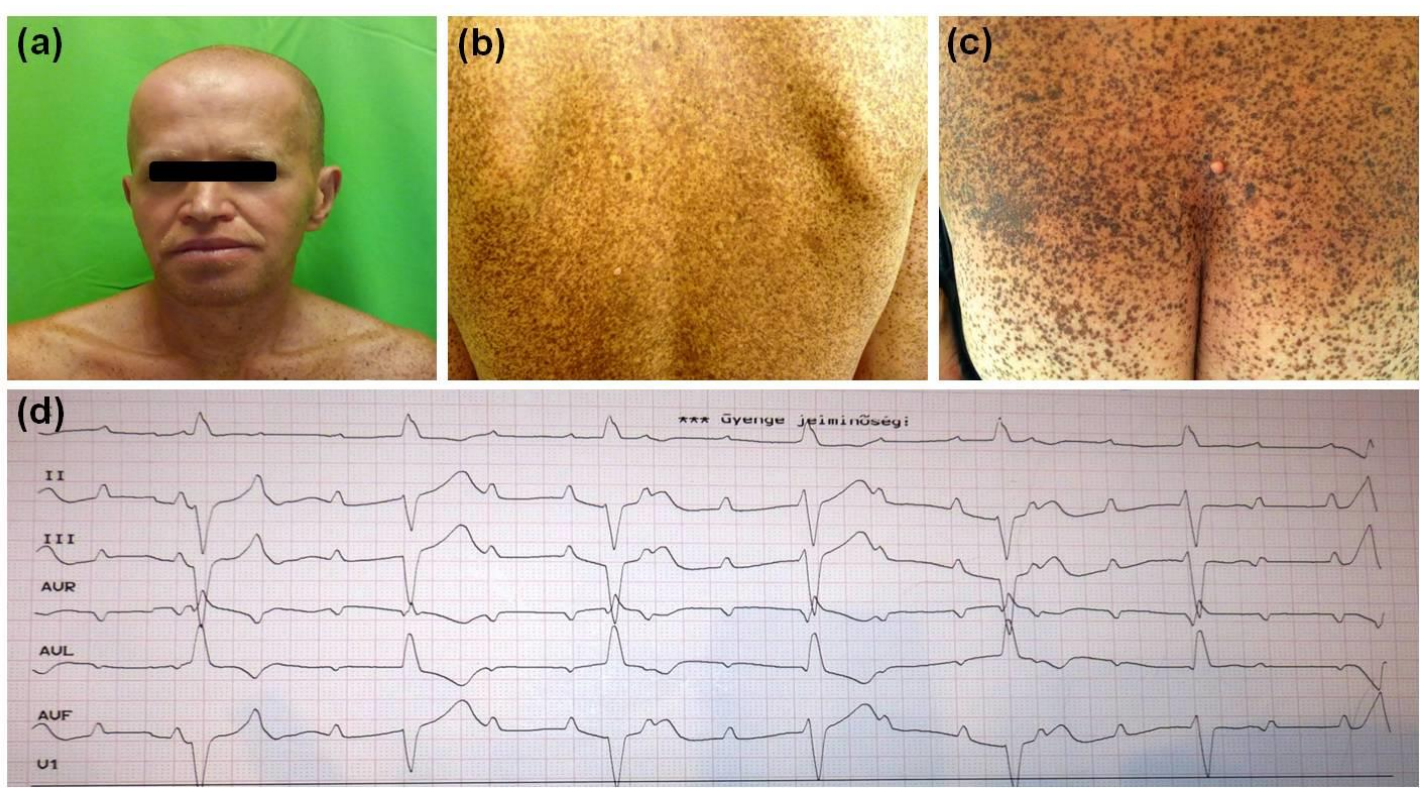

Figure 4. The clinical symptoms of the patient. Facial dysmorphims including ocular hypertelorism, palpebral ptosis, slight mandibular prognathism and dysmorphic ears (a). Pigmentational abnormalitieson the skin: multiple lentigines (b) and café-au-lait spots (c). On electrocardiography a third degree antrioventricular block was present d). (Nemes and Farkas et al., 2015) 
The patient was born out of wedlock, however the family members of his father and his mother were available for the clinical and genetic investigations. They were all clinically unaffected individuals (Figure 5).

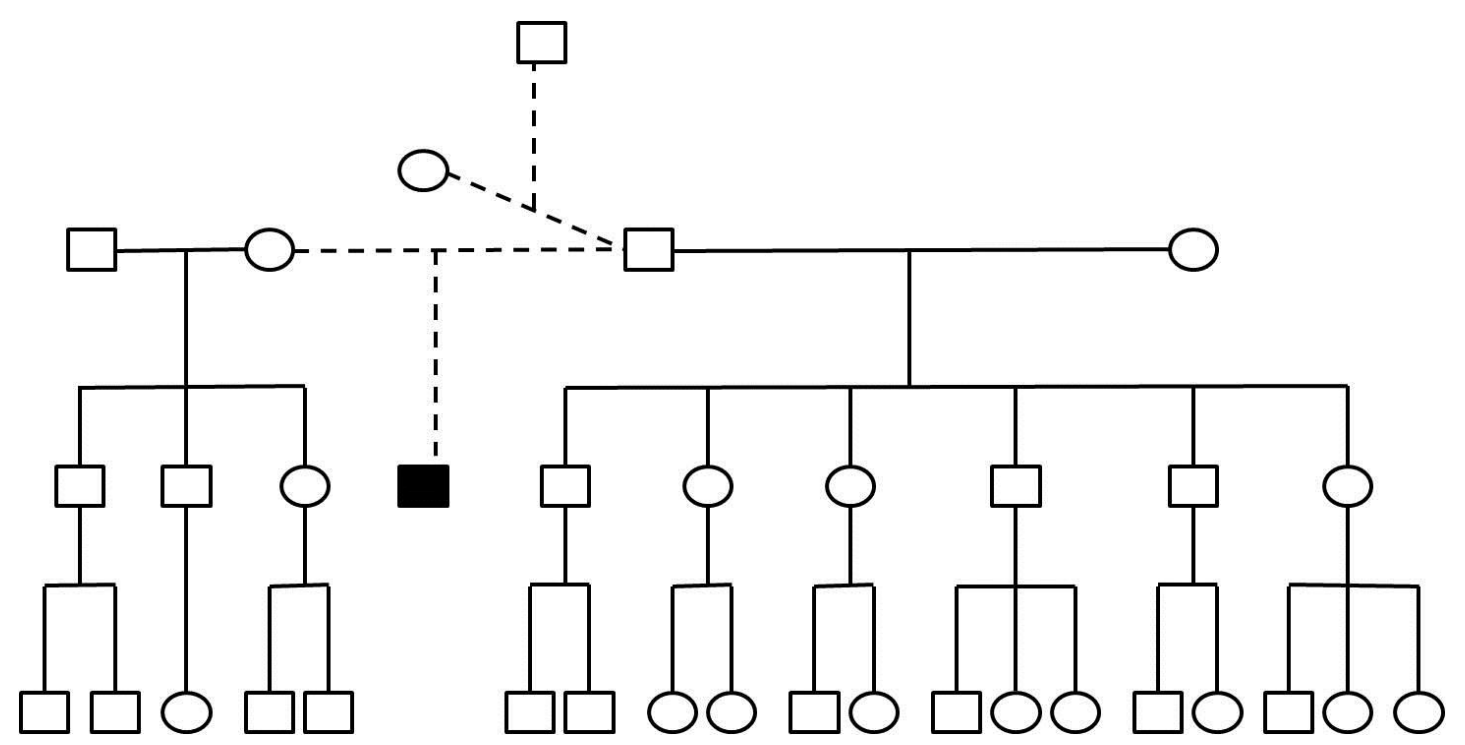

Figure 5. Hungarian pedigree affected by LS. (Nemes and Farkas et al., 2015)

\subsubsection{Spanish pedigree affected by multiple familial trichoepithelioma type 1}

The Spanish MFT1 pedigree of Hispanic origin was identified in the Levant region of Valencia, Spain. The 62-year-old father exhibited skin lesions that developed progressively on the central area of the face since the age of 14. Multiple skin-colored papules were present in both nasolabial folds (Figure 6a), on the forehead, above the eyebrows and, to a lesser extent, on the ears, on the back of the head and on the back. Histological examination revealed the diagnosis of trichoepithelioma (Figure 6b). The patient has been followed for 24 years, during which time the lesions have increased in number and size.

The patient's only child, a 33-year-old daughter, has lesions similar to those of her father but are fewer in number (Figure 6c). The lesions first appeared in both nasolabial folds and, over time, began to appear on her forehead, temples, ears and scalp.

No other clinically affected member has been identified in this pedigree (Figure 6d). 

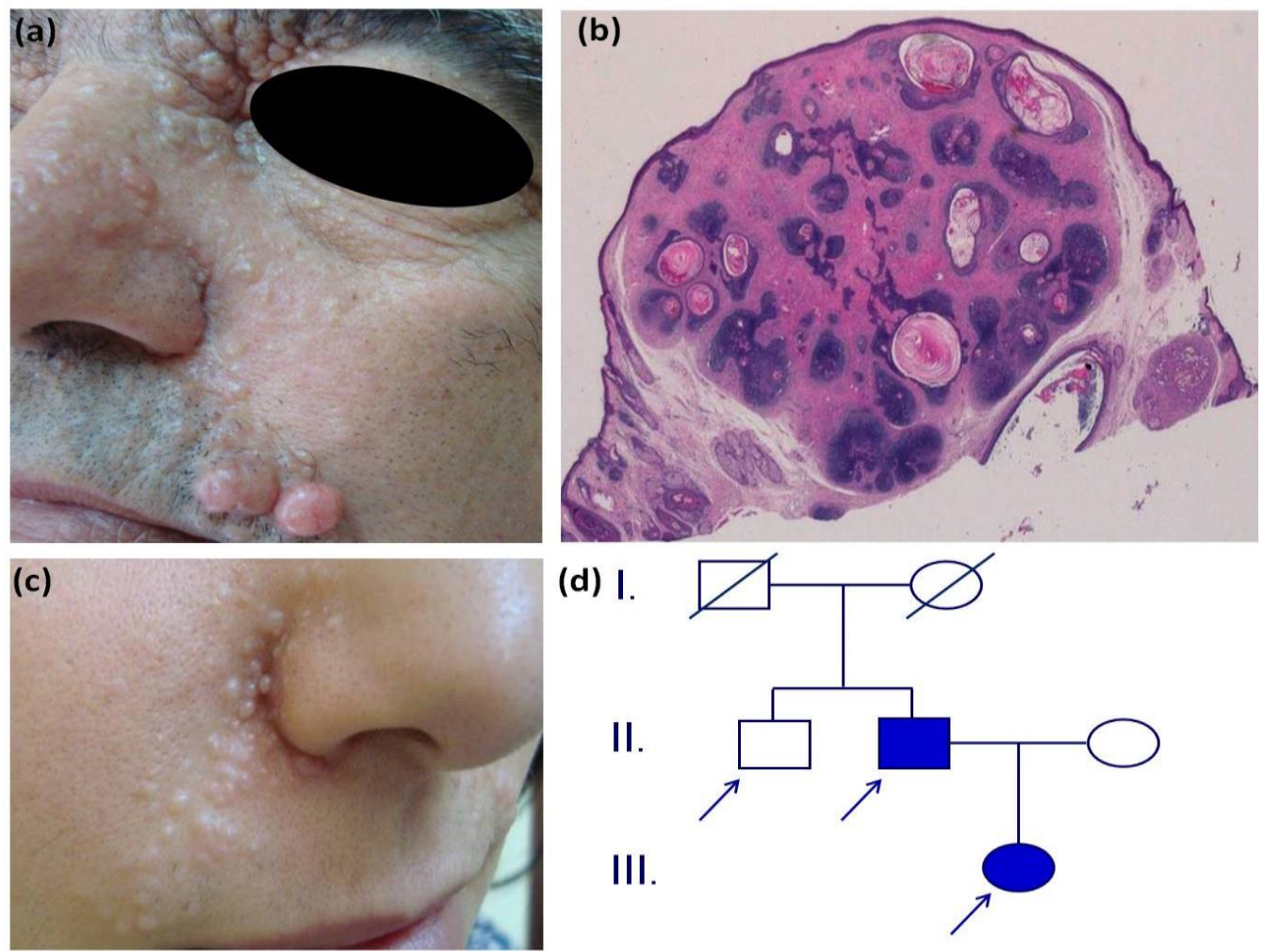

(d) I.

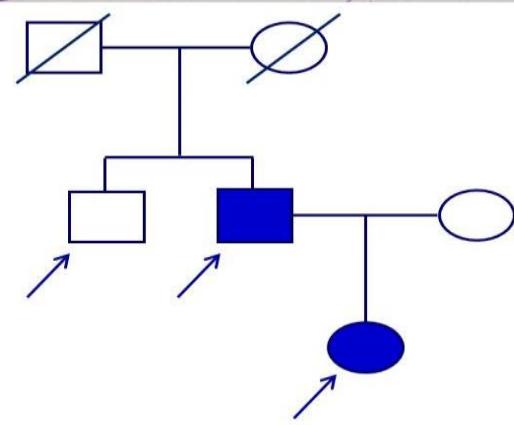

Figure 6. Skin symptoms (a,c), histology findings (b) and pedigree (d) of a Spanish family with multiple familial trichoepithelioma type 1. (Farkas et al., 2016)

\subsubsection{Dutch patients affected by familial cylindromatosis}

The investigated Dutch patients were previously reported by Van den Ouweland et al. Based on the development of cylindromas, these patients were diagnosed with FC. Their detailed clinical description is present in the report of Van den Ouweland et al. (Van den Ouweland et al., 2011).

\subsubsection{Austrian patient affected by Brooke-Spiegler syndrome}

The investigated Austrian patient was previously reported by Grossmann et al. Based on the development of different skin appendage tumors, the diagnosis of BSS was established. The detailed clinical description of the symptoms is available in the study of Grossmann et al. (Grossmann et al., 2013). 


\subsubsection{Hungarian pedigree from Szekszárd affected by Brooke-Spiegler syndrome}

A Hungarian pedigree, located in Hungary close to Szekszárd, has Bukovinian (Romania) origin affected by BSS was investigated. 21 affected family members were in the seven-generation family (Figure 7).

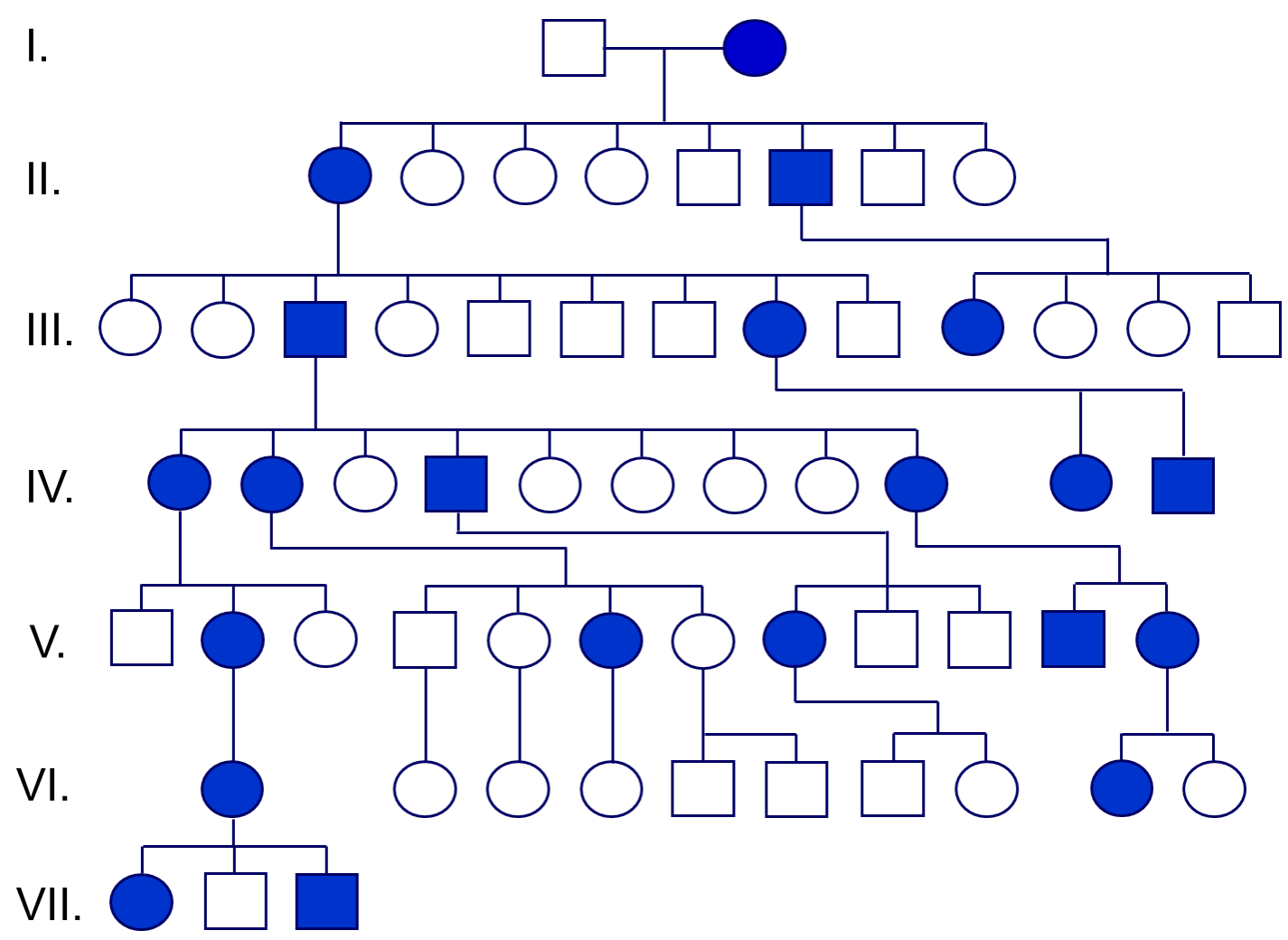

Figure 7. The investigated Hungarian BSS pedigree contains 21 affected family members spanning seven-generations. (Nagy et al., 2013)

The affected individuals have serious skin appendage tumors (Figure 8). Some of them have cylindromas on the scalp and trichoepitheliomas on the face. The tumors appeared in early life as small nodule and progressively enlarged and developed also on the back and on the extremities of the patients. 


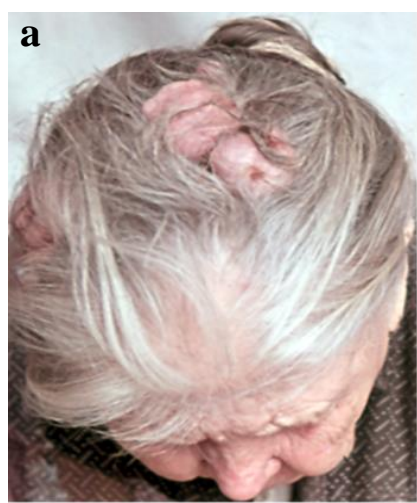

II/1

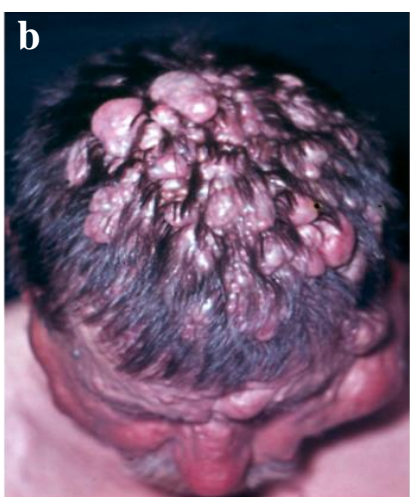

III/3

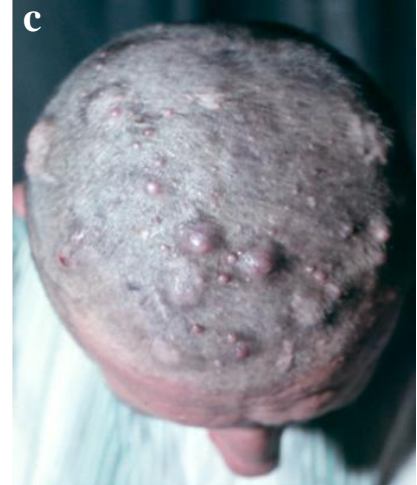

IV/4

Figure 8. Clinical pictures of the severe hairy scalp symptoms of the affected individuals are represented from the $2^{\text {nd }}(a), 3^{\text {rd }}\left(\right.$ b) and $4^{\text {th }}(c)$ generations. (Nagy et al., 2013)

\subsubsection{Anglo-Saxon pedigree affected by Brooke-Spiegler syndrome}

The Anglo-Saxon BSS pedigree from the north of England was also investigated. This pedigree contained 8 affected family members spanning five generations (Figure 9).

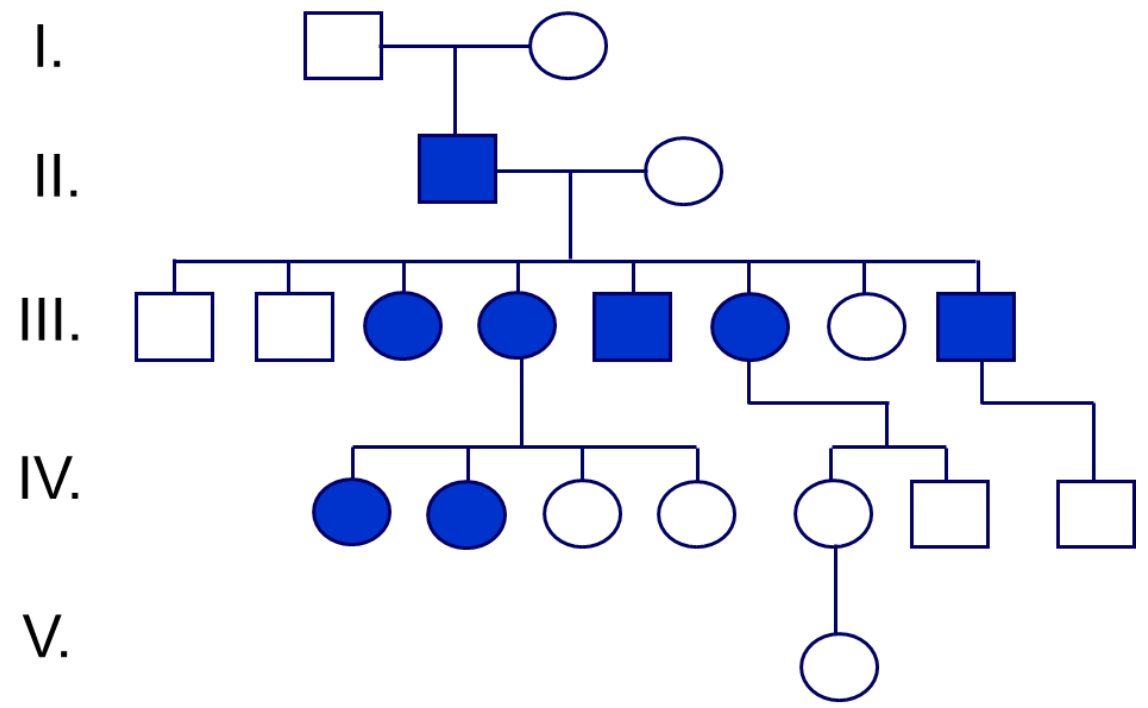

Figure 9. The investigated Anglo-Saxon pedigree from the North of England contains 8 affected family members spanning five-generations. (Nagy et al., 2013)

The affected individuals had a comparatively milder phenotype, with cylindromas and spiradenomas on the scalp and trichoepitheliomas on the face (Figure 10). 


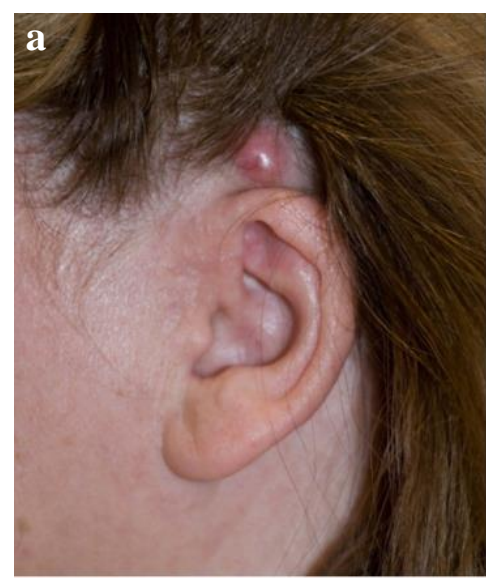

IV/1

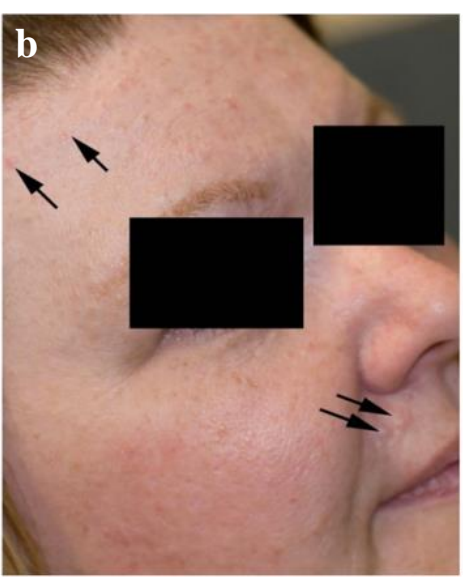

IV/1

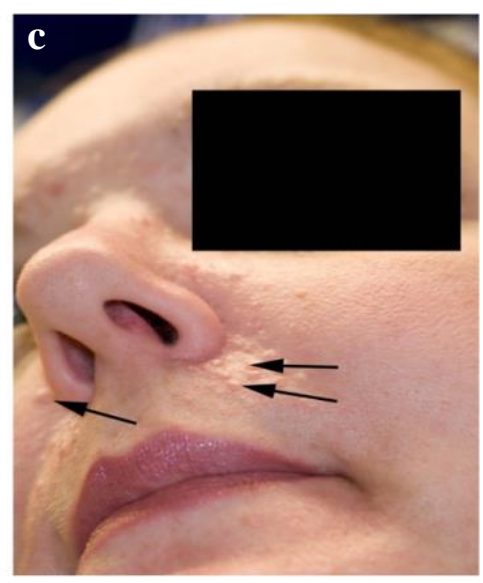

IV/2

Figure 10. Clinical pictures of the affected individuals from the $4^{\text {th }}$ generation shows tumors above the ear (a), on the forehead (b) and around the nose (c). (Nagy et al., 2013)

\subsubsection{Hungarian pedigree from Szeged affected by Brooke-Spiegler syndrome}

A pedigree from the Southern part of Hungary (Szeged region) affected by BSS was investigated. The pedigree has 2 affected and 5 unaffected individuals spanning two generations (Figure 11).

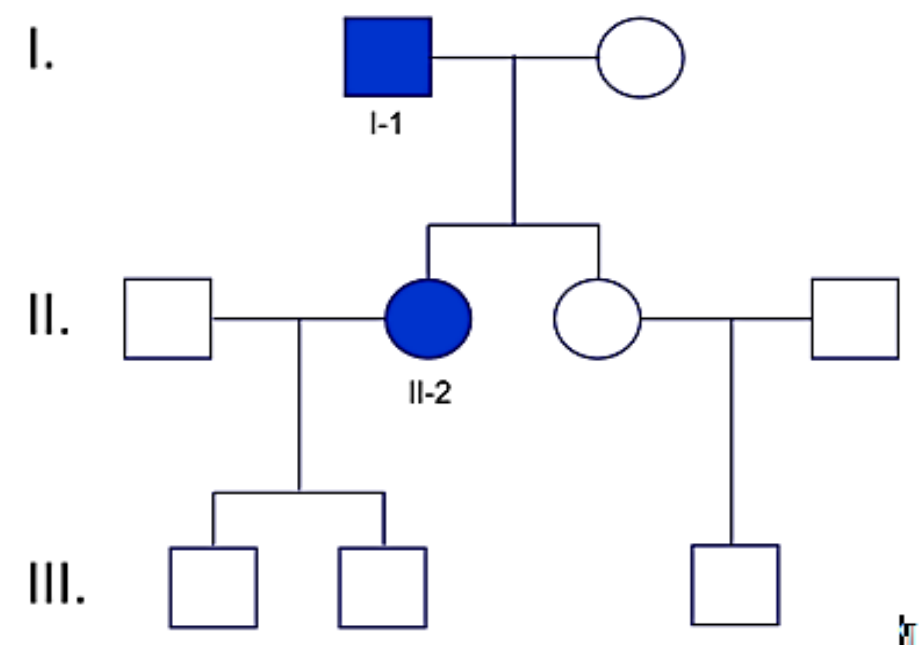

Figure 11. The investigated Hungarian pedigree has two clinically affected individuals. (Nagy et al., 2012)

One of the affected individuals, a 60-year-old male (I-1), has numerous soft, hairless, skin-colored papules around his nose, in his ears, on his scalp and on his shoulders (Figure 12). Some of the tumors in the head and neck region were surgically removed. Routine histological examination of the excised tumors 
suggested the diagnosis of the BSS. His daughter (II-2), a 35-year-old female, presented with milder symptoms.
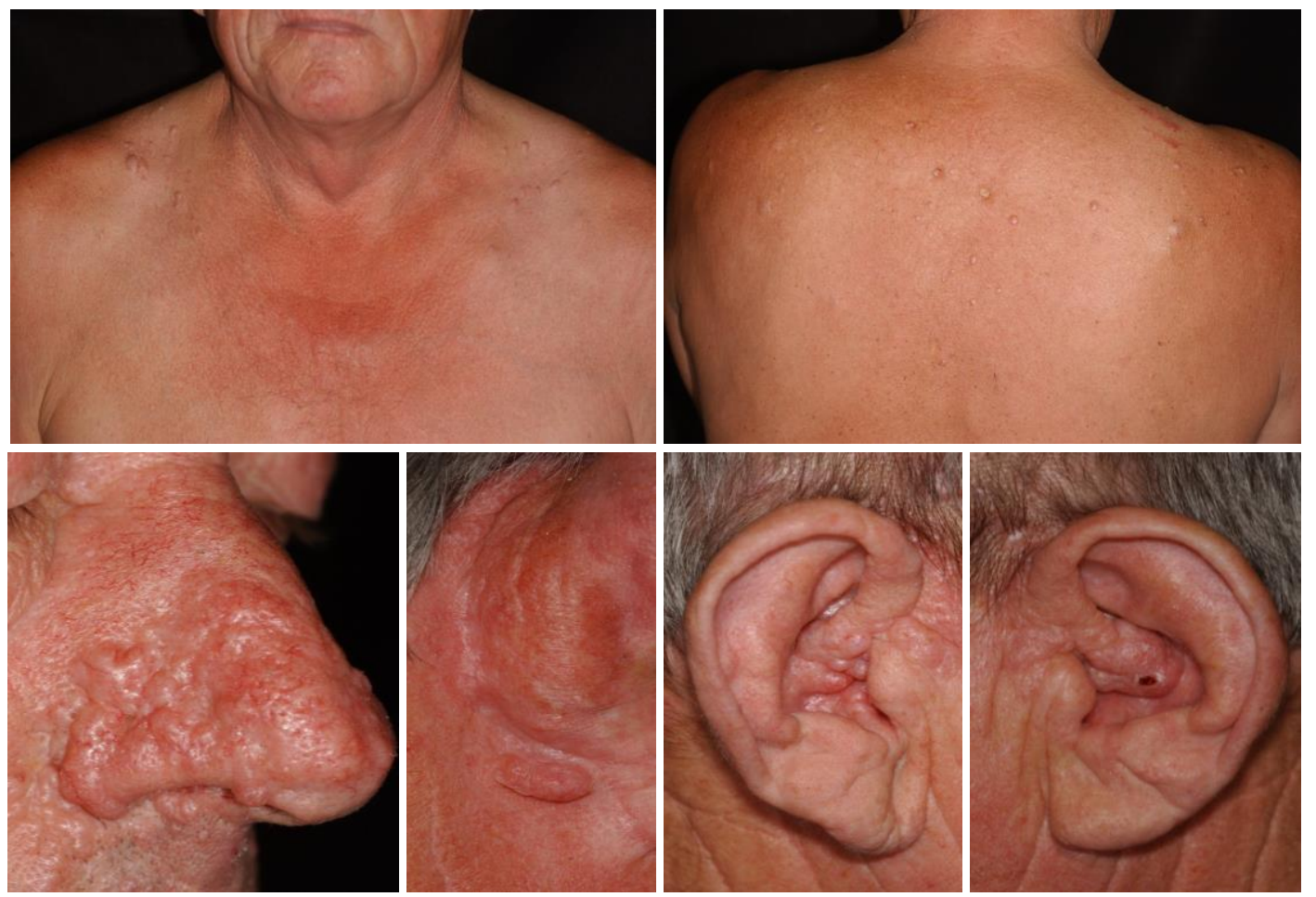

Figure 12. Numerous skin-colored, dome-shaped tumors are present on the shoulder $(a)$, on the back $(b)$, around the nose (c), in the retroauricular region $(d)$ and in the ears (e-f) of patient I-1. (Nagy et al., 2012)

\subsection{Methods}

\subsubsection{DNA isolation}

After pre-test genetic counseling was performed and written informed consents were obtained from the enrolled patients and controls according to a protocol approved by the Local Ethics Committee in adherence to the Helsinki guidelines, blood samples were taken from the patients. Genomic DNA was isolated from whole blood samples using a QIAamp DNA Blood Mini Kit (QIAGEN; Hilden, Germany). During the isolation, after proteinase K digestion, washings with alcohol were done following the instructions. Genomic DNA was dissolved in $100 \mu 1$ distilled water. 


\subsubsection{Polymerase chain reaction (PCR) amplification}

During PCR amplification, $4 \mu$ genomic DNA was used as template. In addition, the reaction mix contains $9 \mu$ Dream Taq Green PCR Master Mix (Fermentas), $4 \mu \mathrm{l}$ distilled water, 1,5 $\mu \mathrm{l}$ forward and 1,5 $\mu 1$ reverse primers. The using primers sequences obtained from the UCSC Genome Browser (www.genome.ucsc.edu) and Primer3 (http://bioinfo.ut.ee/primer3-0.4.0/). A MyCycler PCR machine (BioRad) was used following the PCR conditions:

1. step: $95^{\circ} \mathrm{C}$ for $10 \mathrm{~min}$

2. step: $95^{\circ} \mathrm{C}$ for $30 \mathrm{sec}$ (denaturation)

3. step: $59^{\circ} \mathrm{C}$ for $30 \mathrm{sec}$ (annealing)

4. step: $72^{\circ} \mathrm{C}$ for $45 \mathrm{sec}$ (synthesis)

5. step: $72^{\circ} \mathrm{C}$ for $10 \mathrm{sec}$

6. step: $4^{\circ} \mathrm{C} \infty$

The $2^{\text {nd }}, 3^{\text {rd }}$ and $4^{\text {th }}$ steps were repeated 40 times. The annealing temperature and the number of the cycles were depended on the primers, the synthesis reaction time was determined according to the length of the reaction product.

\subsubsection{Gel electrophoresis and gel documentation}

The PCR products were checked on 2\% agarose gel (SeaKem LE agarose, Lonza) using TBE buffer (Lonza) and visualized by 2,5 $\mu$ l GelRed (Biotium) staining. The gel was analyzed by BioRad Molecular Imager ${ }^{\circledR}$ GelDoc ${ }^{\mathrm{TM}}$ XR gel documentation system with QuantityOne software.

\subsubsection{Sequencing}

The sequencing was performed after the suitable purifying of the PCR reaction products using Big Dye Terminator v3.1 Cycle sequencing kit (Applied Biosystems) with ABI Prism 7000 (Applied Biosystems) sequencing machine. The service of the sequencing was offered by Delta Bio $2000 \mathrm{Kft}$. 


\subsubsection{Haplotype analysis}

For the haplotype analysis, common polymorphisms located in the 3' and 5' prime region of the identified mutation were genotyped using direct sequencing of the flanking coding and non-coding regions of the CYLD gene.

\subsubsection{Immunoprecipitation}

Four-mm punch biopsy samples were collected from patients affected by Brooke-Spiegler syndrome $(\mathrm{n}=2)$ and from healthy individuals $(\mathrm{n}=2)$. After Dispase (Grade II, Roche Applied Science) digestion, fibroblasts were isolated and cultured using standard methods. After washing with PBS, fibroblasts were suspended in $1 \mathrm{ml}$ lysis buffer (Sigma) then samples were homogenized with a pre-chilled homogenizer. According to the instructions of the Immunoprecipitation Kit Protein $\mathrm{G}$ (Roche Applied Science), NEMO protein was immunoprecipitated with anti-human NEMO mouse antibody (BD Pharmingen) from fibroblasts of BSS patients and healthy donors.

\subsubsection{Western blot analysis}

Equal amounts of the immunoprecipitated NEMO proteins were run on $10 \%$ SDS-polyacrylamide gel. The proteins were transferred from the gel to nitrocellulose membrane by dry blot system (iBlot Gel Transfer System, Invitrogen). The membranes were saturated in TBS containing 3\% nonfat dry milk for 2 hours. Western blot was performed using anti-human ubiquitin mouse primary antibody (Santa Cruz Biotechnology) to detect the ubiquitination of the loaded samples. The nitrocellulose membrane was incubated in TBS containing 3\% nonfat dry milk overnight. After washings, alkaline phosphatase-conjugated rabbit anti-mouse $\operatorname{IgG}$ (Sigma) was used as secondary antibody and blots were developed by using 5bromo-4-chloro-3-indolyl phosphate/nitroblue tetrazolium (Sigma) as substrate. 


\section{RESULTS}

\subsection{Genetic investigation of the protein-tyrosine phosphatase nonreceptor-type}

\section{1 (PTPN11) gene}

The coding regions and the flanking introns of the PTPN11 gene were amplified. Primers were used as displayed on the UCSC Genome Browser (www.genome.ucsc.edu) (Table 2).

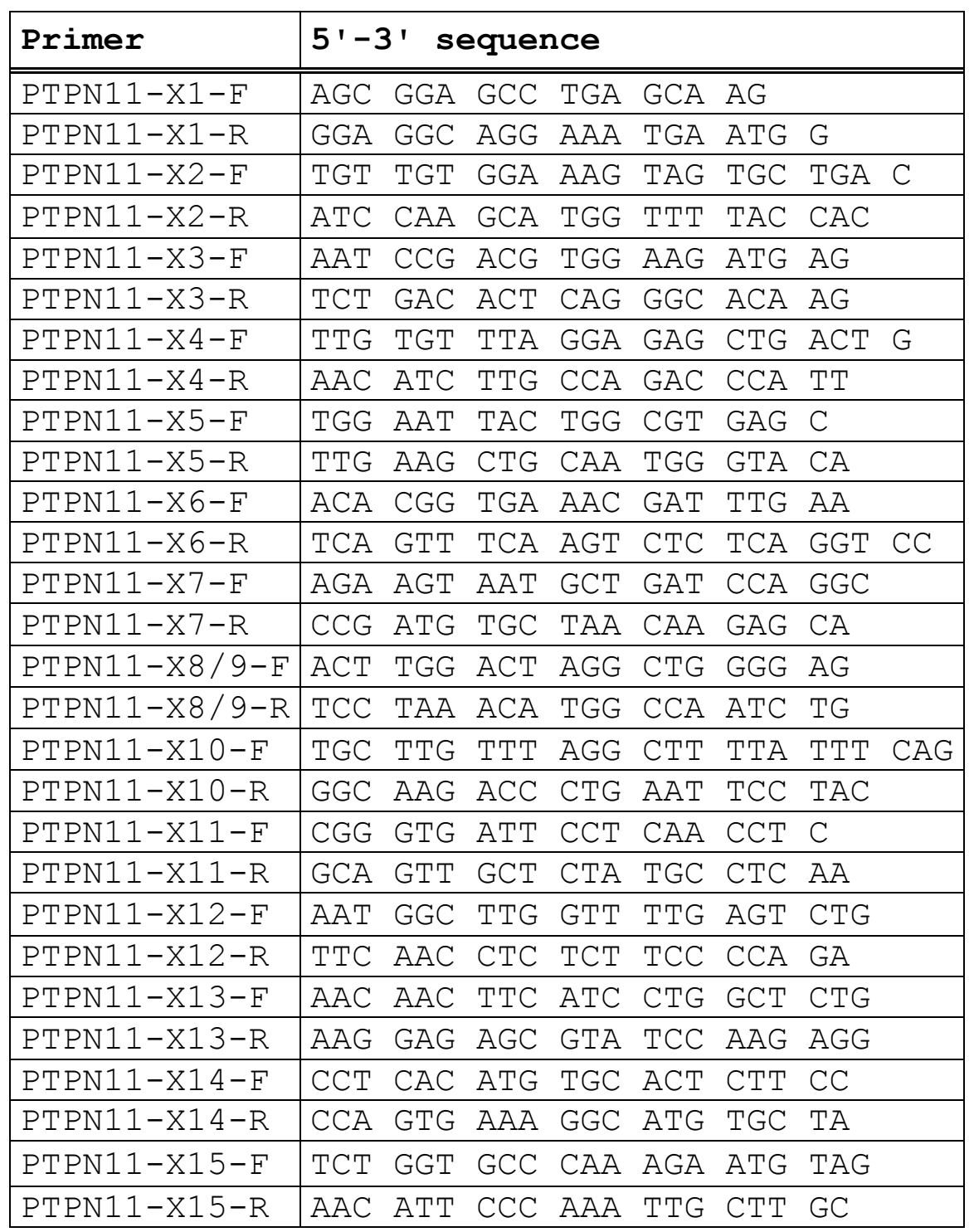

Table 2. The list of primers used for the genetic investigations.

The results of PCR were checked by agarose gel electrophoresis (Figure 13) and DNA sequencing was performed. 


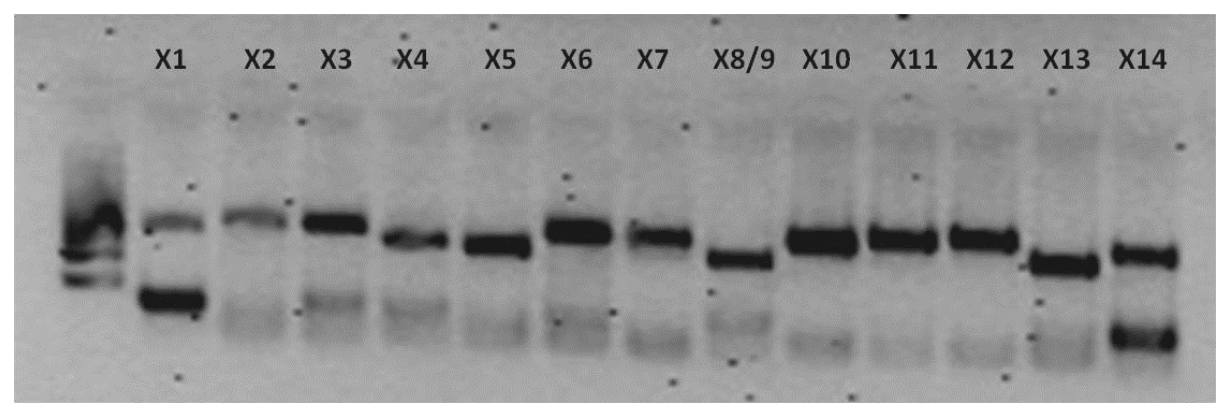

Figure 13. Examination of the samples on agarose gel after the amplification.

Direct sequencing of the coding regions and the flanking introns of the PTPN11 gene revealed a heterozygous missense mutation (c.836A/G; p.Tyr279Cys) in the seventh exon (Figure 14a). The clinically affected patient carried the mutation in heterozygous form, while the unrelated healthy controls $(n=30)$ carried the wild type sequence (Figure 14b).

(a)
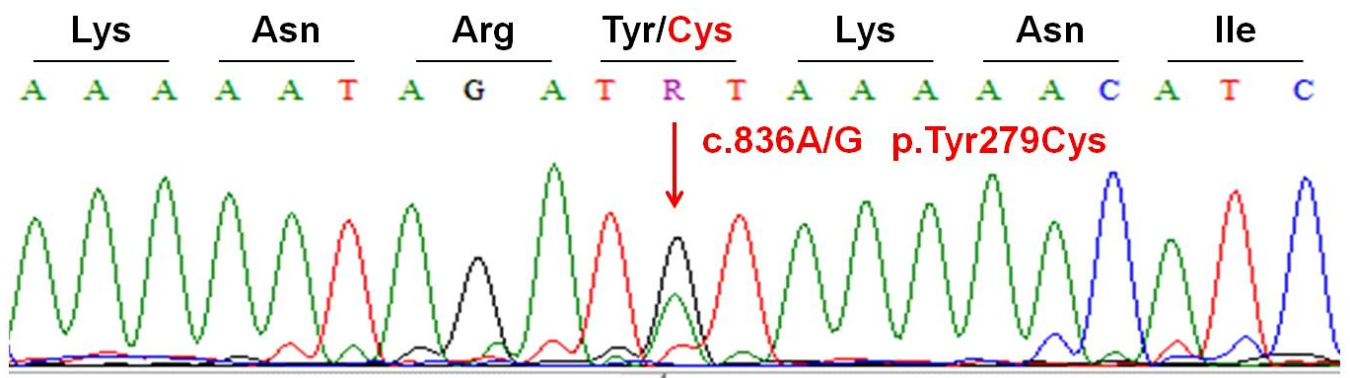

DNA sequence of the patient

(b)
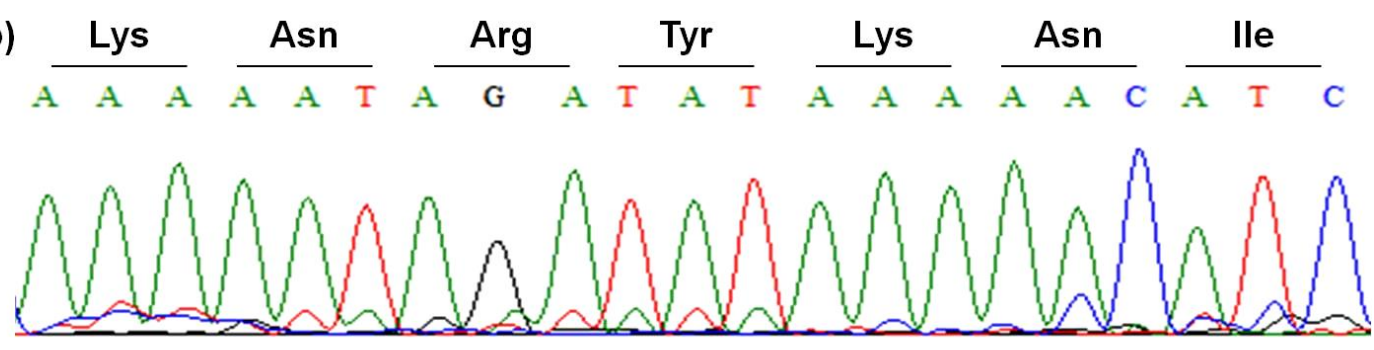

Control DNA sequence

Figure 14. Direct sequencing revealed a heterozygous missense mutation (c.836A/G; p.Tyr279Cys) in the seventh exon of the PTPN11 gene. The patient carried the mutation in heterozygous form (a), while the unrelated controls carried the wild type sequence (b). (Nemes and Farkas et al., 2015)

The investigated Hungarian LS patient carries one of the most common missense mutation of the PTPN11 gene. Functional studies demonstrated that the p.Tyr279Cys heterozygous missense mutation of the PTPN11 gene perturbs the switching of the SHP-2 protein between its catalytically inactive and active conformation and engenders loss of SHP-2 catalytic activity (Tartaglia et al., 2006). 


\subsection{Genetic, haplotype and functional investigation of the cylindromatosis (CYLD) gen}

\subsubsection{Genetic investigation of the Spanish pedigree}

Since the $99 \%$ of the identified mutation of the CYLD gene are located in exons 9-20, these coding regions and the flanking introns of the CYLD gene were amplified. Primers were used as displayed on the UCSC Genome Browser (www.genome.ucsc.edu) (Table 3).

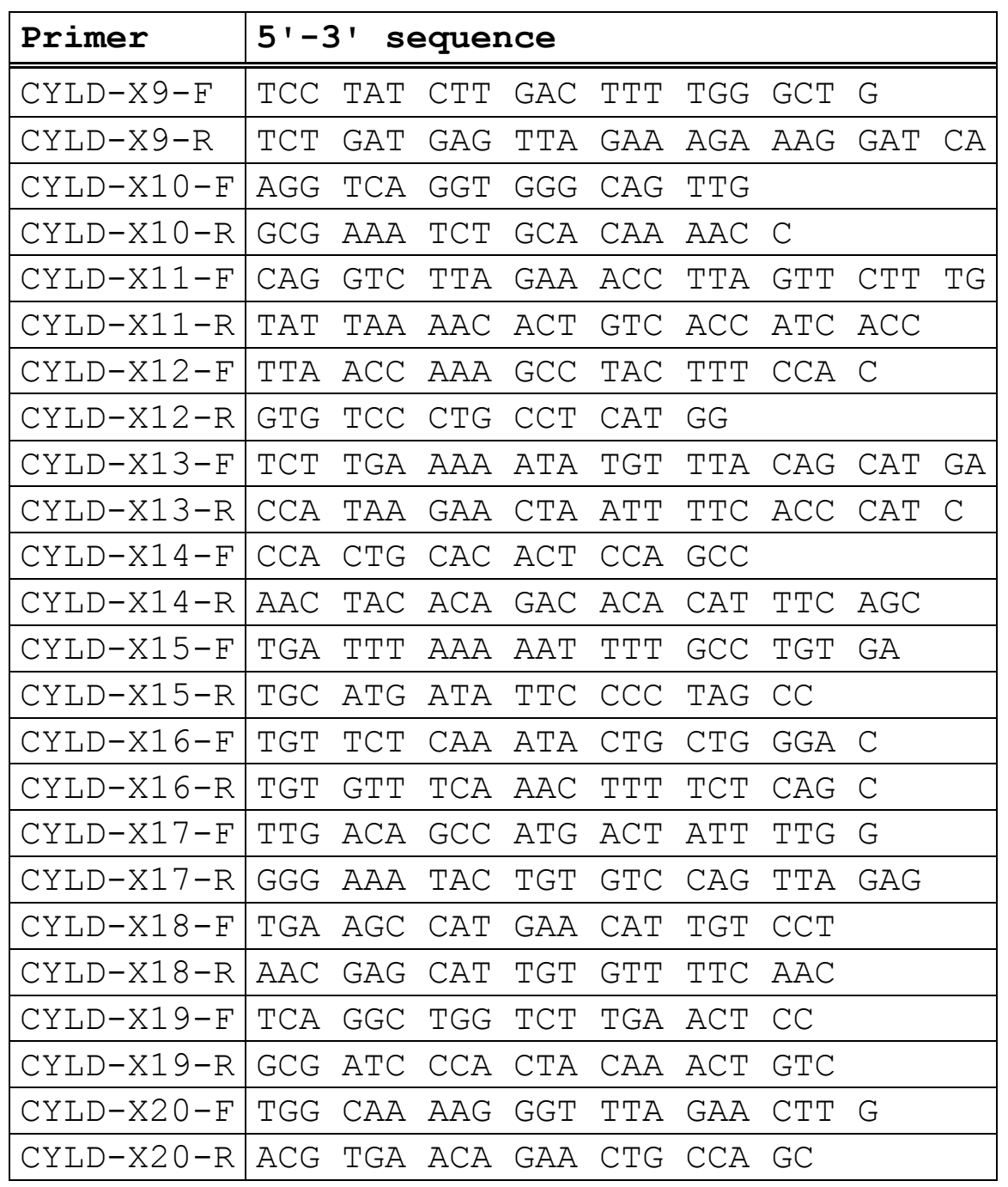

Table 3. The list of primers used for the genetic investigations.

The results of PCR were checked by agarose gel electrophoresis (Figure 15) and DNA sequencing was performed. 


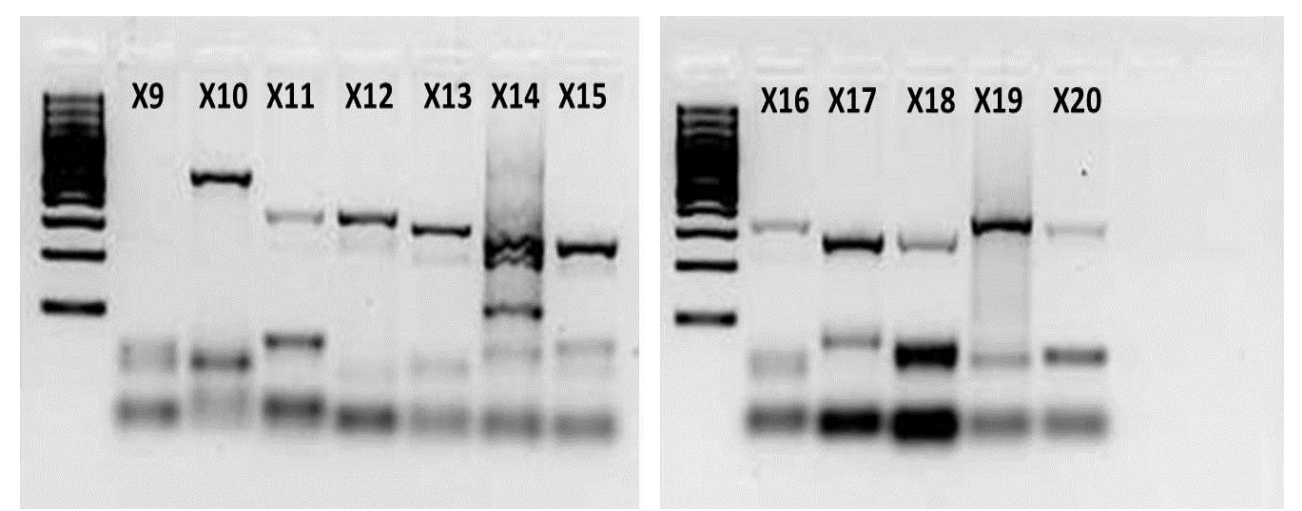

Figure 15. Examination of the samples on agarose gel after the amplification

Direct sequencing of the coding regions and the flanking introns of the CYLD gene from the investigated Spanish patients revealed a previously described nonsense mutation in exon 17 (c.2272C/T, p.R758X, CM001116, rs121908388). Both patients carried the mutation in heterozygous form (Figure 16a), whereas the unaffected family members and the unrelated controls carried the wild-type sequence (Figure $16 b)$.

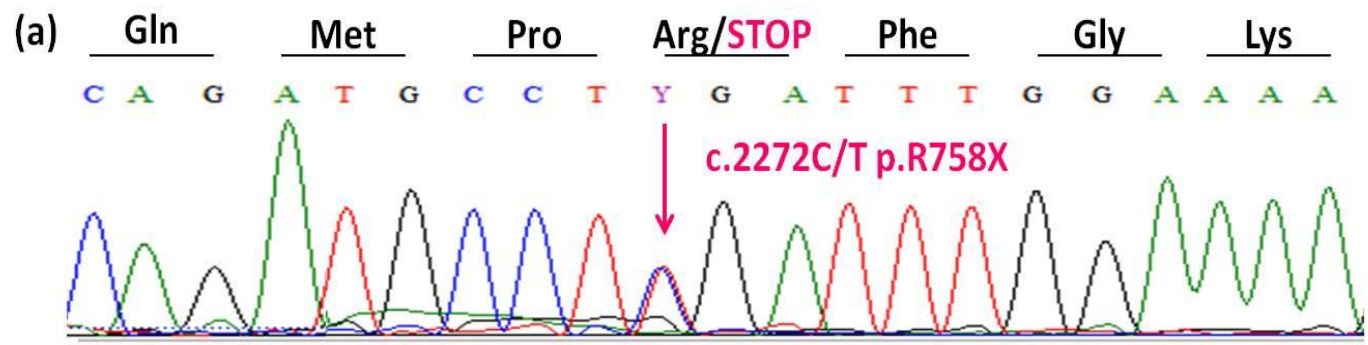

DNA sequence from the affected patients

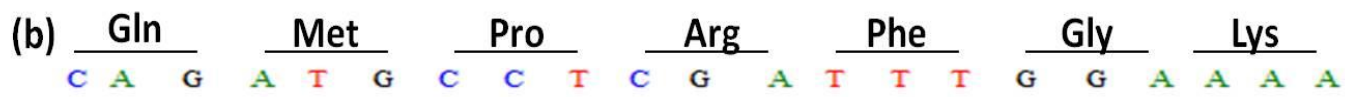

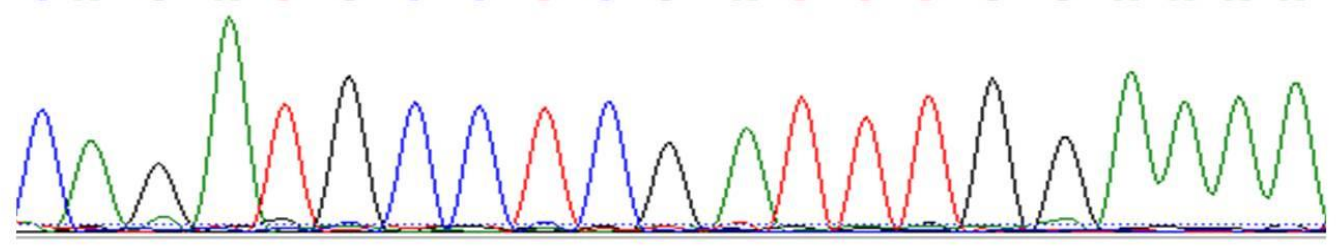

DNA sequence from an unaffected patient

Figure 16. Direct sequencing of the CYLD gene. The affected family members carried the nonsense mutation (c.2272C/T, p.R758X) in heterozygous form (a). The unaffected family members carried the wild-type sequence (b). (Farkas et al., 2016) 


\subsubsection{Haplotype analysis of the Spanish pedigree, the Dutch and the Austrian patients}

Previously reported Dutch and Austrian cases carrying the same mutation that was identified in the Spanish pedigree (c.2272C/T, p.R758X) - were also investigated (Van den Ouweland et al., 2011; Grossmann et al., 2013). Haplotype analysis of the Spanish patients with MFT1, as well as Dutch patients with FC and an Austrian patient with BSS was performed to investigate whether the same or different mutational events are responsible for the development of these cases.

The surrounding polymorphisms were examined upstream and downstream from the mutation (c.2272C/T, p.R758X) by direct sequencing. The using primers sequences obtained from Primer3 (http://primer3.ut.ee/) and listed in Table 4.

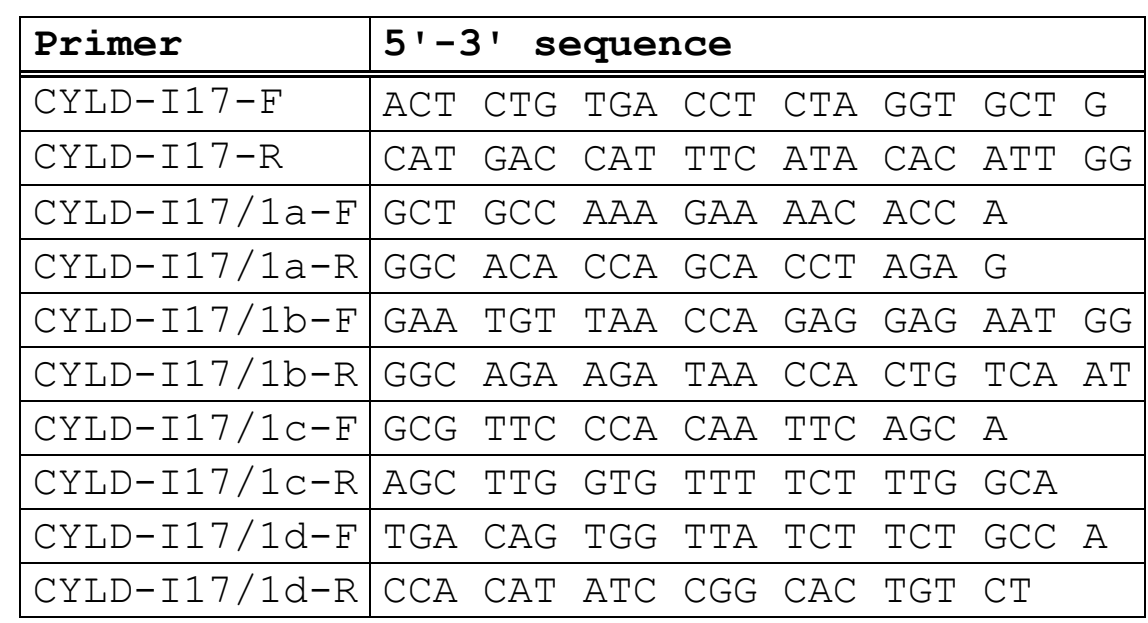

Table 4. The list of primers used for the haplotype analysis.

The results demonstrated that the Spanish and the Dutch pedigrees carry the same haplotype, whereas the Austrian patient carries a different haplotype. Thus, it can be assumed that different mutational events are responsible for the development of the Austrian case and the Spanish and Dutch cases (Table 5). 


\begin{tabular}{|c|c|c|c|c|c|c|c|}
\hline \multirow[t]{2}{*}{ Nationality } & & \multicolumn{3}{|c|}{ Spanish } & \multicolumn{2}{|c|}{ Dutch } & \multirow[t]{2}{*}{ Austrian } \\
\hline & & $\mathrm{II} / 1$ & $\mathrm{II} / 2$ & $\mathrm{III} / 1$ & & & \\
\hline & & healthy & symptomatic & symptomatic & symptomatic & symptomatic & symptomatic \\
\hline $\begin{array}{c}\text { Polymorphism } \\
\text { ID }\end{array}$ & $\begin{array}{c}\text { Frequent } \\
\text { allele }\end{array}$ & & & & & & \\
\hline rs35072258 & $\mathrm{TC} /-$ & TCTC & TCTC & TCTC & ТСТС & TCTC & TCTC \\
\hline rs11866167 & $C / A$ & CC & CC & CC & CC & CC & CC \\
\hline rs111543527 & $\mathrm{T} / \mathrm{C}$ & TT & TT & TT & TT & TT & TT \\
\hline rs72796392 & $\mathrm{T} / \mathrm{C}$ & TT & TT & TT & TT & TT & TT \\
\hline rs141129479 & $A / G$ & $\mathrm{AA}$ & AA & $\mathrm{AA}$ & AA & $\mathrm{AA}$ & AA \\
\hline rs146946436 & $A / G$ & $\mathrm{AA}$ & AA & $\mathrm{AA}$ & AA & $\mathrm{AA}$ & AA \\
\hline rs185111122 & $\mathrm{T} / \mathrm{C}$ & $\mathrm{TT}$ & TT & $\mathrm{TT}$ & $\mathrm{TT}$ & $\mathrm{TT}$ & TT \\
\hline rs149201712 & $\mathrm{AC} /-$ & ACAC & ACAC & ACAC & ACAC & ACAC & ACAC \\
\hline rs368656359 & $\mathrm{G} / \mathrm{A}$ & GG & GG & GG & GG & GG & GG \\
\hline rs137990687 & $\mathrm{G} / \mathrm{A}$ & GG & GG & GG & GG & GG & GG \\
\hline rs201757487 & G/- & GG & GG & GG & GG & GG & GG \\
\hline rs10451132 & $\mathrm{G} / \mathrm{T}$ & GG & GG & GG & GG & GG & GT \\
\hline rs370702435 & $A / G$ & AA & AA & AA & AA & AA & AA \\
\hline \begin{tabular}{|l|} 
CM001116 \\
rs121908388
\end{tabular} & $\mathrm{C} / \mathrm{T}$ & CC & CT & CT & CT & CT & CT \\
\hline rs199912760 & $\mathrm{G} / \mathrm{A}$ & GG & GG & GG & GG & GG & GG \\
\hline rs375106322 & $\mathrm{G} / \mathrm{A}$ & GG & GG & GG & GG & GG & GG \\
\hline r201860550 & $\mathrm{G} / \mathrm{T}$ & GG & GG & GG & GG & GG & GG \\
\hline rs149502055 & $\mathrm{C} / \mathrm{T}$ & CC & CC & CC & CC & $\mathrm{CC}$ & CC \\
\hline rs376795685 & $\mathrm{G} / \mathrm{A}$ & GG & GG & GG & GG & GG & GG \\
\hline rs144013604 & $A / G$ & AA & AA & AA & AA & AA & AA \\
\hline rs75157714 & $\mathrm{G} / \mathrm{A}$ & GG & GG & GG & GG & GG & GG \\
\hline rs201233994 & AT/- & AT & AT & AT & AT & AT & AT \\
\hline rs200973965 & ATAC/- & ATAC & ATAC & ATAC & ATAC & ATAC & ATAC \\
\hline rs77528321 & $\mathrm{T} / \mathrm{C}$ & TT & TT & TT & TT & TT & TT \\
\hline rs146702654 & $T /-$ & $\mathrm{TT}$ & $\mathrm{TT}$ & $\mathrm{TT}$ & $\mathrm{TT}$ & $\mathrm{TT}$ & TT \\
\hline rs6145827 & ACACAC/- & $\begin{array}{l}\text { ACACAC } \\
\text { ACACAC }\end{array}$ & $\begin{array}{l}\text { ACACAC } \\
\text { ACACAC }\end{array}$ & $\begin{array}{l}\text { ACACAC } \\
\text { ACACAC }\end{array}$ & $\begin{array}{l}\text { ACACAC } \\
\text { ACACAC }\end{array}$ & $\begin{array}{l}\text { ACACAC } \\
\text { ACACAC }\end{array}$ & $\begin{array}{l}\text { ACACAC } \\
\text { ACACAC }\end{array}$ \\
\hline rs3064638 & ACACAC/- & $\begin{array}{l}\text { ACACAC } \\
\text { ACACAC }\end{array}$ & $\begin{array}{l}\text { ACACAC } \\
\text { ACACAC }\end{array}$ & $\begin{array}{l}\text { ACACAC } \\
\text { ACACAC }\end{array}$ & $\begin{array}{l}\text { ACACAC } \\
\text { ACACAC }\end{array}$ & $\begin{array}{l}\text { ACACAC } \\
\text { ACACAC }\end{array}$ & -- \\
\hline rs73584492 & $A / G$ & AA & $\mathrm{AA}$ & AA & $\mathrm{AA}$ & AA & AA \\
\hline rs190892314 & $A / G$ & AA & AA & AA & AA & AA & AA \\
\hline rs200678983 & $\mathrm{C} / \mathrm{T}$ & $\mathrm{CC}$ & $\mathrm{CC}$ & $\mathrm{CC}$ & $\mathrm{CC}$ & CC & $\mathrm{CC}$ \\
\hline rs76797023 & $\mathrm{A} / \mathrm{T}$ & AA & $\mathrm{AA}$ & AA & AA & AA & $\mathrm{AA}$ \\
\hline rs77678929 & $\mathrm{T} / \mathrm{A}$ & $\mathrm{TT}$ & TT & TT & TT & TT & TT \\
\hline rs376799359 & $\mathrm{A} / \mathrm{T}$ & AA & AA & AA & AA & AA & AA \\
\hline rs201103123 & $\mathrm{C} / \mathrm{T}$ & $\mathrm{CC}$ & $\mathrm{CC}$ & CC & $\mathrm{CC}$ & CC & $\mathrm{CC}$ \\
\hline
\end{tabular}

Table 5. Haplotype analysis of Spanish, Dutch and Austrian patients carrying the same recurrent nonsense mutation. (Farkas et al., 2016) 


\subsubsection{Genetic investigation of the Hungarian pedigree from Szekszárd}

The coding regions (exon 9-20) and the flanking introns of the CYLD gene were amplified. Primers were used as displayed on the UCSC Genome Browser (www.genome.ucsc.edu) (Table 3). The results of PCR were checked by agarose gel electrophoresis and DNA sequencing was performed.

Direct sequencing of the coding regions and the flanking introns of the $C Y L D$ gene revealed a nonsense mutation (c.2806C > T, p.Arg936X) previously described by Bignell et al. in exon 20. The investigated affected family members of the Hungarian BSS pedigree carried the mutation in heterozygous form (Figure 17a), while the available, clinically unaffected family members and the unrelated healthy controls carried the wild type sequence (Figure 17b).

(a)

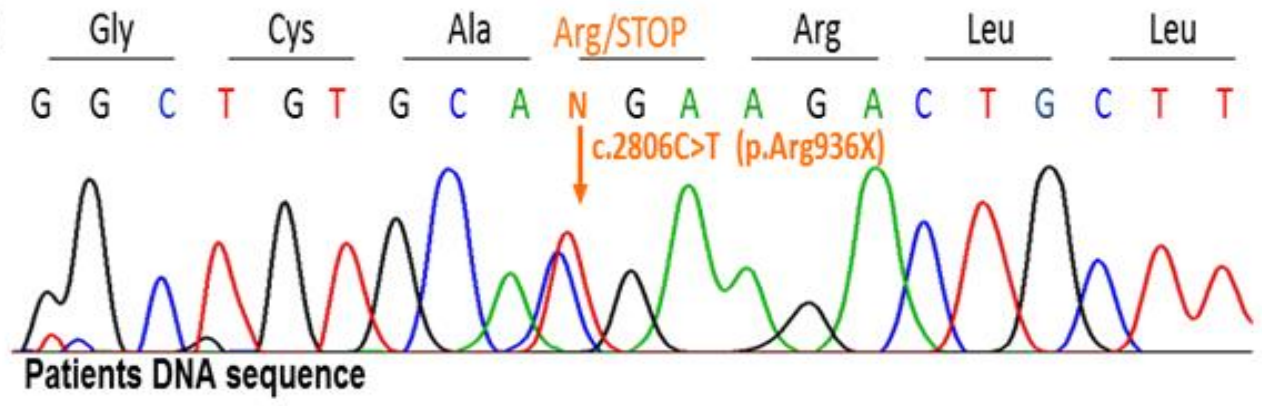

(b)

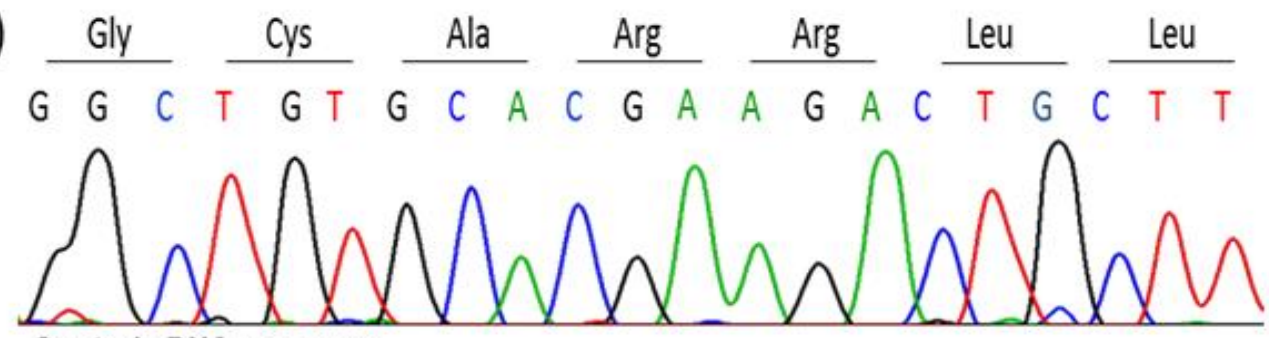

Controls DNA sequence

Figure 17. The DNA sequence of the affected patients shows a heterozygous single nucleotide substitution: c.2806C>T, p.Arg936X (a). Wild-type sequence of the CYLD gene. (Nagy et al., 2013)

\subsubsection{Haplotype analysis of the Hungarian pedigree from Szekszárd and the} Anglo-Saxon pedigree

Based on the literature, an Anglo-Saxon BSS pedigree from the north of England also carried the same nonsense mutation (c.2806C>T, p.Arg936X), that was identified the Hungarian pedigree from Szekszárd. Since this nonsense mutation is present in an Anglo-Saxon pedigree, I planned to perform the haplotype analysis of 
the two geographically distant pedigrees to reveal whether the mutation they carry is the result of two independent mutational events or they are carrying the same founding mutation.

The surrounding polymorphisms were examined upstream and downstream from the mutation (c.2806C > T, p.Arg936X) by direct sequencing. The using primers sequences obtained from Primer3 (http://primer3.ut.ee/) and listed in Table 6.

\begin{tabular}{|l|l|}
\hline Primer név & Bázissorrend (5'-3') \\
\hline \hline CYLD-I19/1-F & GCA TTA ACA ACC TTG CTA GCT GA \\
\hline CYLD-I19/1-R & ATG GTG GCA TAT GCG TGT AG \\
\hline CYLD-I19/2-F & TCA CAC CCC AGA GCA CCT \\
\hline CYLD-I19/2-R & GAG GTA AGC CCC CAA CCT \\
\hline CYLD-I20/1-F & TGC ATG TAC CAG AGT CCA ACA \\
\hline CYLD-I20/1-R & AAG AGG CTT TAA ACT TCC ACA A \\
\hline CYLD-I20/2-F & AAT GGG GCA AAG TAA ATT GAT G \\
\hline CYLD-I20/2-R & GAG AAT GCA CAT TCC ACA GC \\
\hline
\end{tabular}

Table 6. The list of primers used for the haplotype analysis.

As the result of the examination, in the case of the Hungarian pedigree from Szekszárd, two polymorphisms (rs2160683, rs115042932) were found, which were inherited linked to the mutation in the CYLD gene (Table 7). Thus all of the clinically affected family members carried the AGT allele determined by these two polymorphisms and the mutation. The AGT allele was not present in the unaffected family members.

In the case of the Anglo-Saxon BSS pedigree, I examined whether the AGT allele (rs2160683, rs115042932, CM001120) identified in the Hungarian pedigree is carried by the affected family members. The results of the haplotype analysis showed that the Anglo-Saxon BSS pedigree did not carry the AGT allele, which means that the same nonsense mutation was the result of two independent mutational events in the two geographically distant pedigrees (Table 8). Thus this part of the CYLD gene could be a mutational hotspot. 


\begin{tabular}{|l|c|c|c|c|c|}
\hline \multicolumn{1}{|c|}{ SNP } & & $\begin{array}{c}\text { Hungarian } \\
\text { affected } \\
\text { patient } \\
\text { (V/2) }\end{array}$ & $\begin{array}{c}\text { Hungarian } \\
\text { affected } \\
\text { patient } \\
\text { (V/11) }\end{array}$ & $\begin{array}{c}\text { Hungarian } \\
\text { affected } \\
\text { patient } \\
\text { (V/12) }\end{array}$ & $\begin{array}{c}\text { Hungarian } \\
\text { unaffected } \\
\text { patient } \\
\text { (VI/10) }\end{array}$ \\
\hline rs 28705891 & C/T & CC & CC & CC & CC \\
\hline rs 28654666 & T/C & TT & TT & TT & TT \\
\hline rs 112993837 & C/T & CC & CC & CC & CC \\
\hline rs 60077744 & G/A & GG & GG & GG & GG \\
\hline rs 2160683 & T/A & TA & AA & TA & TT \\
\hline rs 115042932 & C/G & CG & CG & CG & CC \\
\hline rs117998712 & C/C & CC & CC & CC & CC \\
\hline CM001120 & C/T & CT & CT & CT & CT \\
\hline rs 116979331 & G/A & GG & GG & GG & GG \\
\hline rs 74822565 & G/T & GG & GG & GG & GG \\
\hline rs 117713908 & A/G & AA & AA & AA & AA \\
\hline rs 3743781 & A/G & AA & AA & AA & AA \\
\hline rs 117537927 & G/A & GA & GG & GG & GG \\
\hline rs 116971974 & A/C & AA & AA & AA & AA \\
\hline rs 114552144 & A/G & AA & AA & AA & AA \\
\hline
\end{tabular}

Table 7. Results of the genotyping of the surrounding common polymorphisms.

\begin{tabular}{|c|c|c|c|c|c|c|}
\hline SNP & & $\begin{array}{c}\text { Hunarian } \\
\text { affected } \\
\text { patient } \\
(\mathrm{V} / 2)\end{array}$ & $\begin{array}{c}\text { Hunarian } \\
\text { affected } \\
\text { patient } \\
(\mathbf{V} / 11)\end{array}$ & $\begin{array}{c}\text { Hunarian } \\
\text { affected } \\
\text { patient } \\
(\mathbf{V} / 12)\end{array}$ & $\begin{array}{c}\text { Anglo- } \\
\text { Saxon } \\
\text { affected } \\
\text { patient } \\
(\text { IV/1) }\end{array}$ & $\begin{array}{c}\text { Anglo- } \\
\text { Saxon } \\
\text { affected } \\
\text { patient } \\
(\text { IV/2) }\end{array}$ \\
\hline rs 2160683 & T/A & TA & AA & TA & TT & TT \\
\hline rs 115042932 & C/G & CG & CG & CG & CC & CC \\
\hline rs 117998712 & C/T & CC & CC & CC & CC & CC \\
\hline CM001120 & C/T & CT & CT & CT & CT & CT \\
\hline
\end{tabular}

Table 8. Genotyping of the surrounding, common polymorphisms demonstrated that the same mutation carried by the two geographically distant pedigrees is surrounded by different haplotypes and was the result of two independent mutational events (Nagy et al., 2013). 


\subsubsection{Genetic investigation of the Hungarian pedigree from Szeged}

The coding regions (exon 9-20) and the flanking introns of the CYLD gene were amplified. Primers were used as displayed on the UCSC Genome Browser (www.genome.ucsc.edu) (Table 3). The results of PCR were checked by agarose gel electrophoresis and DNA sequencing was performed.

Mutation analysis with direct sequencing of the coding regions of the CYLD gene revealed a novel missense mutation (c.2613C $>\mathrm{G}$ p.His871Gln) located in exon 19, in heterozygous form in both affected patients (Figure 18a). This mutation could not be identified in any of the clinically unaffected family members or in the screened 95 Hungarian generally healthy controls (Figure 18b).

(a)

$\frac{\text { Glu }}{G \text { A A A C A }} \frac{\text { Thr }}{A \text { A C }} \frac{\text { Ser }}{C A N} \frac{\text { His/GIn }}{T A} \frac{\text { Tyr }}{T} \frac{\text { Val }}{G \quad T} \frac{\text { Ala }}{G \quad C \quad T}$ c. $2613 \mathrm{C}>\mathrm{G}(\mathrm{p} . \mathrm{His} 871 \mathrm{Gln})$

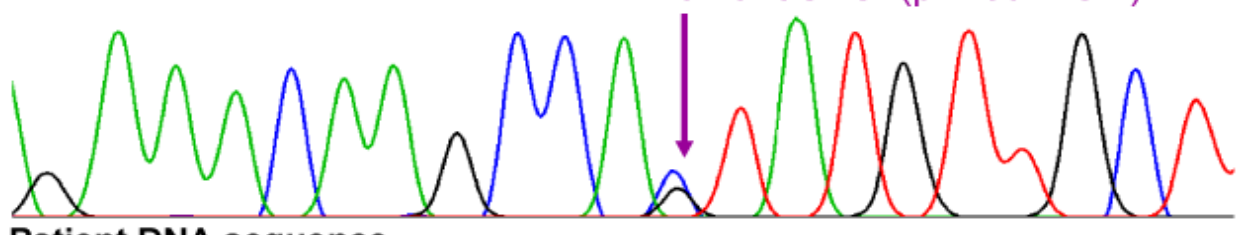

Patient DNA sequence

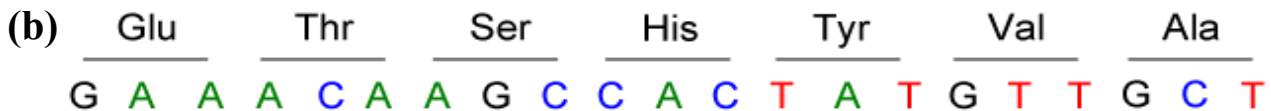

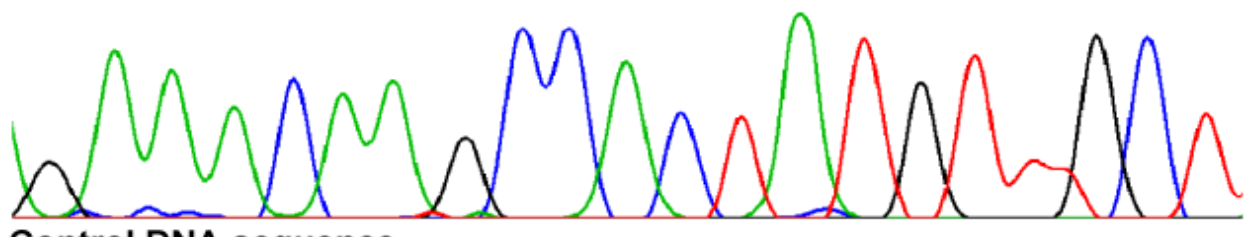

Control DNA sequence

Figure 18. The DNA sequence of the affected patients shows a heterozygous single nucleotide substitution c.2613C>G, p.His871Gln (a). Wild-type sequence of the CYLD gene (b). (Nagy et al., 2012)

The mutation is situated in a highly conserved region of the CYLD gene (Figure 19), encoding a histidine-box structure, which is part of a larger structure forming the ubiquitin-specific protease (USP) domain. This novel mutation leads to a change from histidine to glutamine at position 871. Interestingly, this position in the amino acid sequence change is localized within an active site where phosphorylation takes place (www.uniprot.org; Accession No: Q9NQC7), suggesting a putative role for this amino acid change in the function of the USP domain. 


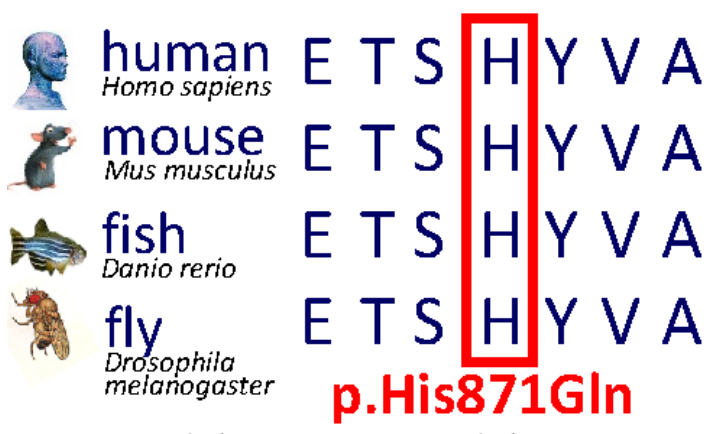

Figure 19. Comparison of the sequences of the CYLD gene among different species demonstrated that the c.2613C>G, p.His871 mutation is located in a highly conserved region, which forms part of a histidine box. (Nagy et al., 2012)

\subsubsection{Functional investigation of the Hungarian pedigree from Szeged}

To reveal the function of this novel missense mutation (c.2613C $>\mathrm{G}$, p.His871Gln), I studied the known CYLD-regulated pathways. CYLD protein is known to directly interact with the NF- $\kappa \mathrm{B}$ signaling NEMO protein. Functional analysis was performed on fibroblasts isolated from biopsy samples of the patients affected by Brooke-Spiegler syndrome $(n=2)$ and from healthy individuals $(n=2)$ (Figure 20).
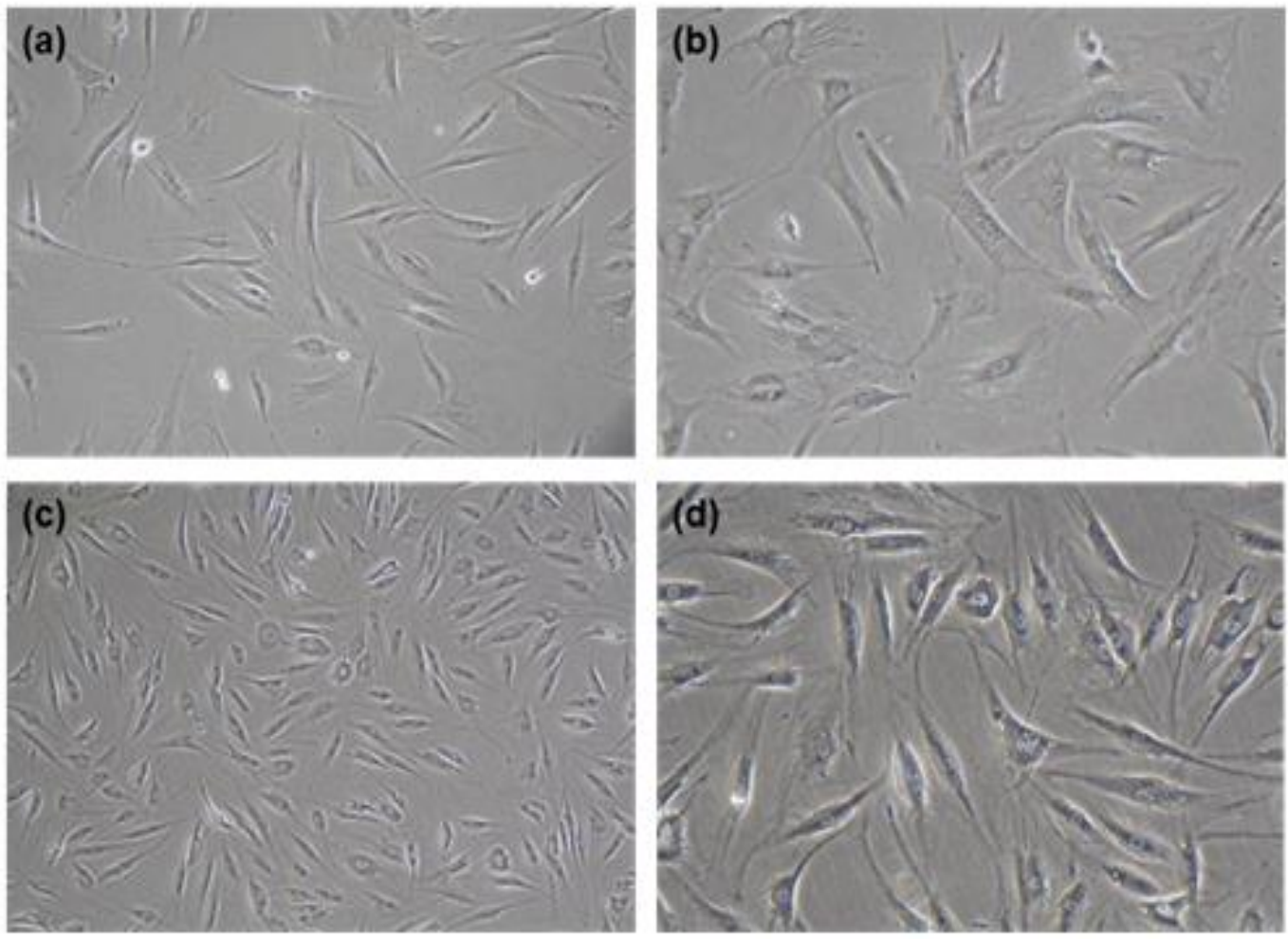

Figure 20. Normal human $(a, b)$ and CYLD mutant human $(c, d)$ fibroblasts. 
NEMO protein was immunoprecipitated from fibroblasts of the BSS patient and healthy controls (anti-human NEMO mouse antibody; BD Pharmingen). After loading equal amounts of the immunoprecipitated NEMO, Western blot was performed to detect the ubiquitination of the loaded samples. My data suggest that decreased NEMO expression is associated with its altered deubiquitination, NEMO immunoprecipitated from fibroblasts carrying the CYLD mutation demonstrated significantly higher ubiquitination than NEMO immunoprecipitated from control fibroblasts (Figure 21).

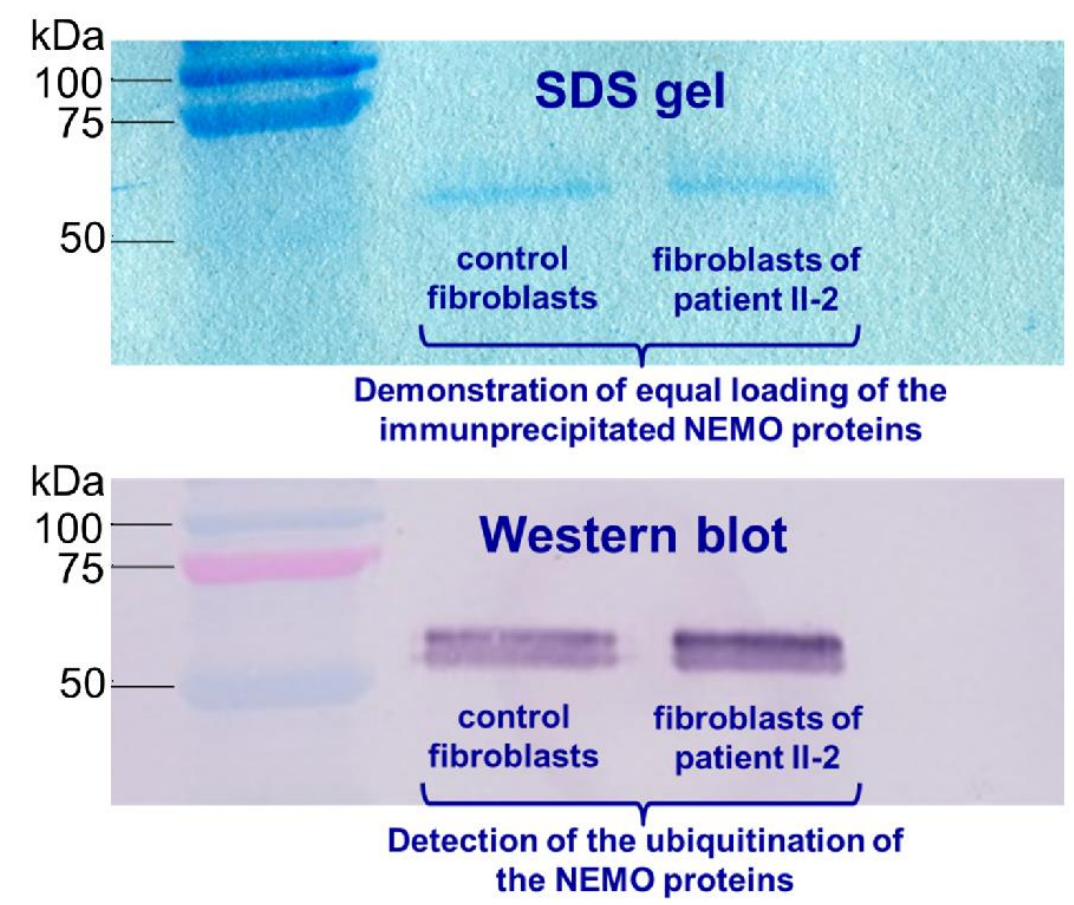

Figure 21. Semi-quantitative analysis of the Western blotting demonstrated increased ubiquitination of NEMO immunporecipitated from fibroblasts of BSS patients compared to healthy fibroblasts. (Nagy et al., 2012) 


\section{DISCUSSION}

\subsection{Comparison of the patient suffering from LEOPARD syndrome with the literature}

I investigated a 51-year-old Hungarian male patient suffering from LEOPARD syndrome. Genetic screening of the PTPN11 gene was performed. The affected patient carries one of the most common missense mutation (c.836A/G; p.Tyr279Cys) in heterozygous form of the PTPN11 gene. The unrelated healthy controls $(n=30)$ carried the wild type sequence. All the investigated relatives were clinically unaffected suggesting the presence of a de novo mutation in the patient.

The p.Tyr279Cys mutation has previously been reported in 47 different LS patients with Italian, French, Spanish, German, Estonian, Bosnian, Chinese Han, South-Korean, Japanese and Australian origin (Begić et al., 2014; Froster et al., 2003; Keren et al., 2004; Kim et al., 2011; Martínez-Quintana et al., 2012; Paradisi et al., 2005; Sarkozy et al., 2004; Tang et al., 2009; Uçar et al., 2006; Wang et al., 2014; Yoshida et al., 2004). Thus this missense mutation is a worldwide recurrent missense mutation. Among the reported LS cases there are ones with de novo mutation (Kim et al., 2011; Wang et al., 2014) and others, in which the disease show familial clustering and affects multiple family members in multiple generations (Begić et al., 2014; Froster et al., 2003). These data suggest a mutational hotspot in the PTPN11 gene.

The most common symptom, which was present in $46(96 \%)$ out of 48 patients is the presence of multiple lentigines. Further skin abnormality such as the development of café-au-lait spots were observed in only $22(46 \%)$ patients. Besides the characteristic multiple lentigines, some of the facial anomalies were also very common among these patients: ocular hypertelorism was detected in 40 (83\%) patients, palpebral ptosis in $32(67 \%)$ patients and dysmorphic ears in $31(65 \%)$ ones. Besides these common ectodermal abnormalities, patients with the p.Tyr279Cys PTPN11 mutation have a great chance to develop cardiovascular anomalies. Hypertrophic cardiomyopathy was diagnosed in 25 (52\%) patients. Although short stature was previously reported to be frequently associated with the p.Tyr279Cys phenotype, it was present only in 19 (40\%) patients out of 48. Regarding the other side of the spectrum, the p.Tyr279Cys mutation is rarely associated with deafness, 
which was reported in $12(25 \%)$ patients. Moreover this analysis identified that certain symptoms - such as cryptorchidism, macrocephaly, horse kidney, hydrothorax, myelodysplasia and umbilical hernia - are rarely associated with the p.Tyr279Cys phenotype. In one of the 48 LS patients with the recurrent p.Tyr279Cys PTPN11 mutation, Marfan syndrome was also present, which is probably a rare independent association (Tang et al., 2009) (Figure 22).

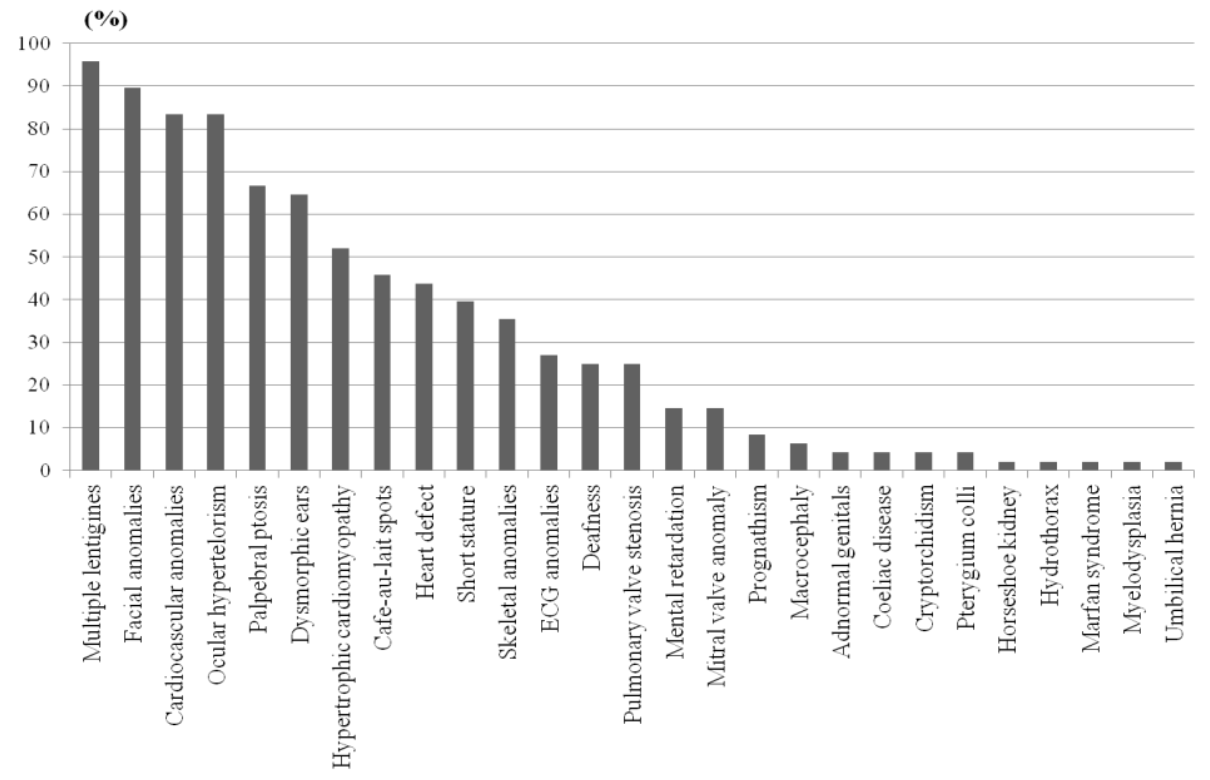

Figure 22. Comparison of the frequency of the different symptoms detected in the p.Tyr279Cys phenotype. (Nemes and Farkas et al., 2015)

The observed differences in the clinical symptoms of the 48 LS patients carrying the same missense mutation clearly demonstrate the wide phenotypic diversity and the variable expressivity of the disease. In general, multiple lentigines, café-au-lait macules, ocular hypertelorism, palpebral ptosis, dysmorphic ears and hertrophic cardiomyopathy are hallmarks of the p.Tyr279Cys PTPN11 mutation related phenotype.

Further studies are needed to identify putative genetic, environmental or life style factors, which can modify the development of the clinical symptoms and responsible for the observed phenotypic diversity. The availability of the extended clinical findings about the p.Tyr279Cys mutation carriers is critical for promoting both our understanding of the disease and the development of causative therapies that will be more specific and effective than the symptomatic treatments currently available for LS patients. 


\subsection{Haplotype analysis of the patients carrying the recurrent nonsense p.Arg758X CYLD mutation represents a mutational hotspot in the gene}

I have identified a Spanish MFT1 pedigree with two affected family members (father and daughter). Direct sequencing of the CYLD gene revealed a worldwide recurrent nonsense mutation (c.2272C/T, p.R758X) in exon 17. Both patients carried the mutation in heterozygous form, whereas the unaffected family members and unrelated controls carried the wild-type sequence.

A review of all previous studies reporting the same c.2272C/T, p.R758X nonsense mutation of the $C Y L D$ gene revealed that this mutation has also been detected in patients with BSS (Grossmann et al., 2013; Kazakov et al., 2009; Zhang et al., 2006), FC (Bignell et al., 2000; Van den Ouweland et al., 2011; Oiso et al., 2004) and MFT1 (Grossmann et al., 2013; Kazakov et al., 2011). Thus, the c. $2272 \mathrm{C} / \mathrm{T}$, p.R758X nonsense mutation of the CYLD gene can lead to the manifestation of any of the clinical variants in the disease spectrum caused by $C Y L D$ mutation, which is associated with high phenotypic diversity. Furthermore, this mutation has been detected in Caucasian American (Bignell et al., 2000), South African (Grossmann et al., 2013), Austrian (Grossmann et al., 2013; Kazakov et al., 2011), Czech (Kazakov et al., 2009), Dutch (Van den Ouweland et al., 2011), Chinese (Zhang et al., 2006) and Japanese patients (Oiso et al., 2004) and is, thus, considered a recurrent worldwide mutation (Table 9). These data suggest that the c. $2272 \mathrm{C} / \mathrm{T}$, p.R758X nonsense mutation is located at a mutational hotspot in the $C Y L D$ gene.

\begin{tabular}{|c|c|c|c|}
\hline \multirow{2}{*}{ CYLD cDNA } & CYLD protein & $\begin{array}{c}\text { Detected in patients } \\
\text { with }\end{array}$ & Nationality \\
\hline \multirow{2}{*}{ c.2272C>T } & \multirow{2}{*}{ p.R758X } & FC & $\begin{array}{c}\text { Caucasian American, Dutch, } \\
\text { Japanese }\end{array}$ \\
\cline { 3 - 4 } & & BSS & $\begin{array}{c}\text { Austrian, South African, } \\
\text { Czech, Chinese }\end{array}$ \\
\cline { 3 - 4 } & & MFT1 & Austrian, Spanish \\
\hline
\end{tabular}

Table 9. Summary of the geographical location and clinical manifestation of the recurrent p.R758X CYLD mutation. (Farkas et al., 2016)

Previously reported Dutch (Van den Ouweland et al., 2011) and Austrian (Grossmann et al., 2013) cases carrying the same mutation were also investigated. To determine whether the worldwide recurrent p.R758X mutation of the CYLD gene is 
the result of one or more independent mutational events, haplotype analysis was performed. The haplotype analysis of the Spanish, Dutch and Austrian patients demonstrated that, although the Spanish and the Dutch patients carry the same haplotype, the clinical appearance, MFT1 and FC, respectively, is different. These results suggest the importance of modifying genetic and/or environmental factors. In contrast with these, the Austrian patient carried a different haplotype than the Spanish and Dutch families. Thus, I assume the presence of the same mutation is the consequence of different mutational events.

\subsection{Haplotype analysis of the patients carrying the recurrent nonsense p.Arg936X CYLD mutation represents a mutational hotspot in the gene}

A large Hungarian BSS pedigree carrying a nonsense mutation (c.2806C $>\mathrm{T}$, p.Arg936X) of the CYLD gene was investigated. This mutation was first reported by Bignell et al. (2000) and later by Bowen et al. (2005) in a European and a Canadian BSS pedigree.

This nonsense p.Arg936X mutation was present in an Anglo-Saxon BSS pedigree, as well, therefore haplotype analysis was performed to elucidate whether the mutation they carry is the result of the same or two independent mutational events. Haplotype analysis of the Hungarian and the Anglo-Saxon BSS pedigrees demonstrated that the same mutation carried by the two geographically distant pedigrees was the result of two independent mutational events. I hypothesize that these positions may be mutational hotspots on the CYLD gene. Notably these hotspots are based within the coding sequence of the gene that encodes for the catalytic residues of CYLD, suggesting a dominant negative effect may be important in manifesting a phenotype.

It is also interesting to note, that I found huge differences in the severity of the symptoms between the investigated Hungarian and the Anglo-Saxon BSS pedigrees despite the fact that the affected members are carrying the same mutation. There are previous studies in the literature, which reported huge phenotypic heterogeneity even within the same BSS pedigrees (Scheinfeld et al., 2003; Rajan et $a l ., 2009)$, and raised the putative role of either environmental factors or modifying genes, which influence the clinical phenotype of the BSS patients (Bignell et al., 2000). 


\subsection{The functional analysis of the newly identified missense mutation represents a disease-causing mutation in the $C Y L D$ gene}

I identified a novel missense mutation (c.2613C $>\mathrm{G}$, p.His871Gln) of CYLD gene in a Hungarian BSS pedigree. CYLD protein has a role in the regulation of many signaling pathways, such as $\mathrm{NF}-\kappa \mathrm{B}$ signaling pathway throuhg the deubiquitination of NEMO protein as its interaction partner. I performed functional analysis to examine the role of the new mutation and measured ubiquitination of NEMO after immunoprecipitation and found an increased level of ubiquitination of the NEMO protein in fibroblasts carrying the novel CYLD mutation. Based on the results I suppose that this novel mutation through the increased ubiquitination of NEMO leads to decreased NEMO expression and as a consequence may influence the NF- $\kappa \mathrm{B}$ pathway.

Identification of the underlying mutation may have a considerable impact on family planning since it offers the possibility of prenatal mutation screening. Further studies are needed to elucidate the exact mechanism of the development of BSS symptoms. Since BSS displays only skin tumors, and mainly appendageal tumor formations, it may be an appropriate model for the development of novel gene therapy methods.

\subsection{Mutations on the $C Y L D$ gene}

To date, a total of 95 mutations have been published for the CYLD gene (Figure 23), and the individuals carrying these mutations present with phenotypic features of BSS, FC and/or MFT1.

The majority of the CYLD mutations (98\%) were reported in coding regions. Distribution of the mutations within exons is unequal: $99 \%$ of the mutations are located within exons 9-20. The majority of the sequence changes are frameshift $(48 \%)$, nonsense $(27 \%)$, missense $(12 \%)$ or splice-site $(11 \%)$ mutations, however, two in-frame deletions have also been reported. 


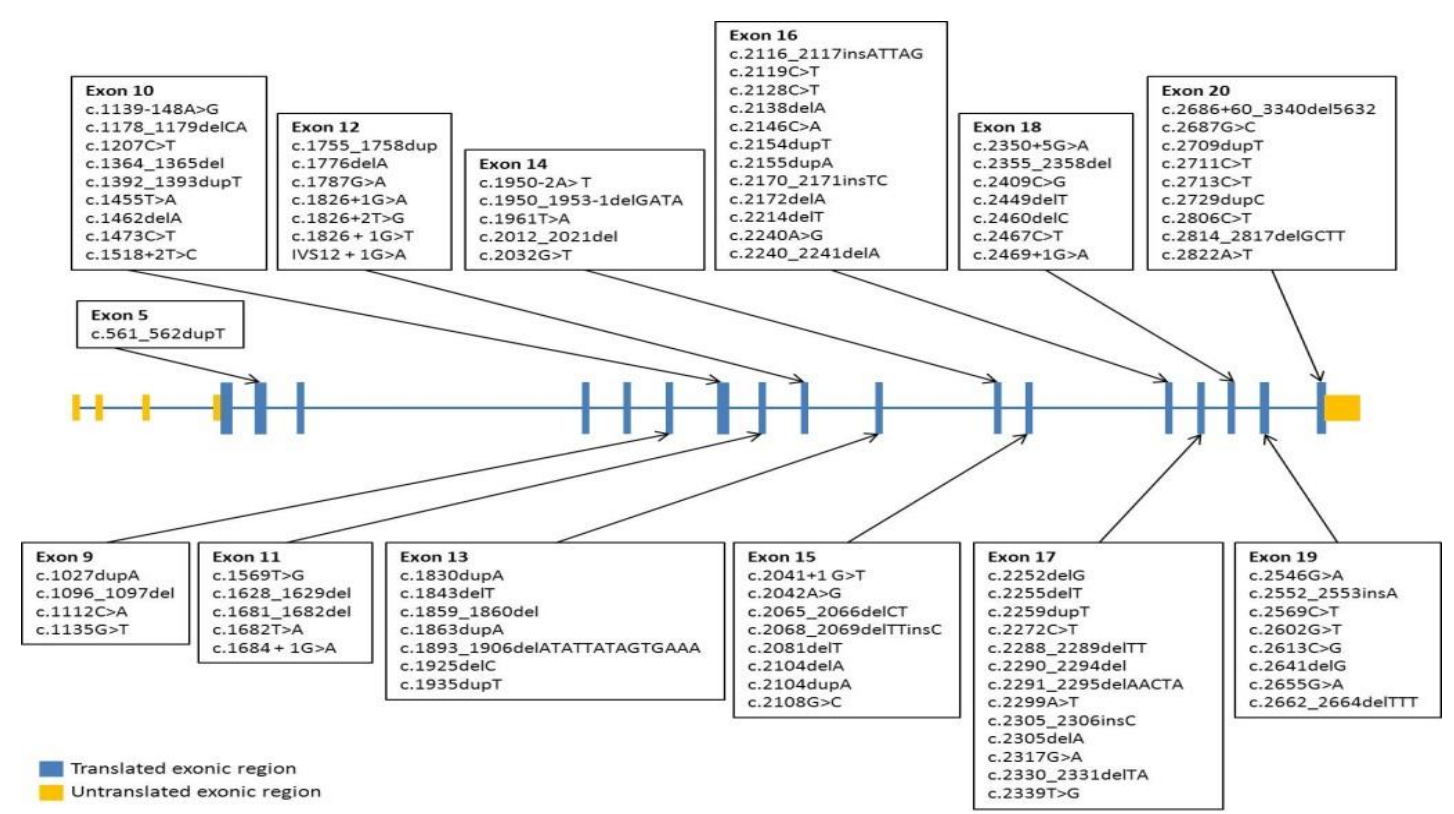

Figure 23. CYLD gene mutations identified to date. (Nagy et al., 2014)

Approximately half of the identified $C Y L D$ mutations (48\%) are frameshift mutations arising from the insertion or deletion of a small number of nucleotides. The majority of these changes lead to the formation of premature stop codons causing truncation and, thus, the dysfunction of the CYLD protein. Frameshift mutations are unequally distributed in the CYLD gene: one third are located within the region spanning exons 5-11 (Bignell et al., 2000; Grossmann et al., 2013; Saggar et al., 2008; Nasti et al., 2009; Ying et al., 2012; Liang et al., 2008; Zheng et al., 2004), whereas the rest (66\%) occur within the region spanning exons 12-20 (Bignell et al., 2000; Bowen et al., 2005; Grossmann et al., 2013; Lv et al., 2008; Saggar et al., 2008; Oiso et al., 2004; Reuven et al., 2013; Chen et al., 2011; Salhi et al., 2004; Melly et al., 2012; Heinritz et al., 2006). Exon 17 is a mutational hotspot, containing $20 \%$ of all identified frameshift mutations (Bignell et al., 2000; Bowen et al., 2005; Grossmann et al., 2013; Lv et al., 2008; Saggar et al., 2008; Oiso et al., 2004). Only a quarter of the frameshift mutations (27\%) are recurrent (Sima et al., 2010; Poblete et al., 2002; Bignell et al., 2000; Bowen et al., 2005; Grossmann et al., 2013; Saggar et al., 2008; Oiso et al., 2004; Scheinfeld et al., 2003; Hester et al., 2013).

Nonsense mutations causing truncation and, thus, CYLD protein dysfunction are also common, accounting for one quarter (27\%) of the CYLD mutations identified so far. The distribution of nonsense mutations is also unequal in the $C Y L D$ gene. One third of the nonsense mutations occur within the region spanning exons 9-11 (Sima 
et al., 2010; Bignell et al., 2000; Bowen et al., 2005; Grossmann et al., 2013; Linos et al., 2011; Lv et al., 2008; Kacerovska et al., 2013; Saggar et al., 2008; Van den Ouweland et al., 2011; Kazakov et al., 2009; Almeida et al., 2008), while the majority $(72 \%)$ are located within the region spanning exons 12-20 (Sima et al., 2010; Bignell et al., 2000; Zhang et al., 2004; Young et al., 2006; Oranje et al., 2008; Bowen et al., 2005; Grossmann et al., 2013; Oiso et al., 2004; Kazakov et al., 2009; Nagy et al., 2013; Nagy et al., 2012; Zheng et al., 2004; Chen et al., 2011; Almeida et al., 2008). This latter region does not seem to contain a further mutational hotspot. It is of interest to note that $25 \%$ of the identified nonsense mutations affect glutamine amino acid residues within the CYLD protein, replacing them with stop codons (Sima et al., 2010; Bignell et al., 2000; Grossmann et al., 2013; Zheng et al., 2004; Chen et al., 2011; Almeida et al., 2008). Nearly half of the nonsense mutations (40\%) are recurrent (Sima et al., 2010; Bignell et al., 2000; Oranje et al., 2008; Bowen et al., 2005; Grossmann et al., 2013; Linos et al., 2011; Lv et al., 2008; Kacerovska et al., 2013; Saggar et al., 2008; Van den Ouweland et al., 2011; Oiso et al., 2004; Zhang et al., 2006; Kazakov et al., 2009; Kazakov et al., 2011; Nagy et al., 2013; Zheng et al., 2004; Chen et al., 2011).

Missense mutations account for $12 \%$ of all mutations identified on the CYLD gene. The distribution of missense mutations is also unequal on the CYLD gene: all are located within the region spanning exons 12-20 (Sima et al., 2010; Hu et al., 2003; Grossmann et al., 2013; Linos et al., 2011; Lv et al., 2008; Kacerovska et al., 2013; Saggar et al., 2008; Van den Ouweland et al., 2011; Kazakov et al., 2009; Nagy et al., 2012; Zheng et al., 2004; Almeida et al., 2008; Espana et al., 2007; Wang et al., 2010; Zuo et al., 2007). Only a quarter (27\%) of these are recurrent mutations (Sima et al., 2010; Hu et al., 2003; Grossmann et al., 2013; Saggar et al., 2008; Kazakov et al., 2009).

Splice-site mutations account for $11 \%$ of all mutations. The distribution of the splice-site mutations is also unequal: all of them occur within the region spanning exons 10-18 (Bignell et al., 2000; Grossmann et al., 2013; Kacerovska et al., 2013; Van den Ouweland et al., 2011; Kazakov et al., 2011; Nasti et al., 2009; Ying et al., 2012; Liang et al., 2008; Huang et al., 2009; Ly et al., 2004). Less than a quarter (18\%) are recurrent (Bignell et al., 2000; Grossmann et al., 2013; Van den Ouweland et al., 2011; Kazakov et al., 2011). 
In addition, two in-frame deletions have also been reported: these mutations are located within exons 19 and 20. Both of them lead to the development of the FC clinical variant (Van den Ouweland et al., 2011).

\subsection{Distribution of the mutations in the CYLD protein}

The protein encoded by the CYLD gene (GenBank NP_056062) exhibits deubiquitinase activity. The N-terminal of the CYLD protein can be divided into two regions based on the occurrence of the mutations: no mutations have been detected in the region encoded by exons 4 and 5, whereas the region encoded by exons 5-11 contains approximately one fifth $(18 \%)$ of the mutations identified to date. The Nterminal of the CYLD protein contains three cytoskeleton-associated glycine rich domains (CAP-GLY), at which the CYLD protein connects to microtubules (Gao et al., 2008). The N-terminal of the CYLD protein is highly conserved through evolution. Mostly frameshift and nonsense mutations occur in this region, as well as the two known splice-site mutations (Sima et al., 2010; Bignell et al., 2000; Bowen et al., 2005; Grossmann et al., 2013; Kacerovska et al., 2013; Saggar et al., 2008; Kazakov et al., 2009; Nasti et al., 2009; Liang et al., 2008; Zheng et al., 2004; Almeida et al., 2008; Ly et al., 2004). Most frameshift mutations occur in the first (amino acids 127 to 203) and the third (amino acids 472 to 540) CAP-GLY domains, whereas most of the nonsense and splice-site mutations occur in the region of the third CAP-GLY domain. Missense mutation has not been detected at the N-terminal of the CYLD protein (Figure 24).

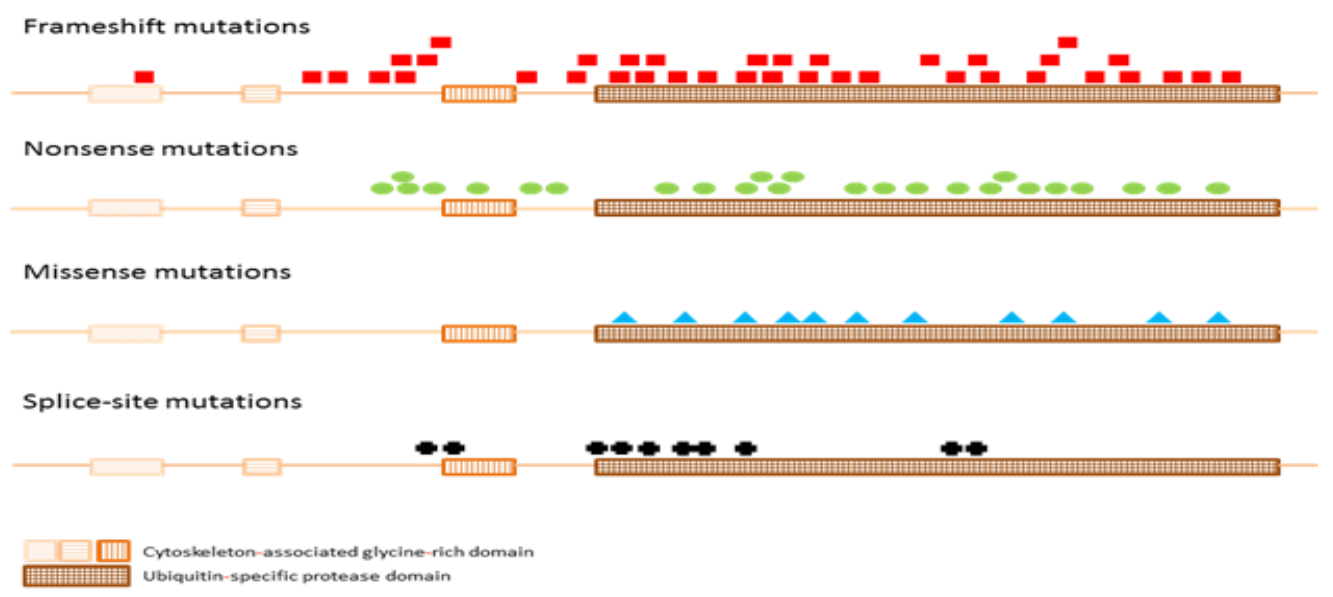

Figure 24. Distribution of the most common type mutations in the CYLD protein. (Nagy et al., 2014) 
The $C Y L D$ gene has changed relatively little through evolution: the similarity between the human and mouse genes is $94 \%$, and the homology is especially high at the 3 ' end of the gene. This region of the CYLD protein, encoded by exons 12-20, contains the ubiquitin-specific protease domain that is responsible for the deubiquitinase activity of the protein. This region contains the majority (82\%) of identified CYLD mutations, including frameshift (72\%), nonsense (72\%) and splicesite (81\%) mutations as well as all known missense mutations (Figure 24). Functional studies of the identified mutations suggest that mutations of this region may decrease the deubiquitinase activity of the CYLD protein (Nagy et al., 2012).

\subsection{Genotype and phenotype correlations in case of patients carrying $C Y L D$ mutation}

Genotype-phenotype correlations are difficult to establish, as all types of known CYLD mutation - frameshift, nonsense, missense and splice-site - lead to the development of each clinical variant of the $C Y L D$ mutation-caused spectrum.

Frameshift mutations of the $C Y L D$ gene have been identified for all clinical variants of the CYLD mutation-caused spectrum. Interestingly, most frameshift mutations occur in the region of exon 17 (Bignell et al., 2000; Bowen et al., 2005; Grossmann et al., 2013; Lv et al., 2008; Saggar et al., 2008; Oiso et al., 2004).

Nonsense mutations of the CYLD gene exhibit the largest phenotypic diversity. Some nonsense mutations (i.e., c.1112C/A p.S371X, c.2272C/T p.R758X and c.2806C/T p.R936X) have been detected in patients diagnosed with FC, BSS or MFT1 (Bignell et al., 2000; Bowen et al., 2005; Grossmann et al., 2013; Linos et al., 2011; Lv et al., 2008; Kacerovska et al., 2013; Saggar et al., 2008; Van den Ouweland et al., 2011; Oiso et al., 2004; Zhang et al., 2006; Kazakov et al., 2009; Kazakov et al., 2011; Nagy et al., 2013). As many recurrent nonsense mutations are due to de novo events, their frequency and location indicates mutational hotspots on the CYLD gene (Bignell et al., 2000; Nagy et al., 2013). Patients carrying the same nonsense mutation from different mutational events often exhibit extreme differences in their clinical manifestations (Nagy et al., 2013). These differences might be the consequences of yet unknown genetic factors that modify the development of the phenotype. Nonsense mutations are also responsible for the most variable expression within families (Bowen et al., 2005; Zhang et al., 2006; Nagy et al., 2013). These 
differences might be explained by environmental and/or lifestyle factors. Further studies are needed to elucidate putative genetic, environmental or lifestyle factors that are responsible for the observed great variation in phenotype.

Missense mutations of the CYLD gene are more frequently associated only with MFT1 (73\%) than the other types of mutations (Sima et al., 2010; Hu et al., 2003; Grossmann et al., 2013; Linos et al., 2011; Lv et al., 2008; Kacerovska et al., 2013; Saggar et al., 2008; Van den Ouweland et al., 2011; Kazakov et al., 2009; Nagy et al., 2012; Zheng et al., 2004; Almeida et al., 2008; Espana et al., 2007; Wang et al., 2010; Zuo et al., 2007). Missense mutations also lead to the development of milder phenotype (Nagy et al., 2012). This observation might be explained by the fact that missense mutations are distributed differently than the other types of mutations: they are located only between exons 12-20 and not at all in the 5 ' end. In general, missense mutations are associated with low phenotypic diversity, as the majority of missense mutations result in the MFT1 phenotype (Nagy et al., 2012; Zheng et al., 2004; Almeida et al., 2008; Espana et al., 2007; Wang et al., 2010; Zuo et al., 2007).

Splice-site mutations of the $C Y L D$ gene can lead to the development of any clinical variant of the $C Y L D$ mutation-caused spectrum, but little is known about their phenotypic significance (Kacerovska et al., 2013; Van den Ouweland et al., 2011; Nasti et al., 2009; Liang et al., 2008; Huang et al., 2009).

The comparison of $C Y L D$ gene mutations and the observed clinical variation of the patients have already revealed significant genotype-phenotype correlations: nonsense mutations are associated with the highest phenotypic diversity and recurrence rate, while missense mutations are associated with mild symptoms and are strongly associated with the MFT1 phenotype. Future efforts might provide insight into the clinical significance of frameshift and splice-site mutations and further elucidate the mechanism of the different phenotypic variants of the CYLD mutationcaused spectrum. Careful investigation of genotype-phenotype correlations are necessary to promote better understanding of the BSS, FC and MFT1 clinical variants and provide insight into the underlying molecular mechanisms. Genetic screening and the identification of disease-causing mutations have already had a significant impact on prenatal and preimplantation genetic diagnosis for family planning. 


\subsection{Geographical occurrence of $C Y L D$-mutation caused disease spectrum}

Mutations of the CYLD gene have been reported among patients with Irish, Japanese, Spanish, German, Algerian, Turkish, Hungarian, Slovakian, Italian, Scandinavian, Taiwanese, Turkish, Canadian and African backgrounds (Bowen et al., 2005; Kacerovska et al., 2013; Saggar et al., 2008; Nagy et al., 2013; Nagy et al., 2012; Nasti et al., 2009; Salhi et al., 2004; Huang et al., 2009; Amaro et al., 2010). However, the majority of the published mutations are reported from the UK, USA and China (Bignell et al., 2000; Lv et al., 2008; Ying et al., 2012; Liang et al., 2008; Zheng et al., 2004; Chen et al., 2011; Wang et al., 2010; Zuo et al., 2007).

Comparing the ethnicity and the reported allelic variants, geographical differences can be observed. The clinical phenotype of MFT1 was observed in African, African American, Taiwanese, Algerian, Turkish, Italian and Spanish patients though the most of it has been reported from China ( $\mathrm{Lv}$ et al., 2008; Kacerovska et al., 2013; Liang et al., 2008; Zheng et al., 2004; Chen et al., 2011; Wang et al., 2010; Zuo et al., 2007). The FC clinical variant was present in Dutch, Italian and Irish patients, however, the majority have been reported from the UK and from the USA (Bignell et al., 2000; Bowen et al., 2005; Nasti et al., 2009). The clinical phenotype of BSS was detected in patients from Hungary, Slovakia, Austrian, Italy, Scandinavia, Spain, Canada and the majority - similarly to FC - is coming from the UK and the USA (Bignell et al., 2000; Bowen et al., 2005; Kacerovska et al., 2013; Nagy et al., 2013; Nagy et al., 2012; Nasti et al., 2009). 


\section{SUMMARY}

In my thesis, I have summarized the genetic and functional investigations in stigmatizing rare diseases: LS and the clinical variants of the CYLD mutation-caused disease spectrum namely MFT1, FC and BSS.

LS is a rare monogenic disorder. The name is an acronym of its major features such as multiple lentigines, electrocardiographic conduction defects, ocular hypertelorism, pulmonary stenosis, abnormalities of genitalia, retardation of growth and sensorineural deafness. LS develops due to mutations in the protein-tyrosine phosphatase nonreceptor-type 11, PTPN11. I have investigated a 51-year-old Hungarian male patient affected by LS. Direct sequencing of the PTPN11 gene revealed a worldwide recurrent missense mutation (c.836A/G; p.Tyr279Cys), which has been previously identified in 47 LS patients. Comparison of the clinical phenotypes of our patient and the ones reported in the literature demonstrates great phenotypic diversity despite of the same genotype.

MFT1 is a rare monogenic skin disease with autosomal dominant inheritance, is characterized by the development of multiple skin-colored papules on the central area of the face, frequently occurring in the nasolabial area. The disease is associated with various mutations in the $C Y L D$ gene that are also responsible for the development of FC and BSS. I have identified a Spanish MFT1 pedigree with two affected family members (father and daughter). Direct sequencing of the CYLD gene revealed a worldwide recurrent heterozygous nonsense mutation (c.2272C/T, p.R758X) in the patients. This mutation has already been detected in patients with all three clinical variants - BSS, FC and MFT1 - of the CYLD-mutation spectrum. Haplotype analysis was performed for the Spanish patients with MFT1, Dutch patients with FC and an Austrian patient with BSS, all of whom carry the same heterozygous nonsense p.R758X CYLD mutation. The results demonstrated that different mutational events are responsible for the development of the Austrian case and the Spanish and Dutch cases. These results indicate that this position is a mutational hotspot in the gene and that patients carrying the mutation exhibit high phenotypic diversity.

BSS is an autosomal dominant rare monogenic skin disease characterized by skin appendage tumors including cylindromas, trichoepitheliomas, and/or spiradenomas. I investigated a Hungarian BSS pedigree with Bukovinian 
(Romanian) origin containing 21 affected family members spanning 7 generations. Direct sequencing of the coding regions of the CYLD gene revealed a nonsense mutation (c.2806C>T, p.Arg936X) in exon 20. Since this nonsense mutation is present in an Anglo-Saxon pedigree from the north of England, I performed the haplotype analysis of the two geographically distant pedigrees and revealed that the mutation they carry is the result of two independent mutational events. The results suggest that this may be a mutational hotspot in the CYLD gene. Regarding the phenotypic features of the investigated pedigrees carrying the same nonsense mutation, I observed huge differences in the severity of the symptoms suggesting the presence of a yet unidentified modulatory factor.

Another Hungarian BSS pedigree has been investigated with two affected members, father and daughter. Direct sequencing demonstrated a novel missense mutation (c.2613C >G; p.His871Gln) in exon 19 of the CYLD gene within the ubiquitin-specific protease domain of the encoded protein. Preliminary analysis has been performed to reveal the functional role of this novel mutation. Data suggest that this novel CYLD mutation leads to increased ubiquitination of NEMO through influencing deubiquitinating activity of the CYLD protein and thus may result in enhanced NF- $\mathrm{B}$ signaling.

CYLD protein is expressed in a wide range of human tissues, the reason why dysfunction manifests only in skin symptoms is still unclear. Moreover, patients carrying the same mutation from different mutational events often exhibit extreme differences in their clinical and histological manifestations. These differences might be the consequences of yet unknown genetic, environmental and/or lifestyle factors that modify the development of the phenotype.

These investigations have great importance because they could be the basis of future genetic studies for the development of novel causative therapies that will be more specific and effective than the symptomatic treatments. Genetic screening and the identification of the disease-causing mutation have great significance for family planning in prenatal and preimplantation diagnosis. 


\section{ACKNOWLEDGEMENT}

I would like to thank to Dr. Nikoletta Nagy for her great supervising activity.

I would like to thank to Prof. Dr. Márta Széll and Prof. Dr. Lajos Kemény for the opportunity to perform the genetic investigations of this study in the molecular laboratory of the Department of Medical Genetics and the Department of Dermatology and Allergology, University of Szeged.

Special thanks to Dr. Ágnes Kinyó and Hilda Polyánka for their professional help.

I am grateful to Dr. István Németh, Dr. János Varga, Dr. Erika Kis, Dr. Klára Bajor, Dr. Eliza Karagity, Dr. Neil Rajan, Dr. Raquel Rodríguez López, Dr. Tomas Vanecek and Dr. Joan N. R. Kromosoeto for the dermatological examinations and for enrolling the pateints into the study.

Special thanks to all my colleagues for their kind help at the Department of Medical Genetics, MTA-SZTE Dermatological Research Group and Department of Dermatology and Allergology. 


\section{ELECTRONIC DATABASE INFORMATION}

Ensemble Genome Browser (for the wild type sequencing data of the human genome, for the gene variation database regarding disease-causing and non-causing alterations and for the taxonomy analysis of the identified mutation) www.ensemble.org

Online Mendelian Inheritance in Man (for the detailed information on the genetics, inheritance, clinical features and identified mutations in monogenic neurogenetic disorders) www.omim.org

Orphanet Database (for the collection and detailed description of rare diseases) www.orpha.net

UCSC Genome Browser, Primer3 (for the design of specific primers used to amplify the sequenced regions of the genes) http://genome.ucsc.edu/; http://bioinfo.ut.ee/primer3-0.4.0/

PubMed (for the literature search to identify the previously published cases) http://www.ncbi.nlm.nih.gov/pubmed 


\section{REFERENCES}

1. Almeida S, Maillard C, Itin P, et al. Five new CYLD mutations in skin appendage tumors and evidence that aspartic acid 681 in CYLD is essential for deubiquitinase activity. J Invest Dermatol 2008;128:587-593.

2. Alsaad KO, Obaidat NA, Ghazarian D. Skin adnexal neoplasms--part 1: an approach to tumours of the pilosebaceous unit. J Clin Pathol 2007;60:129-144.

3. Ancell H. History of a remarkable case of tumours, developed on the head and face; accompanied with a similar disease in the abdomen. Med Chir Trans 1842;25:227-306.

4. Begić F, Tahirović H, Kardašević M, et al. Leopard syndrome: a report of five cases from one family in two generations. Eur J Pediatr 2004;173:819-822.

5. Biggs PJ, Chapman P, Lakhani SR, et al. The cylindromatosis gene (cyld1) on chromosome 16q may be the only tumour suppressor gene involved in the development of cylindromas. Oncogene 1996;12:1375-1377.

6. Biggs PJ, Wooster R, Ford D, et al. Familial cylindromatosis (turban tumour syndrome) gene localised to chromosome 16q12-q13: evidence for its role as a tumour suppressor gene. Nat Genet 1995;11:441-443.

7. Bignell GR, Warren W, Seal S, et al. Identification of the familial cylindromatosis tumoursuppressor gene. Nat Genet 2000;25:160-165.

8. Blake PW, Toro JR. Update of cylindromatosis gene (CYLD) mutations in Brooke-Spiegler syndrome: novel insights into the role of deubiquitination in cell signaling. Hum Mutat 2009;30:1025-1036.

9. Bowen S, Gill M, Lee DA, et al. Mutations in the CYLD gene in Brooke-Spiegler syndrome, familial cylindromatosis, and multiple familial trichoepithelioma: lack of genotype-phenotype correlation. J Invest Dermatol 2005;124:919-920.

10. Brooke HG. Epithelioma adenoides cysticum. Brirish Journal of Dermatology 1892;4:269-287.

11. Chen M, Liu H, Fu X, et al. Mutation analysis of the CYLD gene in two Chinese families with multiple familial Trichoepithelioma. Australas J Dermatol 2011;52:146-147.

12. Chou SC, Lin SL, Tseng HH. Malignant eccrine spiradenoma: a case report with pulmonary metastasis. Pathol Int 2004;54:208-212.

13. Cooper PH, Frierson HF, Jr., Morrison AG. Malignant transformation of eccrine spiradenoma. Arch Dermatol 1985;121:1445-1448.

14. Digilio MC, Conti E, Sarkozy A, et al. Grouping of multiple-lentigines/LEOPARD and Noonan syndromes on the PTPN11 gene. Am J Hum Genet 2002;71:389-394.

15. Digilio MC, Sarkozy A, De Zorzi A, et al. LEOPARD syndrome: clinical diagnosis in the first year of life. Am J Med Genet A 2006;140:740-746.

16. Engel CJ, Meads GE, Joseph NG, Stavraky W. Eccrine spiradenoma: a report of malignant transformation. Can J Surg 1991;34:477-480.

17. Espana A, Garcia-Amigot F, Aguado L, Garcia-Foncillas J. A novel missense mutation in the CYLD gene in a Spanish family with multiple familial trichoepithelioma. Arch Dermatol 2007;143:1209-1210.

18. Evans CD. Turban tumour. Br J Dermatol 1954;66:434-443.

19. Farkas K, Kocsis-Deák B, Sánchez LC, et al. The CYLD p.R758X worldwide recurrent nonsense mutation detected in patients with multiple familial trichoepithelioma type 1, BrookeSpiegler syndrome and familial cylindromatosis represents a mutational hotspot in the gene. BMC Genet 2016;17:36.

20. Fenske C, Banerjee P, Holden C, Carter N. Brooke-Spiegler syndrome locus assigned to 16q12q13. J Invest Dermatol 2000;114:1057-1058.

21. Fordyce JA. Multiple benign cystic epithelioma of the skin. Journal of Cutaneous Diseases 1892;10:459-473.

22. Froster UG, Glander HJ, Heinritz W. Molecular genetic mutation analysis of the PTPN11 gene in the multiple lentigines (LEOPARD) syndrome. Hautarzt 2003;54:1190-1192.

23. Gao J, Huo L, Sun X, et al. The tumor suppressor CYLD regulates microtubule dynamics and plays a role in cell migration. J Biol Chem 2008;283:8802-8809.

24. Gorlin RJ, Anderson RC, Blaw ME. Multiple lentigines syndrome: complex comprising multiple lentigines, electrocardiographic conduction abnormalities, ocular hypertelorism, pulmonary stenosis, abnormalities of genitalia, retardation of growth, sensorineural deafness, and autosomal dominant hereditary pattern. Am J Dis Child 1969;117:652-662. 
25. Grossmann $\mathrm{P}$, Vanecek T, Steiner $\mathrm{P}$, et al. Novel and recurrent germline and somatic mutations in a cohort of 67 patients from 48 families with Brooke-Spiegler syndrome including the phenotypic variant of multiple familial trichoepitheliomas and correlation with the histopathologic findings in 379 biopsy specimens. Am J Dermatopathol 2013;35:34-44.

26. Gutierrez PP, Eggermann T, Holler D, et al. Phenotype diversity in familial cylindromatosis: a frameshift mutation in the tumor suppressor gene CYLD underlies different tumors of skin appendages. J Invest Derm 2002;119:527-531.

27. Haglund K, Dikic I. Ubiquitylation and cell signaling. EMBO J 2005;24:3353-3359.

28. Heinritz W, Grunewald S, Strenge S, et al. A case of Brooke-Spiegler syndrome with a new mutation in the CYLD gene. Br J Dermatol 2006;154:992-994.

29. Hester CC, Moscato EE, Kazakov DV, et al. A new Cylindromatosis (CYLD) gene mutation in a case of Brooke-Spiegler syndrome masquerading as basal cell carcinoma of the eyelids. Ophthal Plast Reconstr Surg 2013;29:10-11.

30. $\mathrm{Hu} \mathrm{G}$, Onder M, Gill M, et al. A novel missense mutation in CYLD in a family with BrookeSpiegler syndrome. J Invest Dermatol 2003;121:732-734.

31. Huang TM, Chao SC, Lee JY. A novel splicing mutation of the CYLD gene in a Taiwanese family with multiple familial trichoepithelioma. Clin Exp Dermatol 2009;34:77-80.

32. Hutti JE, Shen RR, Abbott DW, et al. Phosphorylation of the tumor suppressor CYLD by the breast cancer oncogene IKKepsilon promotes cell transformation. Mol Cell 2009;34:461-472.

33. Kacerovska D, Szep Z, Kollarikova L, et al. A novel germline mutation in the CYLD gene in a Slovak patient with Brooke-Spiegler syndrome. Cesk Patol 2013;49:89-92.

34. Kalev I, Muru K, Teek R, et al. LEOPARD syndrome with recurrent PTPN11 mutation Y279C and different cutaneous manifestations: two case reports and a review of the literature. Eur J Pediatr 2010;169:469-473.

35. Kazakov DV, Magro G, Kutzner H, Spagnolo, et al. Spiradenoma and spiradenocylindroma with an adenomatous or atypical adenomatous component: a clinicopathological study of 6 cases. Am J Dermatopathol 2008;30:436-441.

36. Kazakov DV, Soukup R, Mukensnabl P, et al. Brooke-Spiegler syndrome: report of a case with combined lesions containing cylindromatous, spiradenomatous, trichoblastomatous, and sebaceous differentiation. Am J Dermatopathol 2005;27:27-33.

37. Kazakov DV, Thoma-Uszynski S, Vanecek T, et al. A case of Brooke-Spiegler syndrome with a novel germline deep intronic mutation in the CYLD gene leading to intronic exonization, diverse somatic mutations, and unusual histology. Am J Dermatopathol 2009;31:664-673.

38. Kazakov DV, Vanecek T, Zelger B, et al. Multiple (familial) trichoepitheliomas: a clinicopathological and molecular biological study, including CYLD and PTCH gene analysis, of a series of 16 patients. Am J Dermatopathol 2011;33:251-265.

39. Kelsall D. With a disease for every day, who will care for the orphans? CMAJ 2013;185:1475.

40. Keren B, Hadchouel A, Saba S, et al. PTPN11 mutations in patients with LEOPARD syndrome: a French multicentric experience. J Med Genet 2004;41:117.

41. Kim J, Kim MR, Kim HJ, et al. LEOPARD Syndrome with PTPN11 Gene Mutation Showing Six Cardinal Symptoms of LEOPARD. Ann Dermatol 2011;23:232-235.

42. Komander D, Lord CJ, Scheel H, et al. The structure of the CYLD USP domain explains its specificity for Lys63-linked polyubiquitin and reveals a B box module. Mol Cell 2008;29:451464.

43. Kovalenko A, Chable-Bessia C, Cantarella G, et al. The tumour suppressor CYLD negatively regulates NF-kappaB signalling by deubiquitination. Nature 2003;424:801-805.

44. Lee DA, Grossman ME, Schneiderman P, Celebi JT. Genetics of skin appendage neoplasms and related syndromes. J Med Genet 2005;42:811-819.

45. Legius E, Schrander-Stumpel C, Schollen E, et al. PTPN11 mutations in LEOPARD syndrome. J Med Genet 2002;39:571-574.

46. Lian F, Cockerell CJ. Cutaneous appendage tumors: familial cylindromatosis and associated tumors update. Adv Dermatol 2005;21:217-234.

47. Liang YH, Sun CS, Ye XY, et al. Novel substitution and frameshift mutations of CYLD in two Chinese families with multiple familial trichoepithelioma. Br J Dermatol 2008;158:1156-1158.

48. Limongelli G, Sarkozy A, Pacileo G, et al. Genotype-phenotype analysis and natural history of left ventricular hypertrophy in LEOPARD syndrome. Am J Med Genet A 2008;146:620-628.

49. Linos K, Schwartz J, Kazakov DV, et al. Recurrent CYLD nonsense mutation associated with a severe, disfiguring phenotype in an African American family with multiple familial trichoepithelioma. Am J Dermatopathol 2011;33:640-642. 
50. Lv HL, Huang YJ, Zhou D, et al. A novel missense mutation of CYLD gene in a Chinese family with multiple familial trichoepithelioma. J Dermatol Sci 2008;50:143-146.

51. Ly H, Black MM, Robson A. Case of the Brooke-Spiegler syndrome. Australas J Dermatol 2004;45:220-222.

52. Martínez-Quintana E, Rodríguez-González F. LEOPARD Syndrome Caused by Tyr279Cys Mutation in the PTPN11 Gene. Mol Syndromol 2012;2:251-253.

53. Massoumi R, Chmielarska K, Hennecke K, et al. Cyld inhibits tumor cell proliferation by blocking Bcl-3-dependent NF-kappaB signaling. Cell 2006;125:665-677.

54. Melly L, Lawton G, Rajan N. Basal cell carcinoma arising in association with trichoepithelioma in a case of Brooke-Spiegler syndrome with a novel genetic mutation in CYLD. J Cutan Pathol 2012;39:977-978.

55. Michal M, Lamovec J, Mukensnabl P, Pizinger K. Spiradenocylindromas of the skin: tumors with morphological features of spiradenoma and cylindroma in the same lesion: report of 12 cases. Pathol Int 1999;49:419-425.

56. Nagy N, Farkas K, Kemény L, Széll M. Phenotype-genotype correlations for clinical variants caused by CYLD mutations. Eur J Med Genet 2015;58:271-278.

57. Nagy N, Farkas K, Kinyo A, et al. A novel missense mutation of the CYLD gene identified in a Hungarian family with Brooke-Spiegler syndrome. Exp Dermatol 2012;21:967-969.

58. Nagy N, Rajan N, Farkas K, et al. A mutational hotspot in CYLD causing cylindromas: a comparison of phenotypes arising in different genetic backgrounds. Acta Derm Venereol 2013;93:743-745.

59. Nasti S, Pastorino L, Bruno W, et al. Five novel germline function-impairing mutations of CYLD in Italian patients with multiple cylindromas. Clin Genet 2009;76:481-485.

60. Nemes E, Farkas K, Kocsis-Deák B, et al. Phenotypical diversity of patients with LEOPARD syndrome carrying the worldwide recurrent p.Tyr279Cys PTPN11 mutation. Arch Derm Res 2015;307:891-895.

61. Obaidat NA, Alsaad KO, Ghazarian D. Skin adnexal neoplasms - part 2: an approach to tumours of cutaneous sweat glands. J Clin Pathol 2007;60:145-159.

62. Oiso N, Mizuno N, Fukai K, et al. Mild phenotype of familial cylindromatosis associated with an R758X nonsense mutation in the CYLD tumour suppressor gene. $\mathrm{Br} \mathrm{J}$ Dermatol 2004;151:1084-1086.

63. Oranje AP, Halley D, Den Hollander JC, et al. Multiple familial trichoepithelioma and familial cylindroma: one cause! J Eur Acad Dermatol Venereol 2008;22:1395-1396.

64. Paradisi M, Pedicelli C, Ciasulli A, et al. PTPN11 gene mutation in LEOPARD syndrome. Minerva Pediatr 2005;57:189-193.

65. Pizinger K, Michal M. Malignant cylindroma in Brooke-Spiegler syndrome. Dermatology 2000;201:255-257.

66. Poblete GP, Eggermann T, Holler D, et al. Phenotype diversity in familial cylindromatosis: a frameshift mutation in the tumor suppressor gene CYLD underlies different tumors of skin appendages. J Invest Dermatol 2002;119:527-531.

67. Rajan N, Langtry JA, Ashworth A, et al. Tumor mapping in 2 large multigenerational families with CYLD mutations: implications for disease management and tumor induction. Arch Dermatol 2009;145:1277-1284.

68. Redler S, Kruse R, Eigelshoven S, et al. Marie Unna hereditary hypotrichosis: Identification of a U2HR mutation int he family from the original 1925 report. J Am Acad Dermatol 2011;64:4550.

69. Reiley WW, Zhang M, Jin W, et al. Regulation of T cell development by the deubiquitinating enzyme CYLD. Nat Immunol 2006;7:411-417.

70. Reuven B, Margarita I, Dov H, Ziad K. Multiple trichoepitheliomas associated with a novel heterozygous mutation in the CYLD gene as an adjunct to the histopathological diagnosis. Am J Dermatopathol 2013;35:445-447.

71. Saggar S, Chernoff KA, Lodha S, et al. CYLD mutations in familial skin appendage tumours. J Med Genet 2008;45:298-302.

72. Salhi A, Bornholdt D, Oeffner F, et al. Multiple familial trichoepithelioma caused by mutations in the cylindromatosis tumor suppressor gene. Cancer Res 2004;64:5113-5117.

73. Sarkozy A, Conti E, Digilio MC, et al. Clinical and molecular analysis of 30 patients with multiple lentigines LEOPARD syndrome. J Med Genet 2004;41:68.

74. Sarkozy A, Digilio MC, Dallapiccola B. Leopard syndrome. Orphanet J Rare Dis 2008;3:13.

75. Scheinfeld $\mathrm{N}, \mathrm{Hu}$ G, Gill M, et al. Identification of a recurrent mutation in the CYLD gene in Brooke-Spiegler syndrome. Clin Exp Dermatol 2003;28:539-541. 
76. Sima R, Vanecek T, Kacerovska D, et al. Brooke-Spiegler syndrome: report of 10 patients from 8 families with novel germline mutations: evidence of diverse somatic mutations in the same patient regardless of tumor type. Diagn Mol Pathol 2010;19:83-91.

77. Spatola M, Wider C, Kuntzer T, Croquelois A. PTPN11 mutation manifesting as leopard syndrome associated with hypertrophic plexi and neuropathic pain. BMC Neurol 2015;15:55.

78. Spiegler E. Über Endotheliome der Haut. Arch Dermatol Syphilol 1899;50:163-176.

79. Takahashi M, Rapley E, Biggs PJ, et al. Linkage and LOH studies in 19 cylindromatosis families show no evidence of genetic heterogeneity and refine the CYLD locus on chromosome 16q12q13. Hum Genet 2000;106:58-65.

80. Tang S, Hoshida H, Kamisago M, et al. Phenotype-genotype correlation in a patient with cooccurrence of Marfan and LEOPARD syndromes. Am J Med Genet A 2009;149:2216-2219.

81. Tartaglia M, Mehler EL, Goldberg R, et al. Mutations in PTPN11, encoding the protein tyrosine phosphatase SHP-2, cause Noonan syndrome. Nat Genet 2001;29:465-468.

82. Tartaglia M, Martinelli S, Stella L, et al. Diversity and functional consequences of germline and somatic PTPN11 mutations in human disease. Am J Hum Genet 2006;78:279-290.

83. Uçar C, Calýskan U, Martini S, Heinritz W. Acute myelomonocytic leukemia in a boy with LEOPARD syndrome (PTPN11 gene mutation positive). J Pediatr Hematol Oncol 2006;28:123125.

84. Uede K, Yamamoto Y, Furukawa F. Brooke-Spiegler syndrome associated with cylindroma, trichoepithelioma, spiradenoma, and syringoma. J Dermatol 2004;31:32-8.

85. Van den Ouweland AM, Elfferich P, Lamping R, et al. Identification of a large rearrangement in CYLD as a cause of familial cylindromatosis. Fam Cancer 2011;10:127-132.

86. Wang FX, Yang LJ, Li M, et al. A novel missense mutation of CYLD gene in a Chinese family with multiple familial trichoepithelioma. Arch Dermatol Res 2010;302:67-70.

87. Wang Y, Chen C, Wang DW. Leopard syndrome caused by heterozygous missense mutation of Tyr 279 Cys in the PTPN11 gene in a sporadic case of Chinese Han. Int J Cardiol 2014;174:101104.

88. Welch JP, Wells RS, Kerr CB. Ancell-Spiegler cylindromas (turban tumours) and BrookeFordyce Trichoepitheliomas: evidence for a single genetic entity. J Med Genet 1968;5:29-35.

89. Ying ZX, Ma HQ, Liu Y, et al. A novel mutation of CYLD in a Chinese family with multiple familial trichoepithelioma. J Eur Acad Dermatol Venereol 2012;26:1420-1423.

90. Yoshida R, Nagai T, Hasegawa T, et al. Two novel and one recurrent PTPN11 mutations in LEOPARD syndrome. Am J Med Genet A 2004;130:432-434.

91. Young AL, Kellermayer R, Szigeti R, et al. CYLD mutations underlie Brooke-Spiegler, familial cylindromatosis, and multiple familial trichoepithelioma syndromes. Clin Genet 2006;70:246249.

92. Zeisler EP, Becker SW. Generalized Lentigo. Arch Dermat Syph 1936;33:109-125.

93. Zhang G, Huang Y, Yan K, et al. Diverse phenotype of Brooke-Spiegler syndrome associated with a nonsense mutation in the CYLD tumor suppressor gene. Exp Dermatol 2006;15:966-970.

94. Zhang XJ, Liang YH, He PP, et al. Identification of the cylindromatosis tumor-suppressor gene responsible for multiple familial trichoepithelioma. J Invest Dermatol 2004;122:658-664.

95. Zheng $\mathrm{G}, \mathrm{Hu} \mathrm{L}$, Huang $\mathrm{W}$, et al. CYLD mutation causes multiple familial trichoepithelioma in three Chinese families. Hum Mutat 2004;23:400. 
9. APPENDIX 


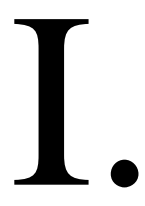




\title{
Phenotypical diversity of patients with LEOPARD syndrome carrying the worldwide recurrent p.Tyr279Cys PTPN11 mutation
}

\author{
Edina Nemes ${ }^{1}$ - Katalin Farkas ${ }^{2}$ - Barbara Kocsis-Deák ${ }^{3}$ - Andrea Drubi ${ }^{3}$. \\ Adrienn Sulák ${ }^{3} \cdot$ Kornélia Tripolszki $^{3} \cdot$ Piroska Dósa $^{5} \cdot$ Lakatos Ferenc $^{4}$. \\ Nikoletta $\mathrm{Nagy}^{2,3,5} \cdot$ Márta Széll $^{2,3}$
}

Received: 21 May 2015/Revised: 31 August 2015/Accepted: 4 September 2015/Published online: 16 September 2015

(C) European Union 2015

\begin{abstract}
LEOPARD syndrome (LS, OMIM 151100) is a rare monogenic disorder. The name is an acronym of its major features such as multiple lentigines, electrocardiographic conduction defects, ocular hypertelorism, pulmonary stenosis, abnormalities of genitalia, retardation of growth and sensorineural deafness. LS develops due to mutations in the protein-tyrosine phosphatase nonreceptortype 11, PTPN11. Here, we have investigated a 51-year-old Hungarian male patient affected by LS. Direct sequencing of the PTPNI1 gene revealed a worldwide recurrent missense mutation (c.836A/G; p.Tyr279Cys), which has been previously identified in $47 \mathrm{LS}$ patients. Comparison of the clinical phenotypes of our patient and the ones reported in the literature demonstrates great phenotypic diversity despite the same genotype.
\end{abstract}

Keywords LEOPARD syndrome - PTPN11 gene · Worldwide recurrent missense mutation - Phenotypic diversity $\cdot$ p.Y279C

E. Nemes and K. Farkas contributed equally to this work.

Nikoletta Nagy

nikoletta.nagy@gmail.com

1 Dermatology and Venereology Unit of the Orosháza Hospital, Orosháza, Hungary

2 MTA-SZTE Dermatological Research Group, University of Szeged, Szeged, Hungary

3 Department of Medical Genetics, University of Szeged, 6 Somogyi Bela Street, Szeged 6724, Hungary

4 Cardiology Unit of the Orosháza Hospital, Orosháza, Hungary

5 Department of Dermatology and Allergology, University of Szeged, Szeged, Hungary

\section{Introduction}

LEOPARD syndrome (LS, OMIM 151100)—a rare monogenic disorder belonging to the family of neuro-cardiofacio-cutaneous syndromes [16] - is inherited as an autosomal dominant trait with full penetrance and variable expressivity $[3,10]$. The major features of LS include multiple lentigines, electrocardiographic conduction abnormalities, ocular hypertelorism, pulmonary stenosis, abnormal genitalia, retardation of growth and sensorineural deafness; this is why the syndrome is referred to as the LEOPARD acronym $[4,10]$. LS develops as a consequence of mutations of the protein-tyrosine phosphatase nonreceptor-type 11 (PTPN11) gene encoding a cytoplasmic protein-tyrosine phosphatase (SHP-2), which regulates intracellular signaling and controls several distinct developmental processes $[15,19]$. In about $85 \%$ of the cases, a heterozygous missense mutation is detected in the exon 7 , 12 or 13 [6, 11]. Among the so far identified missense mutations, there are two (p.Tyr279Cys and p.Thr468Met), which account for about $65 \%$ of all LS cases worldwide $[6,11]$.

Here, we report a Hungarian LS patient carrying the most common p.Tyr279Cys heterozygous missense mutation and compare his clinical features with the symptoms of previously reported LS patients $(n=47)$, in whom the same causative mutation was identified.

\section{Patients and methods}

\section{Patients}

A 51-year-old Hungarian male patient was admitted to the cardiology unit of the Orosháza Hospital (Orosháza, 
Fig. 1 The clinical symptoms, the pedigree of the patient and the identified recurrent mutation of the PTPN11 gene. On examination, facial dysmorphisms including ocular hypertelorism, palpebral ptosis, slight mandibular prognathism and dysmorphic ears were observed (a). Pigmentation abnormalities such as multiple lentigines (b) and café-au-lait spots (c) were also present on the patient's skin. On electrocardiography a thirddegree atrioventricular block was present $(\mathbf{d})$. The patient was born outside marriage. The family members of his father and mother were all clinically unaffected individuals suggesting (e). Direct sequencing revealed a heterozygous missense mutation (c.836A/G; p.Tyr279Cys) in the seventh exon of the PTPN11 gene. The patient carried the mutation in heterozygous form (f), while the unrelated controls carried the wild-type sequence (g)
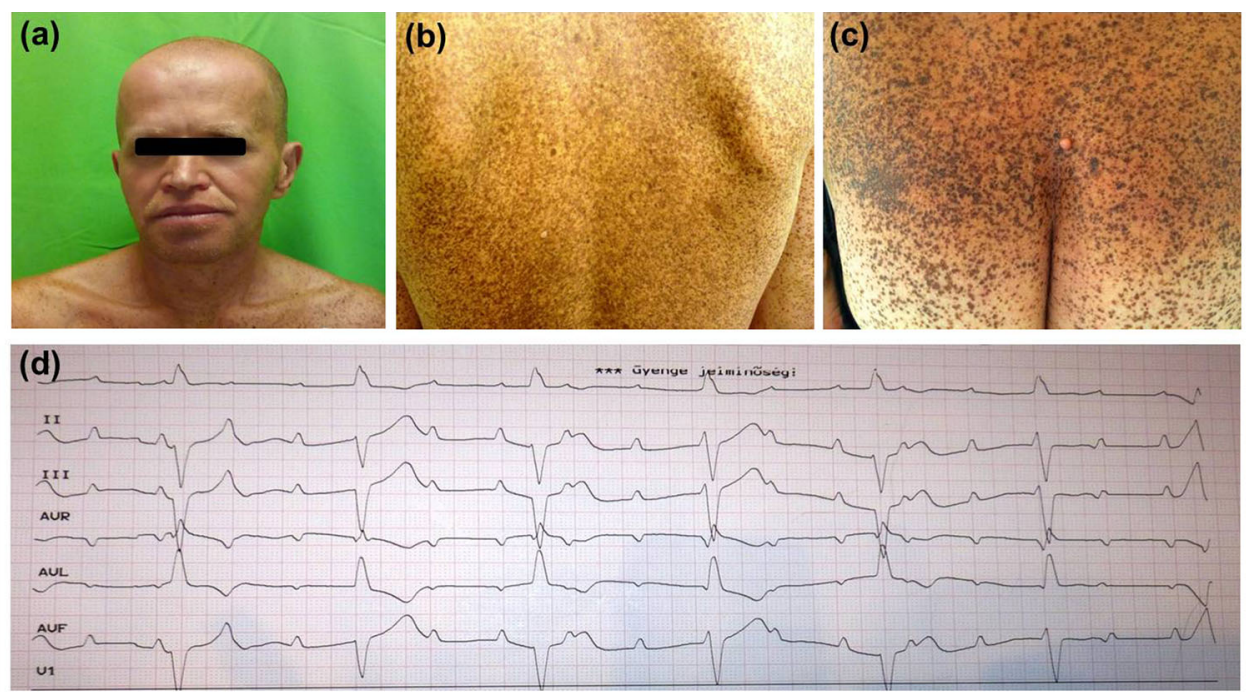

(e)

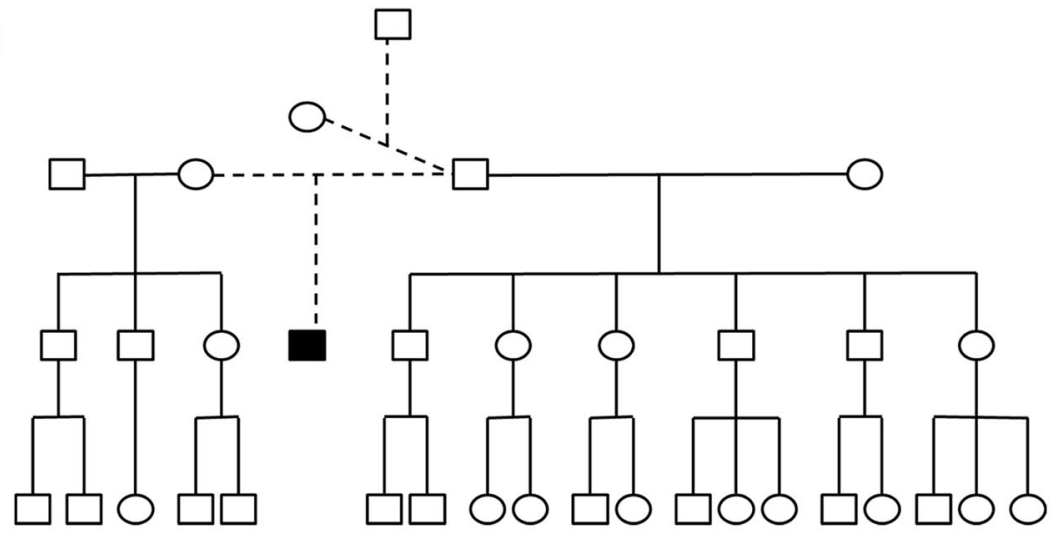

(f)

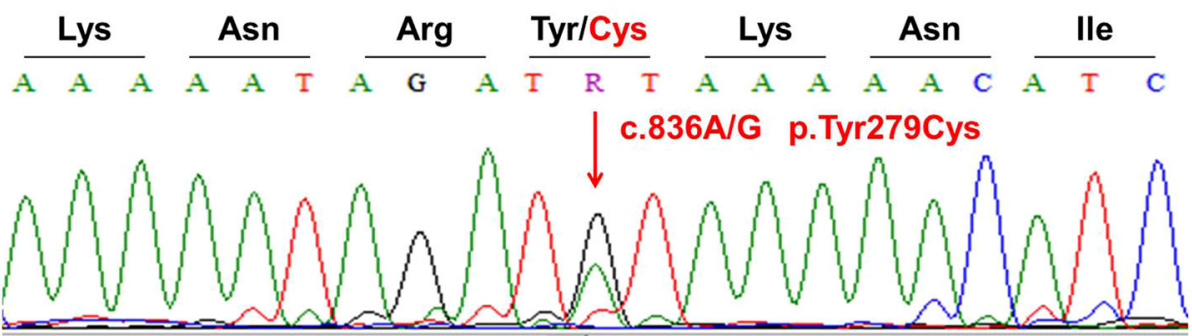

DNA sequence of the patient

(g)

g) $\frac{\text { Lys }}{\text { A A A A A T A }} \frac{\text { Asn }}{\frac{\text { Arg }}{A}} \frac{\text { Tyr }}{\text { T A T A A A A A C A }} \frac{\text { Lys C }}{\text { A A }}$

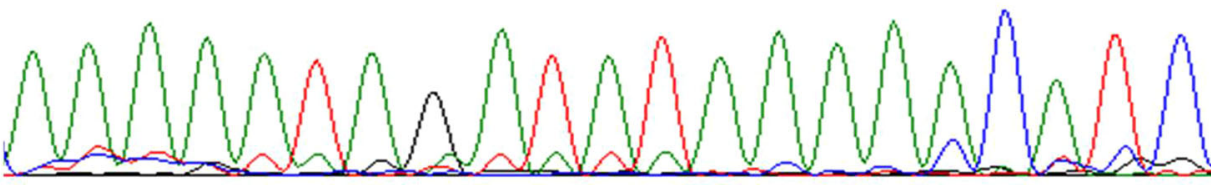

Control DNA sequence 
Hungary) with dizziness and palpitation. On investigation, facial anomalies including ocular hypertelorism, palpebral ptosis, dysmorphic ear, slight mandibular prognathism(Fig. 1a) and pigmentation abnormalities such as multiple lentigines (Fig. 1b) and café-au-lait spots (Fig. 1c) were also observed. Cardiology investigations revealed third degree atrioventricular block (Fig. 1d). The patient is deaf and dumb since he was born and mild growth as well as mental retardations were also present. Urological investigation revealed mild genital abnormalities such as atrophic testes. These clinical symptoms suggested LS; therefore, genetic screening of the PTPN11 gene was also performed. The patient was born out of wedlock; however, the family members of his father and his mother were available for the clinical and genetic investigations (Fig. 1e). All the investigated relatives were clinically unaffected, suggesting the presence of a de novo mutation in the patient.

\section{Genetic investigations}

Blood sample was taken from the patient and genomic DNA isolated by a BioRobot EZ1 DSP Workstation (Qiagen; Godollo, Hungary). All the coding regions of the PTPN11 gene and the flanking introns were amplified and sequenced (primers were used as displayed on the UCSC Genome Browser http://www.genome.ucsc.edu). The investigation was approved by the Internal Review Board of the University of Szeged. Written informed consent was obtained from the patient, and the study was conducted according to the Principles of the Declaration of Helsinki.

\section{Results}

Direct sequencing of the coding regions and the flanking introns of the PTPN11 gene revealed a heterozygous missense mutation (c.836A/G; p.Tyr279Cys) in the seventh exon (Fig. 1f). The clinically affected patient carried the mutation in heterozygous form, while the unrelated healthy controls carried the wild-type sequence (Fig. 1g).

\section{Discussion}

The investigated Hungarian LS patient carries one of the most common missense mutation (p.Tyr279Cys) of the PTPN11 gene. Functional studies demonstrated that the p.Tyr279Cys heterozygous missense mutation of the PTPN11 gene perturbs the switching of the SHP-2 protein between its catalytically inactive and active conformation and engenders loss of SHP-2 catalytic activity [18].
The p.Tyr279Cys mutation has previously been reported in 47 different LS patients with Italian, French, Spanish, German, Estonian, Bosnian, Chinese Han, South-Korean, Japanese and Australian origin [1, 5, 8, 9, 12-14, 17, 20$22]$. Thus, this is a worldwide recurrent missense mutation. Among the reported LS cases, there are ones with de novo mutation [9, 21], and others in which the disease show familial clustering and affects multiple family members in multiple generations $[1,5]$. These data suggest a mutational hotspot on the PTPN11 gene.

Previous reports demonstrated that the p.Tyr279Cys PTPN11 mutation is associated with short stature, deafness and hypertrophic cardiomyopathy [6, 11]. The detailed comparison of the clinical symptoms of the $48 \mathrm{LS}$ patients with the same causative mutation further complicated the analysis of the genotype-phenotype correlations of this mutation.

The most common symptom, which was present in 46 (96\%) out of 48 patients is the presence of multiple lentigines (Fig. 2). Further skin abnormality such as the development of café-au-lait spots were observed in only 22 $(46 \%)$ patients. Besides the characteristic multiple lentigines, some of the facial anomalies were also very common among these patients: ocular hypertelorism was detected in $40(83 \%)$, palpebral ptosis in $32(67 \%)$ and dysmorphic ears in $31(65 \%)$ patients. Besides these common ectodermal abnormalities, patients with the p.Tyr279Cys PTPN11 mutation have a great chance to develop cardiovascular anomalies. Hypertrophic cardiomyopathy was diagnosed in 25 (52\%) patients. Although short stature was previously reported to be frequently associated with the p.Tyr279Cys phenotype, it was present only in $19(40 \%)$ patients out of 48.

Regarding the other side of the spectrum, the p.Tyr279Cys mutation is rarely associated with deafness, which was reported in 12 (25\%) patients (Fig. 2). Moreover, our analysis identified that certain symptoms-such as cryptorchidism, macrocephaly, horse kidney, hydrothorax, myelodysplasia and umbilical hernia-are rarely associated with the p.Tyr279Cys phenotype. In 1 of the 48 LS patients with the recurrent p.Tyr279Cys PTPN11 mutation, Marfan syndrome was also present, which is probably a rare independent association [17].

The observed differences in the clinical symptoms of the 48 LS patients carrying the same missense mutation clearly demonstrate the wide phenotypic diversity and the variable expressivity of the disease. In general, multiple lentigines, café-au-lait macules, ocular hypertelorism, palpebral ptosis, dysmorphic ears and hypertrophic cardiomyopathy are hallmarks of the p.Tyr279Cys PTPN11 mutation-related phenotype. However, there is no similar analysis investigating the most frequently associated clinical features in LS patients carrying the other common, recurrent missense 
Fig. 2 Comparison of the frequency of the different symptoms detected in the p.Tyr279Cys phenotype. The most common symptoms were the pigmentation abnormalities including multiple lentigines and café-au-lait spots and mild facial dysmorphisms such as ocular hypertelorism, palpebral ptosis and dysmorphic ears. In contrast with these,

cryptorchidism, mental retardation, macrocephaly, horse kidney, hydrothorax, myelodysplasia and umbilical hernia were rarely associated with the p.Tyr279Cys phenotype
(\%)

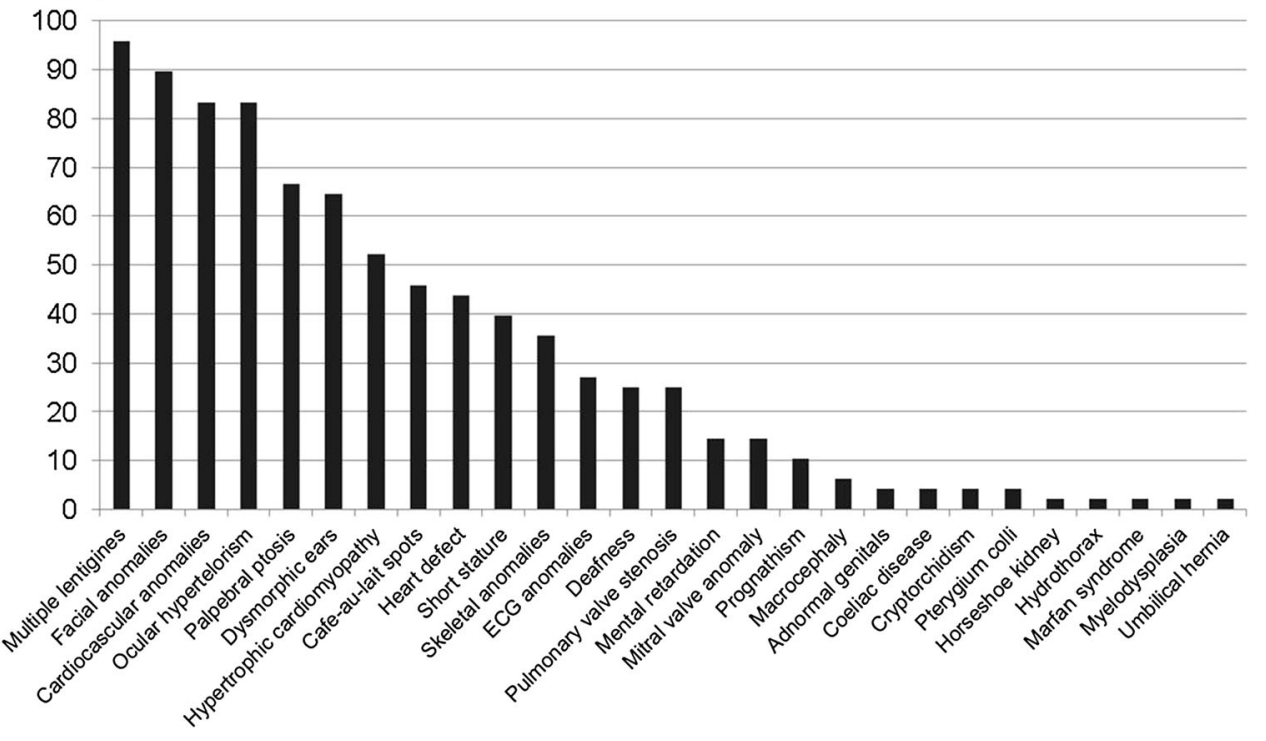

mutation (p.Thr468 Met) of the PTPN11 gene; the published reports suggest that the p.Thr468 Met mutation is also associated with high phenotypic diversity [2, 7].

Further studies are needed to identify putative genetic, environmental or lifestyle factors, which can modify the development of clinical symptoms and responsible for the observed phenotypic diversity. The availability of the extended clinical findings about the p.Tyr279Cys mutation carriers, as provided by this study, is critical for promoting both our understanding of the disease and the development of causative therapies that will be more specific and effective than the symptomatic treatments currently available for LS patients.

Acknowledgments This study was supported by the Hungarian TÁMOP-4.2.2.A-11/1/KONV-2012-0035 grant, TÁMOP-4.2.2/B-10/ 1/KONV-2010-0012 grant, TÁMOP-4.2.4.A/2-11-1-2012-0001 grant and TÁMOP-4.2.2.A3 grant. Nikoletta Nagy was supported by the Hungarian Scientific Research Foundation (OTKA) PD104782 2012-2015 grant.

\section{Compliance with ethical standards}

Conflict of interest The authors declare that they have no conflict of interest.

\section{References}

1. Begić F, Tahirović H, Kardašević M, Kalev I, Muru K (2014) Leopard syndrome: a report of five cases from one family in two generations. Eur J Pediatr 173:819-822

2. Carcavilla A, Pinto I, Muñoz-Pacheco R, Barrio R, Martin-Frías M, Ezquieta B (2011) LEOPARD syndrome (PTPN11, T468M) in three boys fulfilling neurofibromatosis type 1 clinical criteria. Eur J Pediatr 170:1069-1074
3. Digilio MC, Conti E, Sarkozy A, Mingarelli R, Dottorini T, Marino B, Pizzuti A, Dallapiccola B (2002) Grouping of multiple-lentigines/LEOPARD and Noonan syndromes on the PTPN11 gene. Am J Hum Genet 71:389-394

4. Digilio MC, Sarkozy A, De Zorzi A, Pacileo G, Limongelli G, Mingarelli R, Calabrò R, Marino B, Dallapiccola B (2006) LEOPARD syndrome: clinical diagnosis in the first year of life. Am J Med Genet A 140:740-746

5. Froster UG, Glander HJ, Heinritz W (2003) Molecular genetic mutation analysis of the PTPN11 gene in the multiple lentigines (LEOPARD) syndrome. Hautarzt 54:1190-1192

6. Kalev I, Muru K, Teek R, Zordania R, Reimand T, Köbas K, Ounap K (2010) LEOPARD syndrome with recurrent PTPN11 mutation Y279C and different cutaneous manifestations: two case reports and a review of the literature. Eur $\mathrm{J}$ Pediatr 169:469-473

7. Kato H, Yoshida R, Tsukamoto K, Suga H, Eto H, Higashino T, Araki J, Ogata T, Yoshimura K (2010) Familial cases of atypical clinical features genetically diagnosed as LEOPARD syndrome (multiple lentigines syndrome). Int J Dermatol 49:11461151

8. Keren B, Hadchouel A, Saba S, Sznajer Y, Bonneau D, Leheup B, Boute O, Gaillard D, Lacombe D, Layet V, Marlin S, Mortier G, Toutain A, Beylot C, Baumann C, Verloes A, Cavé H, French Collaborative Noonan Study Group (2004) PTPN11 mutations in patients with LEOPARD syndrome: a French multicentric experience. J Med Genet 41:117

9. Kim J, Kim MR, Kim HJ, Lee KA, Lee MG (2011) LEOPARD syndrome with PTPN11 gene mutation showing six cardinal symptoms of LEOPARD. Ann Dermatol 23:232-235

10. Legius E, Schrander-Stumpel C, Schollen E, Pulles-Heintzberger C, Gewillig M, Fryns JP (2002) PTPN11 mutations in LEOPARD syndrome. J Med Genet 39:571-574

11. Limongelli G, Sarkozy A, Pacileo G, Calabrò P, Digilio MC, Maddaloni V, Gagliardi G, Di Salvo G, Iacomino M, Marino B, Dallapiccola B, Calabrò R (2008) Genotype-phenotype analysis and natural history of left ventricular hypertrophy in LEOPARD syndrome. Am J Med Genet A 146:620-628

12. Martínez-Quintana E, Rodríguez-González F (2012) LEOPARD syndrome caused by Tyr279Cys mutation in the PTPN11 gene. Mol Syndromol 2:251-253 
13. Paradisi M, Pedicelli C, Ciasulli A, Pinto F, Conti E, Sarkozy A, Angelo C (2005) PTPN11 gene mutation in LEOPARD syndrome. Minerva Pediatr 57:189-193

14. Sarkozy A, Conti E, Digilio MC, Marino B, Morini E, Pacileo G, Wilson M, Calabrò R, Pizzuti A, Dallapiccola B (2004) Clinical and molecular analysis of 30 patients with multiple lentigines LEOPARD syndrome. J Med Genet 41:68

15. Sarkozy A, Digilio MC, Dallapiccola B (2008) Leopard syndrome. Orphanet J Rare Dis 3:13

16. Spatola M, Wider C, Kuntzer T, Croquelois A (2015) PTPN11 mutation manifesting as leopard syndrome associated with hypertrophic plexi and neuropathic pain. BMC Neurol 15:55

17. Tang S, Hoshida H, Kamisago M, Yagi H, Momma K, Matsuoka $\mathrm{R}$ (2009) Phenotype-genotype correlation in a patient with cooccurrence of Marfan and LEOPARD syndromes. Am J Med Genet A 149:2216-2219

18. Tartaglia M, Martinelli S, Stella L, Bocchinfuso G, Flex E, Cordeddu V, Zampino G, van der Burgt I, Palleschi A, Petrucci TC, Sorcini M, Schoch C, Foa R, Emanuel PD, Gelb BD (2006)
Diversity and functional consequences of germline and somatic PTPN11 mutations in human disease. Am $\mathbf{J}$ Hum Genet 78:279-290

19. Tartaglia M, Mehler EL, Goldberg R, Zampino G, Brunner HG, Kremer H, Van Der Burgt I, Crosby AH, Ion A, Jeffery S, Kalidas K, Patton MA, Kucherlapati RS, Gelb BD (2001) Mutations in PTPN11, encoding the protein tyrosine phosphatase SHP-2, cause Noonan syndrome. Nat Genet 29:465-468

20. Uçar C, Calýskan U, Martini S, Heinritz W (2006) Acute myelomonocytic leukemia in a boy with LEOPARD syndrome (PTPN11 gene mutation positive). J Pediatr Hematol Oncol 28:123-125

21. Wang Y, Chen C, Wang DW (2014) Leopard syndrome caused by heterozygous missense mutation of Tyr 279 Cys in the PTPN11 gene in a sporadic case of Chinese Han. Int J Cardiol 174:101-104

22. Yoshida R, Nagai T, Hasegawa T, Kinoshita E, Tanaka T, Ogata $T$ (2004) Two novel and one recurrent PTPN11 mutations in LEOPARD syndrome. Am J Med Genet A 130:432-434 


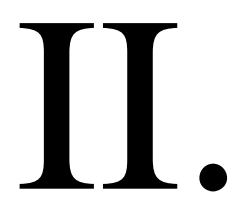




\title{
The CYLD p.R758X worldwide recurrent nonsense mutation detected in patients with multiple familial trichoepithelioma type 1, Brooke-Spiegler syndrome and familial cylindromatosis represents a mutational hotspot in the gene
}

Katalin Farkas', Barbara Kocsis Deák², Laura Cubells Sánchez³, Ana Mercedes Victoria Martínez³, Juan José Vilata Corell ${ }^{3}$, Alfredo Montoro Botella ${ }^{4}$, Goitzane Marcaida Benito ${ }^{4}$, Raquel Rodríguez López ${ }^{4}$, Tomas Vanecek ${ }^{5}$, Dmitry V. Kazakov ${ }^{6}$, Joan N. R. Kromosoeto ${ }^{7}$, Ans M. W. van den Ouweland ${ }^{7}$, János Varga ${ }^{8}$, Márta Széll ${ }^{1,2}$ and Nikoletta Nagy ${ }^{1,2,8^{*}}$

\begin{abstract}
Background: Multiple familial trichoepithelioma type 1 (MFT1; MIM 601606), a rare monogenic skin disease with autosomal dominant inheritance, is characterized by the development of multiple skin-colored papules on the central area of the face, frequently occurring in the nasolabial area. The disease is associated with various mutations in the cylindromatosis (CYLD; MIM 605018) gene that are also responsible for familial cylindromatosis (FC) and Brooke-Spiegler syndrome (BSS).

Methods: Recently we have identified a Spanish MFT1 pedigree with two affected family members (father and daughter). Direct sequencing of the CYLD gene revealed a worldwide recurrent heterozygous nonsense mutation (c.2272C/T, p.R758X) in the patients.
\end{abstract}

Results: This mutation has already been detected in patients with all three clinical variants - BSS, FC and MFT1 - of the CYLD-mutation spectrum. Haplotype analysis was performed for the Spanish patients with MFT1, Dutch patients with FC and an Austrian patient with BSS, all of whom carry the same heterozygous nonsense p.R758X CYLD mutation.

Conclusions: Our results indicate that this position is a mutational hotspot on the gene and that patients carrying the mutation exhibit high phenotypic diversity.

Keywords: Multiple familial trichoepithelioma type 1, Familial cylindromatosis, Brooke-Spiegler syndrome, Worldwide recurrent mutation, Haplotype analysis

\footnotetext{
* Correspondence: nikoletta.nagy@gmail.com

${ }^{1}$ MTA-SZTE Dermatological Research Group, University of Szeged, Szeged,

Hungary

${ }^{2}$ Department of Medical Genetics, University of Szeged, 4 Somogyi B., H-6720

Szeged, Hungary

Full list of author information is available at the end of the article
} 


\section{Background}

Multiple familial trichoepithelioma type 1 (MFT1; MIM 601606) is an autosomal dominant condition characterized by numerous firm skin-colored papules that are trichoepitheliomas (follicular tumors). The tumors grow slowly in size and number throughout life, often producing significant cosmetic disfigurement.

MFT1, familial cylindromatosis (FC; MIM 132700) and Brooke-Spiegler syndrome (BSS, MIM 605041) have been independently mapped to chromosome 16q12-q13 by several groups [1-3]. First, FC was mapped to this region in 1995 [1], and its candidate gene, the CYLD gene, was identified in 2000 [3]. Later BSS was mapped to the same region in 2000 [4]. In the mapped region, the same causative gene was identified in 2002 [5]. Regarding MFT1, the same causative gene was identified in 2003 [6]. These genetic investigations supported the previous clinical hypothesis, that MFT1 and FC might be the consequence of the dysfunction of the same gene, since their clinical symptoms can occur in the same patient or in different patients within the same family [7].

In the mapped region, the cylindromatosis (CYLD) gene [NM_015247] was identified as the causative gene responsible for the development of these three diseases [3]. The gene encodes an enzyme with deubiquitinase activity, which is involved in the post-translational modification of its target proteins and removes Lys63-linked ubiquitin chains [8]. The protein interacts with and negatively regulates the TRAF2, TRAF6, NEMO and BCL3 proteins, affecting the NF- $\mathrm{kB}$ signaling pathway [8].

Here we report a Spanish MFT1 pedigree with an affected father and daughter, in whom we have identified the recurrent p.R758X CYLD mutation. Previously reported cases carrying the same mutation are reviewed to compare the reported clinical phenotypes and to determine the geographical distribution of the mutation. Moreover, haplotype analysis of the Spanish patients with MFT1, as well as Dutch patients with FC and an Austrian patient with BSS was performed to investigate whether the same or different mutational events are responsible for the development of these cases.

\section{Methods}

Patients

The Spanish MFT1 pedigree of Hispanic origin reported here was identified in the Levant region of Valencia, Spain. The 62-year-old father exhibited skin lesions that developed progressively on the central area of the face since the age of 14 . Physical examination revealed multiple skin-colored papules measuring a few millimeters and coalescing to form plaques in both nasolabial folds (Fig. 1a), on the forehead, above the eyebrows and, to a lesser extent, on the ears, on the back of the head and on the back. Histological examination of one of the lesions from the right eyebrow revealed multiple basaloid cell aggregates with small keratinized cystic spaces surrounded

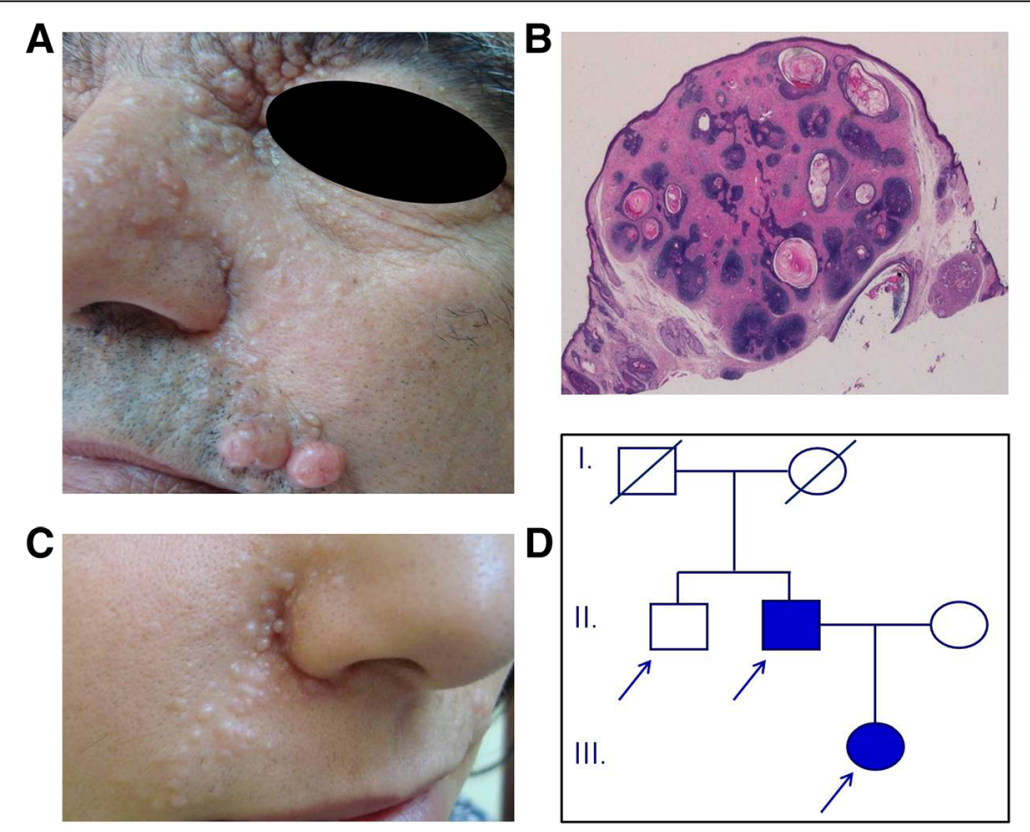

Fig. 1 Skin symptoms, histology findings and pedigree of a Spanish family with multiple familial trichoepithelioma type 1. Two affected family members were identified. a The father presented skin-colored papules in the periorbital region, nose, nasolabial folds and upper lip. b Histological features of trichoepithelioma were islands of basaloid cells with peripheral palisading and small horny cysts (hematoxylin-eosin staining; original magnification $\times 10)$. $\mathbf{c}$ The daughter presented similar but smaller and fewer lesions in the nasolabial fold. $\mathbf{d}$ The pedigree of the investigated family. Written informed consent was obtained from all participants to publish this article and its accompanying images 
by specific follicular stroma (Fig. 1b). These findings were consistent with the diagnosis of trichoepithelioma (cribriform trichoblastoma). Subsequently several biopsies were taken and all histological results supported the diagnosis of trichoepithelioma. The patient has been followed for 24 years, during which time the lesions have increased in number and size. Treatment consisted of block excision of multiple localized trichoepithelioma plaques in the nasolabial fold. Other lesions were treated mainly with electrocoagulation. The patient is currently receiving $\mathrm{CO}_{2}$ laser treatment.

The patient's only child, a 33-year-old daughter, has lesions similar to those of her father but are fewer in number (Fig. 1c). The lesions first appeared in both nasolabial folds and, over time, began to appear on her forehead, temples, ears and scalp. Trichoepithelioma was confirmed with a biopsy of a lesion from the right temple. The daughter has been treated with electrocoagulation and cryotherapy, followed by $5 \%$ imiquimod cream. Trichoepitheliomas in the left nasolabial fold were also treated with a single session of photodynamic therapy which had to be discontinued after a few minutes due to intense pain the area. A burn subsequently appeared in the treated area and took weeks to heal. Trichoepitheliomas were resolved but new lesions subsequently appeared in the same area. At present, the patient is receiving a $\mathrm{CO}_{2}$ laser treatment and is exhibiting good tolerance and acceptable aesthetic results. To date, no clinical or histological evidence for cylindromas or spiradenomas has been observed in either the father or the daughter. No other clinically affected member has been identified in this pedigree (Fig. 1d).

The data for Dutch and Austrian patients is publically available, and we did not take any samples from these patients ourselves. The investigated Dutch patients were previously reported by Van den Ouweland et al. [9]. Based on the development of cylindromas, these patients were diagnosed with FC. Their detailed clinical description is present in the report of Van den Ouweland et al. [9]. The investigated Austrian patient was previously reported by Grossmann et al. [10]. Based on the development of different skin appendage tumors, the diagnosis of BSS was established. The detailed clinical description of the symptoms is available in the study of Grossmann et al. [10].

\section{Genetic investigation}

The enrollment of the Spanish patients into the genetic investigations have been approved by the Clinical Research Ethics Committee (CEIC) of Consorcio Hospital General Universitario de Valencia. The performed genetic investigation was approved by the Internal Review Board of the University of Szeged, Szeged, Hungary. Written informed consents have been obtained from all the investigated subjects. The study was conducted according to the Principles of the Declaration of Helsinki.

Blood samples for genetic analyses were taken from the Spanish patients and from their clinically unaffected family members, as well as from unrelated controls. Genomic DNA was isolated with a BioRobot EZ1 DSP Workstation (QIAGEN; Godollo, Hungary). The coding regions of the $C Y L D$ gene and the flanking introns were amplified and sequenced (primer sequences were obtained from the UCSC Genome Browser, www.genome.ucsc.edu).

For haplotype analysis of the Spanish, Dutch and Austrian patients, common polymorphisms $(n=33)$ were genotyped from regions upstream $(n=20$; rs199912760, rs375106322, rs201860550, rs149502055, rs376795685, rs144013604, rs75157714, rs201233994, rs200973965, rs77528321, rs146702654, rs6145827, rs3064638, rs73584492, rs190892314, rs200678983, rs76797023, rs77678929, rs376799359, rs201103123) and downstream $(n=13 ; \quad$ rs370702435, rs10451132, rs201757487, rs137990687, rs368656359, rs149201712, rs185111122, rs146946436, rs141129479, rs72796392, rs111543527, rs11866167, rs35072258) of the identified mutation. A detailed list of the investigated polymorphisms is presented in Table 1. Genotypes of the investigated polymorphisms were determined with direct sequencing.

\section{Results and discussion}

Direct sequencing of the coding regions and the flanking introns of the CYLD gene from the investigated Spanish patients revealed a previously described nonsense mutation in exon 17 (c.2272C/T, p.R758X, rs121908388). This mutation results in a premature termination codon causing truncation and, thus, dysfunction of the CYLD protein. Both patients carried the mutation in heterozygous form (Fig. 2a), whereas the unaffected family members and unrelated controls carried the wild-type sequence (Fig. 2b, Additional file 1.). The identified mutation was located in the ubiquitin-specific protease domain of the CYLD protein (Fig. 2c).

Previously reported Dutch and Austrian cases carrying the same mutation were also investigated in this study $[9,10]$. Haplotype analysis of the Spanish patients with MFT1, the Dutch patients with FC and Austrian patients with BSS was performed (Table 1.). Our results demonstrated that the Spanish and the Dutch pedigrees carry the same haplotype, whereas the Austrian patient carries a different haplotype. Thus, it can be assumed that different mutational events are responsible for the development of the Austrian case and the Spanish and Dutch cases.

A review of all previous studies reporting the same c.2272C/T, p.R758X nonsense mutation of the CYLD gene revealed that this mutation has also been detected in patients with BSS [10-12], FC [3, 9, 13] and MFT1 $[10,14]$. Thus, the c.2272C/T, p.R758X nonsense mutation 
Table 1 Haplotype analysis of Spanish, Dutch and Austrian patients carrying the same recurrent nonsense mutation

\begin{tabular}{|c|c|c|c|c|c|c|c|}
\hline \multirow[t]{3}{*}{ Nationality } & & \multicolumn{3}{|l|}{ Spanish } & \multicolumn{2}{|l|}{ Dutch } & \multirow{3}{*}{$\begin{array}{l}\text { Austrian } \\
\text { Symptomatic }\end{array}$} \\
\hline & & \multirow{2}{*}{$\begin{array}{l}\text { II/1 } \\
\text { Healthy }\end{array}$} & \multirow{2}{*}{$\begin{array}{l}\text { II/2 } \\
\text { Symptomatic }\end{array}$} & \multirow{2}{*}{$\begin{array}{l}\text { III/1 } \\
\text { Symptomatic }\end{array}$} & & & \\
\hline & & & & & Symptomatic & Symptomatic & \\
\hline Polymorphism ID & $\begin{array}{l}\text { Frequent } \\
\text { allele }\end{array}$ & & & & & & \\
\hline rs35072258 & $\mathrm{TC} /-$ & TCTC & TCTC & TCTC & TCTC & TCTC & TCTC \\
\hline rs11866167 & $C / A$ & $C C$ & $\mathrm{CC}$ & $C C$ & CC & CC & CC \\
\hline rs111543527 & $\mathrm{T} / \mathrm{C}$ & $\pi$ & $\pi$ & $\pi$ & $\pi$ & $\pi$ & $\pi$ \\
\hline rs72796392 & $\mathrm{T} / \mathrm{C}$ & $\pi$ & $\Pi$ & $\pi$ & $\Pi$ & $\pi$ & $\pi$ \\
\hline rs141129479 & $\mathrm{A} / \mathrm{G}$ & AA & AA & AA & AA & AA & AA \\
\hline rs146946436 & $A / G$ & AA & AA & $\mathrm{AA}$ & AA & AA & AA \\
\hline rs185111122 & $\mathrm{T} / \mathrm{C}$ & $\pi$ & $\Pi$ & $\pi$ & $\pi$ & $\pi$ & $\pi$ \\
\hline rs149201712 & $\mathrm{AC} /-$ & ACAC & ACAC & ACAC & ACAC & ACAC & ACAC \\
\hline rs368656359 & $\mathrm{G} / \mathrm{A}$ & GG & GG & GG & GG & GG & GG \\
\hline rs137990687 & $\mathrm{G} / \mathrm{A}$ & GG & GG & GG & GG & GG & GG \\
\hline rs201757487 & G/- & GG & GG & GG & GG & GG & GG \\
\hline rs10451132 & $\mathrm{G} / \mathrm{T}$ & GG & GG & GG & GG & GG & GT \\
\hline rs370702435 & $A / G$ & $A A$ & AA & $A A$ & AA & $A A$ & $\mathrm{AA}$ \\
\hline rs121908388 & $C / T$ & CC & $\mathrm{CT}$ & $C T$ & $C T$ & $C T$ & $C T$ \\
\hline rs199912760 & $\mathrm{G} / \mathrm{A}$ & GG & GG & GG & GG & GG & GG \\
\hline rs375106322 & $\mathrm{G} / \mathrm{A}$ & GG & GG & GG & GG & GG & GG \\
\hline r201860550 & $\mathrm{G} / \mathrm{T}$ & GG & GG & GG & GG & GG & GG \\
\hline rs149502055 & $C / T$ & CC & CC & CC & CC & CC & CC \\
\hline rs376795685 & $\mathrm{G} / \mathrm{A}$ & GG & GG & GG & GG & GG & GG \\
\hline rs144013604 & $A / G$ & $A A$ & AA & $A A$ & AA & $A A$ & $\mathrm{AA}$ \\
\hline rs75157714 & $\mathrm{G} / \mathrm{A}$ & GG & GG & GG & GG & GG & GG \\
\hline rs201233994 & AT/- & AT & AT & AT & AT & AT & AT \\
\hline rs200973965 & ATAC/- & ATAC & ATAC & ATAC & ATAC & ATAC & ATAC \\
\hline rs77528321 & $\mathrm{T} / \mathrm{C}$ & $\pi$ & $\pi$ & $\pi$ & $\pi$ & $\pi$ & $\pi$ \\
\hline rs146702654 & $\mathrm{T} /-$ & $\pi$ & $\Pi$ & $\pi$ & $\pi$ & $\pi$ & $\pi$ \\
\hline rs6145827 & ACACAC/- & $\begin{array}{l}\text { ACACAC } \\
\text { ACACAC }\end{array}$ & $\begin{array}{l}\text { ACACAC } \\
\text { ACACAC }\end{array}$ & $\begin{array}{l}\text { ACACAC } \\
\text { ACACAC }\end{array}$ & $\begin{array}{l}\text { ACACAC } \\
\text { ACACAC }\end{array}$ & $\begin{array}{l}\text { ACACAC } \\
\text { ACACAC }\end{array}$ & $\begin{array}{l}\text { ACACAC } \\
\text { ACACAC }\end{array}$ \\
\hline rs3064638 & ACACAC/- & $\begin{array}{l}\text { ACACAC } \\
\text { ACACAC }\end{array}$ & $\begin{array}{l}\text { ACACAC } \\
\text { ACACAC }\end{array}$ & $\begin{array}{l}\text { ACACAC } \\
\text { ACACAC }\end{array}$ & $\begin{array}{l}\text { ACACAC } \\
\text { ACACAC }\end{array}$ & $\begin{array}{l}\text { ACACAC } \\
\text { ACACAC }\end{array}$ & -- \\
\hline rs73584492 & $A / G$ & $\mathrm{AA}$ & AA & $A A$ & AA & AA & AA \\
\hline rs190892314 & $A / G$ & $A A$ & AA & $A A$ & AA & $A A$ & AA \\
\hline rs200678983 & $C / T$ & CC & CC & CC & CC & CC & CC \\
\hline rs76797023 & $A / T$ & $A A$ & $\mathrm{AA}$ & $A A$ & $A A$ & $A A$ & AA \\
\hline rs77678929 & T/A & $\pi$ & $\pi$ & $\pi$ & $\pi$ & $\pi$ & $\pi$ \\
\hline rs376799359 & $A / T$ & AA & $\mathrm{AA}$ & $A A$ & $\mathrm{AA}$ & $\mathrm{AA}$ & AA \\
\hline rs201103123 & $C / T$ & $\mathrm{CC}$ & CC & CC & CC & CC & CC \\
\hline
\end{tabular}

of the CYLD gene can lead to the manifestation of any of the clinical variants in the disease spectrum caused by CYLD mutation, which is associated with high phenotypic diversity. Furthermore, this mutation has been detected in Caucasian American [3], South African [10], Austrian
[10, 14], Czech [11], Dutch [9], Chinese [12] and Japanese patients [13] and is, thus, considered a recurrent worldwide mutation (Table 2.). These data suggest that the c. $2272 \mathrm{C} / \mathrm{T}$, p.R758X nonsense mutation is located at a mutational hotspot in the CYLD gene. 


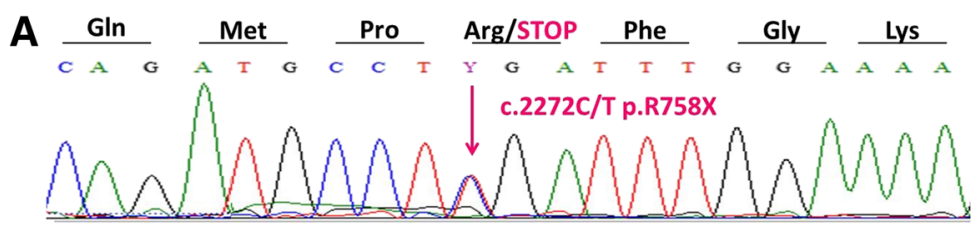

DNA sequence from the affected patient (II/2)

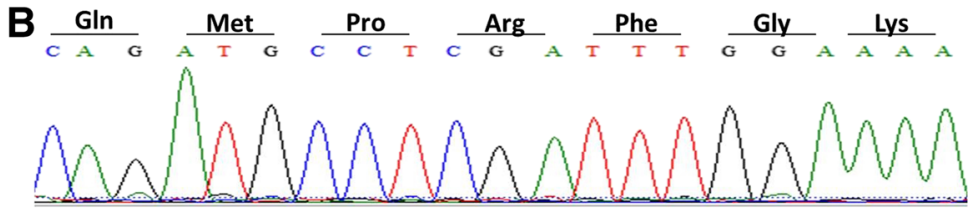

DNA sequence from the unaffected patient (II/1)

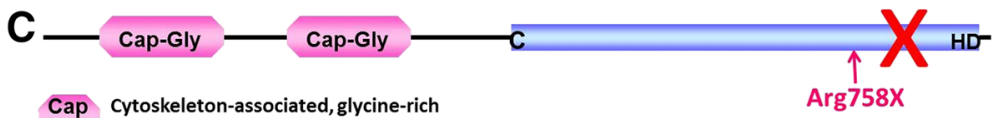

-Gly domain

C ${ }_{D}^{H}$ Ubiquitin-specific protease domain

Fig. 2 Direct sequencing of the CYLD gene. Direct sequencing revealed a nonsense mutation (c.2272C/T, p.R758X) in exon 17. a The affected family members carried the deletion in heterozygous form. $\mathbf{b}$ The unaffected family members carried the wild-type sequence. c The mutation is located in the region of the ubiquitin-specific protease domain of the CYLD protein

To determine whether the worldwide recurrent p.R758X mutation of the CYLD gene is the result of one or more independent mutational events, we performed haplotype analysis. The haplotype analysis of the Spanish, Dutch and Austrian patients demonstrated that, although the Spanish and the Dutch patients carry the same haplotype, the clinical appearance, MFT1 and FC, respectively, is different (Table 1.). These results suggest the importance of modifying genetic and/or environmental factors. In contrast with these, the Austrian patient carried a different haplotype than the Spanish and Dutch families. Thus, we assume the presence of the same mutation is the consequence of different mutational events (Table 1.).

\section{Conclusion}

Our results support the conclusion that position 2272 in the nucleotide sequence of the CYLD cDNA [NM_015247] is a mutational hotspot on the CYLD gene. This result correlates well with our previous findings for Hungarian and Anglo-Saxon BSS families carrying the same heterozygous nonsense mutation (c.2806C $>$ T, p.Arg936X) but different haplotypes [15]. Of note, both mutational hotspots are the location of recurrent nonsense mutations.
Regarding the encoded functional domains, both of mutational hotspots affect the ubiquitin-specific protease domain of the CYLD protein (Fig. 2c). Both recurrent nonsense mutations have been reported for all three clinical variants (MFT1, BSS, FC) of the CYLD-mutation based disease spectrum and have been associated with high intra- and interfamilial phenotypic diversity [15].

These reports raise the question of how these two worldwide recurrent nonsense mutations can lead to the development of the different clinical variants of the CYLD-mutation based disease spectrum. Further studies are needed to identify putative genetic, environmental or lifestyle factors and to elucidate the mechanism leading to the enormous phenotypic differences observed in patients carrying the same c.2272C/T, p.R758X nonsense mutation.

\section{Availability of supporting data}

All the supporting data are included as additional file.

\section{Consent to publish}

Written informed consent was obtained from all participants to publish this article.

Table 2 Summary of the geographical location and clinical manifestation of the recurrent p.R758X CYLD mutation

\begin{tabular}{lllll}
\hline CYLD cDNA & CYLD protein & Detected in patients with & Nationality & References \\
\hline c.2272C $>$ T & p.R758X & FC & Caucasian American, Dutch, Japanese & {$[3,9,13]$} \\
& & Austrian, South African, Czech, Chinese & {$[10-12]$} \\
& & MFT1 & Austrian, Spanish & {$[10,14]$, present study } \\
\hline
\end{tabular}




\section{Additional file}

Additional file 1: Sequencing data of Patient III/1 demonstrated the same heterozygous mutation, which has been detected in case of Patient II/2. (JPG $163 \mathrm{~kb}$ )

\section{Abbreviations}

MFT1: Multiple familial trichoepithelioma type 1; FC: familial cylindromatosis; BSS: Brooke-Spiegler syndrome; CYLD: cylindromatosis gene; TRAF2: TNF receptor-associated factor 2; TRAF6: TNF receptor-associated factor 6; NEMO: NF-kappa-B essential modulator; BCL3: B-cell lymphoma 3-encoded protein; NF-kB: nuclear factor kappa-light-chain-enhancer of activated B cells.

\section{Competing interests}

The authors declare that they have no competing interests.

\section{Authors' contributions}

KF carried out the mutation and haplotype analysis and the first draft of the manuscript. BKD and JV participated in the mutation and haplotype analysis. LCS, AMVM, JJVC, AMB, GMB and RRL cared for Spanish patients and perform the histological examination. TV and DVK cared for Austrian patient and carried out the mutation analysis. JNRK and AMWO cared for Dutch patients and carried out the mutation analysis. MS and NN were mentors who designed and guided the research study. All authors read and approved the final manuscript.

\section{Acknowledgements}

This research was supported by the European Union and the State of Hungary, co-financed by the European Social Fund in the framework of TÁMOP-4.2.4.A/ 2-11/1-2012-0001 "National Excellence Program." Nikoletta Nagy was also supported by the Hungarian Scientific Research Fund (OTKA) PD104782 grant.

\section{Author details}

${ }^{1}$ MTA-SZTE Dermatological Research Group, University of Szeged, Szeged, Hungary. ${ }^{2}$ Department of Medical Genetics, University of Szeged, 4 Somogyi B., H-6720 Szeged, Hungary. ${ }^{3}$ Department of Dermatology and Venereology of Consorcio Hospital Universitario de Valencia, Valencia, Spain. ${ }^{4}$ Genetics Laboratory of Clinical Analysis, Consorcio Hospital General Universitario de Valencia, Valencia, Spain. ${ }^{5}$ Unit of Molecular Genetics, Bioptical Laboratory, Pilsen, Czech Republic. ${ }^{6}$ The Sikl Department of Pathology, Charles University Medical Faculty Hospital, Medical Faculty in Pilsen, Charles University in Prague, Pilsen, Czech Republic. ${ }^{7}$ Department of Clinical Genetics, Erasmus MC, Rotterdam, Netherlands. ${ }^{8}$ Department of Dermatology and Allergology, University of Szeged, Szeged, Hungary.

Received: 20 July 2015 Accepted: 3 February 2016

Published online: 09 February 2016

\section{References}

1. Biggs PJ, Wooster R, Ford D, Chapman P, Mangion J, Quirk Y, et al. Familial cylindromatosis (turban tumour syndrome) gene localised to chromosome 16q12-q13: evidence for its role as a tumour suppressor gene. Nat Genet. 1995;11:441-3

2. Biggs PJ, Chapman P, Lakhani SR, Burn J, Stratton MR. The cylindromatosis gene (cyld1) on chromosome 16q may be the only tumour suppressor gene involved in the development of cylindromas. Oncogene. 1996:12:1375-7.

3. Bignell GR, Warren W, Seal S, Takahashi M, Rapley E, Barfoot R, et al. Identification of the familial cylindromatosis tumour-suppressor gene. Nat Genet. 2000;25:160-5.

4. Fenske C, Banerjee P, Holden C, Carter N. Brooke-Spiegler syndrome locus assigned to 16q12-q13. J Invest Dermatol. 2000;114:1057-8.

5. Gutierrez PP, Eggermann T, Holler D, Jugert FK, Beermann T, Grussendorf-Conen $\mathrm{E}-\mathrm{l}$, et al. Phenotype diversity in familial cylindromatosis: a frameshift mutation in the tumor suppressor gene CYLD underlies different tumors of skin appendages. J Invest Dermatol. 2002;119:527-31.

6. Hu G, Onder M, Gill M, Aksakal B, Oztas M, Gurer MA, et al. A novel missense mutation in CYLD in a family with Brooke-Spiegler syndrome. J Invest Dermatol. 2003;121:732-4.
7. Gerretsen AL, Beemer FA, Deenstra W, Hennekam FAM, van Vloten WA. Familial cutaneous cylindromas: investigations in five generations of a family. J Am Acad Dermatol. 1995;33:199-206.

8. Kovalenko A, Chable-Bessia C, Cantarella G, Israël A, Wallach D, Courtois G. The tumour suppressor CYLD negatively regulates NF-kappa-B signalling by deubiquitination. Nature. 2003:424:801-5.

9. Van den Ouweland AM, Elfferich P, Lamping $R$, van de Graaf $R$, van VeghelPlandsoen MM, Franken SM, et al. Identification of a large rearrangement in CYLD as a cause of familial cylindromatosis. Fam Cancer. 2011;10:127-32.

10. Grossmann P, Vanecek T, Steiner P, Kacerovska D, Spagnolo DV, Cribier B, et al. Novel and recurrent germline and somatic mutations in a cohort of 67 patients from 48 families with Brooke-Spiegler syndrome including the phenotypic variant of multiple familial trichoepitheliomas and correlation with the histopathologic findings in 379 biopsy specimens. Am J Dermatopathol. 2013:35:34-44.

11. Kazakov DV, Thoma-Uszynski S, Vanecek T, Kacerovska D, Grossmann P, Michal M. A case of Brooke-Spiegler syndrome with a novel germline deep intronic mutation in the CYLD gene leading to intronic exonization, diverse somatic mutations, and unusual histology. Am J Dermatopathol. 2009;31:664-73.

12. Zhang G, Huang Y, Yan K, Li W, Fan X, Liang Y, et al. Diverse phenotype of Brooke-Spiegler syndrome associated with a nonsense mutation in the CYLD tumor suppressor gene. Exp Dermatol. 2006;15:966-70.

13. Oiso N, Mizuno N, Fukai K, Nakagawa K, Ishii M. Mild phenotype of familial cylindromatosis associated with an R758X nonsense mutation in the CYLD tumour suppressor gene. Br J Dermatol. 2004;151:1084-6.

14. Kazakov DV, Vanecek T, Zelger B, Carlson JA, Spagnolo DV, Schaller J, et al Multiple (familial) trichoepitheliomas: a clinicopathological and molecular biological study, including CYLD and PTCH gene analysis, of a series of 16 patients. Am J Dermatopathol. 2011;33:251-65.

15. Nagy N, Rajan N, Farkas K, Kinyó A, Kemény L, Széll M. A mutational hotspot in CYLD causing cylindromas: a comparison of phenotypes arising in different genetic backgrounds. Acta Derm Venereol. 2013;93:743-5.

\section{Submit your next manuscript to BioMed Central and we will help you at every step:}

- We accept pre-submission inquiries

- Our selector tool helps you to find the most relevant journal

- We provide round the clock customer support

- Convenient online submission

- Thorough peer review

- Inclusion in PubMed and all major indexing services

- Maximum visibility for your research

Submit your manuscript at www biomedcentral com/submit
BioMed Central 